\title{
Measuring Well-Being and Exclusion in Europe's Regions
}

\author{
Kitty Stewart
}

\section{Contents}

Editorial Note and Acknowledgements .......................................................................iii

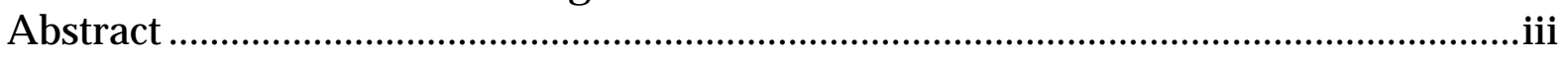

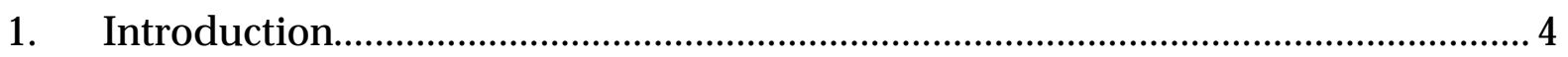

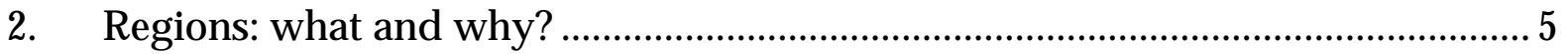

3. Choice of indicators - and how do we measure disparity? ................................. 8

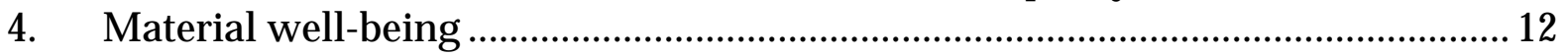

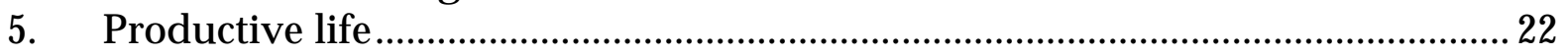

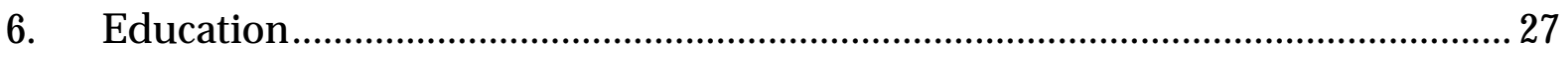

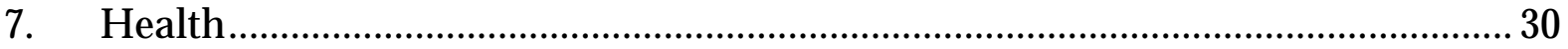

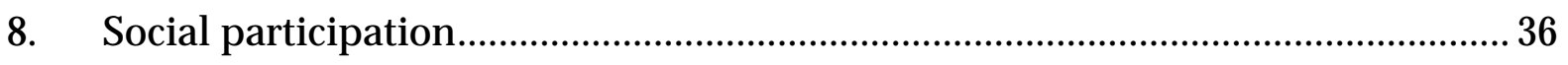

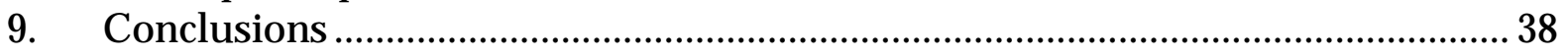

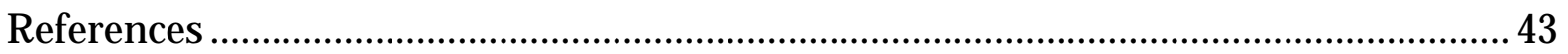

CASEpaper 53

March 2002
Centre for Analysis of Social Exclusion London School of Economics Houghton Street London WC2A $2 \mathrm{AE}$ CASE enquiries - tel: 02079556679 


\section{Centre for Analysis of Social Exclusion}

The ESRC Research Centre for Analysis of Social Exclusion (CASE) was established in October 1997 with funding from the Economic and Social Research Council. It is located within the Suntory and Toyota International Centres for Economics and Related Disciplines (STICERD) at the London School of Economics and Political Science, and benefits from support from STICERD. It is directed by Howard Glennerster, John Hills, Kathleen Kiernan, Julian Le Grand, Anne Power and Carol Propper.

Our Discussion Paper series is available free of charge. We also produce summaries of our research in CASEbriefs, and reports from various conferences and activities in CASEreports. To subscribe to the CASEpaper series, or for further information on the work of the Centre and our seminar series, please contact the Centre Administrator, Jane Dickson, on:

Telephone: UK+20 79556679

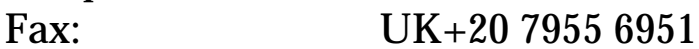

Email: $\quad$ j.dickson@lse.ac.uk

Web site: $\quad$ http://sticerd.lse.ac.uk/Case

(C) Kitty Stewart

All rights reserved. Short sections of text, not to exceed two paragraphs, may be quoted without explicit permission provided that full credit, including (c) notice, is given to the source. 


\section{Editorial Note and Acknowledgements}

Kitty Stewart is a STICERD Post-Doctoral Fellow at CASE. She can be contacted at k.j.stewart@lse.ac.uk. The author is grateful to John Hills, Tony Atkinson, Tania Burchardt, John Micklewright and participants at a STICERD Work in Progress seminar for comments and suggestions.

\section{Abstract}

The Lisbon summit of the European Council in March 2000 declared the number of people living in poverty and social exclusion in the European Union to be unacceptable, and called for steps to tackle the issue, beginning with the setting of targets for particular indicators. The targets suggested have been broad in nature but have largely concentrated on national averages. This paper seeks to marry this approach with the EU's traditional focus on regional cohesion, by developing regional indicators of well-being and exclusion for EU countries. It draws on a range of sources to put together indicators in five dimensions of well-being: material wellbeing, health, education and participation in two spheres - productive and social. It explores, first, how far national indicators disguise geographical inequalities in these different dimensions; and second, the extent to which regional performance differs according to which dimension is being examined. At the same time, the paper draws attention to the limits of currently available data, in light of the fact that one key aspect of the Lisbon summit conclusions was a commitment to the collection of better data on poverty and social exclusion in the EU.

Keywords: regional disparities, EU, well-being, exclusion.

JEL classification: I00, I31, I32, R20. 


\section{Introduction}

The EU has long been committed to greater social cohesion in Europe. The Maastricht Treaty of 1992 called prominently for the 'strengthening of economic and social cohesion' so as to promote the Union's 'overall harmonious development' (Articles 2 and 130a). Cohesion in this context has been understood to refer to regional disparities: a series of regional policies and funds have aimed to raise average incomes in poorer regions up to the EU mean, while the European Commission's series of Cohesion Reports (European Commission 1996 and 2001) have focused heavily on regional indicators.

More recently, however, there has been a move towards a greater focus on poverty and social exclusion at individual level, culminating in the Lisbon summit of the European Council in March 2000. The summit conclusions declared the number of people living in poverty and social exclusion in the EU to be unacceptable, and called for decisive steps to tackle the issue, beginning with the setting of national targets for particular indicators. The Social Agenda subsequently agreed at the Nice summit in December 2000 called on member states to draw up national plans of action for tackling social exclusion, and in Stockholm in March 2001 the Commission presented a provisional set of target indicators for the EU as a whole. After an extensive consultation process, a revised list of indicators was adopted at the Laeken Summit in December 2001.

This paper calls for a marriage of these two approaches. The Cohesion Reports are regionally focused but stick to very traditional measures of well-being largely regional GDP and employment measures. The indicators agreed in Laeken are much broader in nature, spanning a number of diverse aspects of life, but they are almost exclusively to be measured at national level (Social Protection Committee, 2001). One indicator, the coefficient of variation of regional unemployment rates, has been included to track regional disparities.

The need for greater information about internal disparities in social indicators was broached in a report commissioned by the Belgian Presidency of the EU to aid the debate: Atkinson et al. (2002) argued that concerns about regional differences arise for all dimensions of social cohesion and that there is no justification for giving primacy to unemployment or any other single indicator. They suggested that a better way of keeping geographical inequality high up on the agenda would be to track regional disparities (subject to data availability) in each of the measures suggested as national indicators, along with breakdowns by other key variables such as gender.

While the Atkinson report was in general very influential in shaping the final choice of indicators, this particular proposal appears to have been overlooked. This paper, however, attempts to put it into practice. It explores regional disparities in a range of different cohesion measures, and looks at the correlation between different indicators. It asks, first, how far national average figures disguise regional pockets of deprivation on different indicators; and second, how far performance on different measures overlaps. The motivation for the second question is twofold. We want to know whether there are regions which suffer from multiple deprivation, and where these regions are; and we want to see how reasonable it is to use just one measure as a proxy for deprivation in other spheres. 
Data constraints loom large in a regional study, and 'subject to availability' turns out to be a significant caveat. Many of the indicators we might like to track are simply not available by region, while household surveys often do not contain regional samples large enough to be helpful. The paper is upfront about these constraints. Indeed, one key aspect of the conclusions of the Lisbon summit was a commitment to the collection of better data on poverty and social exclusion in the EU, so identifying the limits of currently available data in itself seems a timely and useful exercise. At the same time, while there are many holes in the picture, there is still much that can be said about the pattern of regional disparity across the EU, and of the degree to which the story changes when different indicators are examined.

The following section discusses the importance of looking at regional disparities at all and the level of region at which the paper's analysis takes place. Section 3 looks at the choice of indicators used in the paper and highlights the question of measurement. Sections 4 to 8 each examine indicators in one domain of well-being, while Section 9 provides an overview and some conclusions.

\section{Regions: what and why?}

\section{Why is cohesion between regions important?}

The first question that needs to be addressed is why we should look at regional disparities at all. There are clear practical reasons for interest in regional differentials in welfare. First, an understanding of where deprivation is concentrated is important in the formulation of targeted policy responses. Second, an analysis of regional differences can also assist in the development of preventative policies, by facilitating the development of hypotheses about the nature of causal mechanisms at work. Both of these are arguments that apply to groups in general, with one's region of residence just one example of membership of a group (gender and ethnicity are others). An additional reason for examining regional disparities in particular is that, in many EU countries, local authorities and regions hold responsibility for provision of key aspects of public services including health and education. Keeping track of disparities in outcomes then becomes a way of measuring the success of alternative policy regimes, and is as relevant at regional as at national level (although regional variation in starting conditions will of course complicate such comparisons).

There are also political reasons for concern about inequality in how well regions fare. Politicians usually have a regional interest to defend, ensuring that geographical differentials remain high up the political agenda; while national governments (and international bodies like the EU) will want to keep all parts of their jurisdiction happy to avoid discontent and (at the extreme) secessionist demands.

But are also there welfare reasons for concern? On the surface it may seem obvious that there are, but it is a question worthy of deeper consideration. Why, for instance, should a situation in which the poverty rate in the South East is the same as that in Yorkshire be regarded as preferable to a situation in which the poverty rate is higher in Yorkshire and lower in the South East (assuming for present purposes that the two regions had similar populations)? 
There seem to me to be two reasons to worry about inter-group disparities in themselves, both of which can be applied to regions. The first is if the inequality is held to reflect discrimination or injustice in the way one of the groups is being treated. While overt discrimination does not seem a plausible explanation of regional disparities, a charge of injustice may in some circumstances apply. Inter-group differences raise the question of why one group is doing better than another. If the infant mortality rate has been reduced to four deaths per 1,000 in one part of the country, why can this not be achieved elsewhere? In some aspects of well-being at least, inter-group disparities suggest that more could be done for the worstperforming groups. Of course, two important assumptions are required for this argument to hold: first, that the nation-state has a responsibility to ensure that national wealth is evenly distributed; and second, that inter-regional mobility is limited.

However, this still only gives us a weak case for regional cohesion. To return to the example above, it makes the non-controversial claim that lowering the poverty rate in Yorkshire while holding the rate in the South East constant would be a good thing to do (assuming we begin from a situation where the rate in Yorkshire is higher). But is there a case for the stronger claim that the rate should be lowered in Yorkshire, even if this required higher poverty in the South East? For instance, we could bring about a fall in disparity in regional poverty rates by taking $£ 100$ from a family $£ 50$ above the poverty line in the South East and giving it to a family $£ 50$ below the poverty line in Yorkshire. But should the social welfare function identify people by where they live in this way?

In a static model there appears to be no reason why between-group disparities should cause greater concern than within-group differences. From behind a Rawlsian veil of ignorance, a rational individual who stood an equal chance of being sent to live in the South East or Yorkshire would be indifferent between a situation in which the poverty rate was zero in the South East and 20 percent in Yorkshire and one in which the poverty rate was 10 percent in both regions. In both scenarios, she stands a 10 percent chance of finishing poor. (Alternatively, she may well opt for the former situation, on the grounds that if she is to be poor she would prefer to be in greater company. See d'Ambrosio and al., 2002.)

However, introducing a dynamic element changes the situation. If one's concern is not just with whether or not one will be allocated into poverty, but also with what happens next and to one's children, the choice from behind the veil looks rather different. For instance, being unemployed in a low unemployment region may offer less in the way of companionship than being unemployed in a region of high unemployment, but more chances of finding a job. Regional levels of poverty and unemployment may also be important in reinforcing or moderating intergenerational transfer mechanisms.

In his 1988 paper, 'Why Should We Care About Group Inequality?', Loury puts forward the following case for concern about differences in outcomes for ethnic groups. He assumes that people begin life with endowments of social capital, 'nontransferable advantages of birth which are conveyed by parental behaviours bearing on later-life productivity' (p.254). Further, families group themselves into social clusters, within which local public goods are provided uniformly to the young. Peer influences, friendship networks and contacts which generate information about the world of work are all examples of such goods. If these community goods (or indeed 
'bads') are provided exclusively to cluster members, with outsiders excluded, and if people tend to cluster within ethnic groups and not across them, he argues that historically generated differences between the groups (in income, for example) will not disappear over time as they might otherwise be expected to do, but will tend to persist, even where there are no underlying differences in tastes or abilities.

'The inequality of family circumstances generated by historical economic discrimination is exacerbated by differential access to the benefits of those quasi-public resources available only in the affiliational clusters...Or, if you prefer, a positive intragroup externality is exerted by the relatively more numerous higher income [ethnic] majority families on the lower income [ethnic] majority families of the same communities' (p.256).

There are some problems with applying this argument to the case of regional disparities, the most obvious being that Loury's very point is that mere geographic proximity will not guarantee the sharing of community goods. Yet the essence of the argument still seems relevant. (Once again, we require the assumption of limited inter-regional mobility, but this seems particularly justified in the case of poorer groups.) It appears very likely that children growing up poor in poor communities will have less chance of finding an exit strategy than those living and going to school in mixed peer groups (even if the day to day effects of being poor are felt more deeply among the latter group). There is indeed evidence to support this: in a review of the literature on this topic, Haveman and Wolfe (1995) find that:

'growing up in a neighbourhood with "good" characteristics (e.g., residents with more education and income, and less unemployment and welfare recipiency) has a positive effect on a child's choices regarding schooling and earnings' (p.1871).

Burgess et al. (2001) find a small but significant role for school and area characteristics in explaining later adult earnings, controlling for individual and family characteristics.

If regional characteristics do have an impact, the most equitable outcome is then to iron out regional disparities (and to make the transfer from the non-poor household in the South East to the poor household in Yorkshire) - although it must be said that the regions we are able to work with here are on a rather larger scale to any of the area categories used in the research referred to. This is the issue we turn to now.

\section{Which level of region?}

I have argued that there are both practical and ethical reasons for concern about regional disparities. But this leads us to the question of which is the right level of region to look at. This paper focuses on the 'NUTS1' region, of which there are 74 altogether in the EU, including twelve in the UK (North West, South East etc), eight in France, sixteen in Germany and seven in Spain. ${ }^{1}$ It is clearly a fairly aggregated level: the regions average nearly 5 million people, and six EU countries consist of 
just one NUTS1 region each (Portugal, Sweden, Finland, Ireland, Luxembourg and Denmark $^{2}$ ).

That we lose the ability to isolate internal disparities in a country the size of Portugal, with 10 million inhabitants, illustrates the weakness of using NUTS1 as our regional level. It would be easy to make a case for analysis at a more detailed level: the smaller NUTS2 regions, corresponding to county level in the UK, région in France, and province in Italy, would seem a more promising starting point. For instance, the travel-to-work area corresponds more closely to the NUTS2 region. If it is the area within which people are likely to travel it may also be the relevant comparison group for relative poverty and exclusion measures. In addition, in several countries regional government coincides with the NUTS2 region (this is true in Italy and Spain, while the French région has considerable planning powers; see Putnam, 1992 and Norton, 1994). Finally, NUTS2 regions are sufficient in number to allow analysis of the relations between different indicators within a country: there are 37 NUTS2 regions in the UK, for example, and 22 in France.

However, the choice of the NUTS1 region is imposed by data availability. NUTS2 level analysis is simply out of the question for many of the variables examined in the paper. In particular, household panel surveys rarely have sufficient sample sizes to allow detailed analysis at this level. Furthermore, while a lower level might be preferable, disparities between NUTS1 regions remain of considerable interest given that the standard is comparison between national average figures. At the same time, the structural factors driving economic opportunities operate on a fairly wide scale - in this respect NUTS1 level analysis may be the more appropriate. In addition, in some countries the level of regional government is in fact the NUTS1 level: this will be true for England if devolution goes ahead, and is already the case for Scotland and Wales and for Germany. (One minor advantage of the NUTS1 region worth noting is that the regions are more similar to one another in size than is the case at NUTS2 level. There are still huge differences: the largest NUTS1 region, North Rhine/Westphalia, has nearly 18 million inhabitants while the smallest, Bremen, has under 700,000 and the second smallest, Brussels, fewer than a million. But the ratio of largest to smallest is now in the region of twenty-five rather than one hundred.)

\section{Choice of indicators - and how do we measure disparity?}

The EU mission was to find indicators of poverty and social exclusion. This paper takes a broader approach, looking for measures of regional well-being. It does this for two reasons.

Åland Island in Finland is in fact a separate NUTS1 region, as are the Portuguese islands of Madeira and the Azores, but these are not analysed separately here: they are much smaller than other NUTS1 regions and in many cases separate data are not available for them. 
First, the broader approach seems the better starting-point when there is still much to be learned about regional disparities even in a standard indicator such as average household income.

Second, while the concept of social exclusion continues to dodge efforts to pin it down definitively, it is broadly agreed that it is concerned with overlap between deprivation in several spheres. Thus according to the UK government, social exclusion is 'a short-hand term for what can happen when people or areas suffer from a combination of linked problems such as unemployment, poor skills, high crime environment, bad health and family breakdown' (Social Exclusion Unit, 2001, p.10). The EU Task Force has similarly called for social exclusion to be analysed as 'the problem field determined by the link between low income position, bad labour market position and disadvantages concerning non-monetary aspects of life' (Eurostat, 2000, p.33), and the Commission's recent report on Income, Poverty and Social Exclusion consequently looks explicitly at the share of the poor who are deprived in other spheres (Eurostat, 2000). (Burchardt et al (2001) are an exception here: they argue that lack of participation in any one of the four 'key activities' they identify is sufficient for social exclusion, although they also investigate the extent of exclusion on multiple dimensions.)

This introduces difficulties for defining social exclusion using regional level data. We know whether a region suffers from high unemployment and whether mortality rates in the region are high and education levels low. But in few cases can we link data sources to discover whether the unemployed are those same individuals with low skills and poor health. ${ }^{3}$

Of course, we could develop a measure of how far a region is excluded, as opposed to the share of individuals within the region suffering from exclusion: the Social Exclusion Unit report above refers to areas as well as individuals. (See e.g. Glennerster et al, 1999, on issues surrounding area exclusion in the UK.) But the regions I am using here are rather too large for this to be a plausible approach: can an area the size of the North East of England be said to be excluded? It seems more sensible to start off by exploring whether it can be said to have lower well-being. (Once our well-being indicators are assembled, we may be able to make some statements about multiple deprivation, and from there about regional exclusion.)

Interestingly, once away from the issue of multiple dimensions of exclusion, there turns out to be little difference between the indicators we would choose to measure well-being and those we would choose to measure exclusion. The Atkinson report (pp.73-4) stresses the importance of capturing cumulative disadvantage, and calls for continued efforts to make this possible, but opts for the most part to measure deprivation in different dimensions separately. But the indicators chosen bear strong similarities to those examined here. This is perhaps in part because social inclusion is effectively seen as synonymous with well-being, making exclusion its inverse; and in part because the share of people who are excluded is itself an important measure of the well-being of a society.

The European Community Household Panel allows many of these links to be made, but sample sizes at regional level are in general not large enough to allow extensive analysis of the interaction between variables. 
The paper aims to measure five dimensions of well-being: material wellbeing, health, education and literacy, and participation in two spheres - productive and social. A concept of well-being (or conversely of deprivation) broken down into these broad areas is widely used and accepted, although with variations. The participation domain is often limited to the labour market alone, for instance. The UNDP Human Poverty Index for industrialised countries includes indicators for each of the first four, with participation treated as a single domain and represented by long term unemployment (HPI2, see UNDP 1998). Robinson and Oppenheim (1998) propose social exclusion indicators in four areas: income, labour market, health and education.

Burchardt et al. (2001)'s framework is rather different in seeking to identify only outcome measures of social exclusion. They look for indicators which reflect direct exclusion in one of four domains - consumption, production, political engagement and social interaction. Poor health and education are seen as factors which might make exclusion in any of these spheres more likely, but are not seen as outcome measures in themselves. Indicators in these areas are not examined, and much more attention than usual is paid to measures of social and political exclusion.

Other studies have used a more extensive set of domains. The Swedish Level of Living Surveys, for instance, include the five used here plus an additional four: housing, exposure to crime, political participation and leisure pursuits (Erikson, 1993). In many cases additional variables fit easily into one of the five, and there seems no strong reason for adding dimensions. Housing is included in this paper under the material well-being domain and political participation and, to a limited extent, leisure pursuits are discussed as part of social participation. But exposure to crime is one area which cannot be slotted in. We might want to add to it measures of air and water quality (although these could also be included under health), perhaps in a 'local environment' domain. Indeed, both crime levels and pollution are of particular interest here: as contextual variables they are perfectly suited to a regional study, while they fit only clumsily (and usually not at all) into individual studies. But because of the lack of data on either of these, this potential sixth domain is ignored here for the moment.

What indicators should the EU be collecting to represent the five domains? The indicators which we might choose if data were no object are discussed within the relevant sections below. The list here shows the indicators which are in practice examined in the paper, reflecting the balance between the ideal and the constraints of data availability.

\section{Material well-being}

* Average equivalised household income (Luxembourg Income Study)

* Poverty rate measured against a national poverty line (LIS)

* Poverty rate measured against a region-specific poverty line (LIS)

* Decile ratio (LIS)

* Measure of housing quality (European Community Household Panel)

$>\quad$ Participation in productive life

* Unemployment rate (European Labour Force Survey)

* Long-term unemployment rate (European LFS)

* Share of working age adults 'not in employment' (European LFS) 
$>\quad$ Education

* Share of adult population with ISCED 3 qualifications or below (European

LFS)

* Share of 17 year olds in full-time education (European LFS)

$>\quad$ Health

* Infant mortality rate (Eurostat)

* Standardized mortality rate (Eurostat)

* Self-assessed health measure (ECHP)

$>\quad$ Social participation

* Club membership (ECHP)

* Social contact with friends, relatives and neighbours (ECHP)

How do these indicators compare to those proposed by the European Commission and the Atkinson report? The list agreed at Laeken, heavily influenced by Atkinson et al., included ten 'primary' indicators, covering all of the first four domains (the idea is that 'secondary' indicators will cover the same areas but provide additional depth, detail and robustness checks). Indicators are included for the distribution of income, poverty incidence and persistence, the poverty gap, longterm unemployment, jobless households, early school leavers, life expectancy and self-assessed health. The indicators looked at here include measures for each of these where data allows; differences are discussed in the relevant sections below.

The main differences not driven simply by data availability are three. First, the paper includes a measure of housing quality. Housing is put forward in the Atkinson report as a primary indicator, but has not been incorporated in the final list agreed on. However, the report on which the Laeken decision is based recommends that more work be done to develop accurate comparative measures in this area (Social Protection Committee, 2001). Second, the paper examines indicators intended to capture some aspects of social participation. This is a domain which both Atkinson and the Social Protection Committee classify as 'to be developed', and indeed, cross-country disparity in results do support the view that more work is needed to make indicators in this area truly comparable.

Finally, of course, the paper differs from the Laeken list on the key issue of the single regional disparity indicator, and this brings us on to the question of how regional disparity is to be measured here. As we have already seen, the Laeken decision is to take the coefficient of variation of regional unemployment rates as the disparity indicator. Atkinson et al. argue that this makes little sense, not just because it is arbitrary to single out unemployment as the basis for the indicator, but also because of the problems of comparing the extent of disparities across countries with differing numbers and sizes of regions (pp.76-7). Taking NUTS1 regions as the unit of measurement solves the size problem to some degree, as the basic concept of the region is at least the same in each country; it would clearly be misleading to compare UK regions with French communes, for example. But it remains true that dispersion will tend to be less in a country with 3 regions than in a country with 30 . Furthermore, as Atkinson et al. also note, disparities can only be interpreted if they are examined alongside the national average: 'a Member State that had a 10 percent unemployment rate across all regions might score well on consistency, but this can 
hardly be a performance to be commended' (p.77). What we want to know is that a national rate of 5 percent disguises a regional low of 1 percent and a high of 10 percent.

This paper does not compare measures of disparity across countries, but explores the extent of regional dispersion using maps and graphs. A graph does not allow for neat rankings of countries by level of dispersion, but does let us size up two aspects of a country's performance at once, balancing the average ranking and the regional dispersion around the average. In most cases the graphs used here also let us take into account how many regions a country has.

Coefficients of variation are used on occasion in the paper, to compare the extent of disparity in the same country at different points in time, and to compare dispersion on different (but similar) indicators. The paper also examines the strength of correlations between some of the indicators, both across the EU as a whole and within particular countries, and in places uses regressions to further explore the links between indicators.

\section{Material well-being}

There are arguably four aspects of material welfare which a study of regional wellbeing must address: average living standards in the region; the level and severity of poverty; the degree of income inequality; and the quality of housing. Existing data sources allow us to say something - although not always something very complete or convincing - about all four of these areas.

\section{Average income}

The material welfare of European regions is most commonly proxied using regional GDP per capita, available from Eurostat right down to NUTS3 level (e.g. European Commission, 1996; Hills, 1995). Regional GDP is of course of some interest in its own right as it reflects regional production, but as a measure of regional living standards it is fairly weak as it fails to take account of the impact of taxes and transfers.

Unfortunately, more accurate sources of regional income data are thin on the ground. In some countries the census may contain information on incomes; in others, including the UK, it does not. Census data are in any case not publicly accessible in many countries. The most promising option is household survey data, but sample sizes at regional level are frequently too small for calculations to be treated as robust, as will be discussed further below.

The data I use in this section are all from the Luxembourg Income Study, which collates and standardises household datasets from a growing number of countries. All EU member states other than Portugal and Greece are currently represented in at least one wave. The advantages of using LIS are obvious: all datasets are gathered in one place and - at least in principle - have been harmonised to make income definitions comparable. The main disadvantage is that the dataset included for each country may not always be the one with the greatest regional possibilities, and there may be something to gain from exploring alternative national data sources. For instance, in the UK case, the Family Expenditure Survey is included in LIS, while the newer Family Resources Survey has larger regional 
samples. (The Family Resources Survey is currently in the process of being 'Lissified' and will soon be available through LIS.)

There are also questions about how comparable income definitions really are across countries. In countries where taxation and spending are higher, post-tax income will be lower but individuals may bear less responsibility for financing services such as health and education. In addition, post-tax income fails to reflect the burden of indirect taxation: countries with a higher share of taxation raised through consumption taxes will have higher nominal disposable income but also higher prices. Finally, variations in housing systems will affect results. In countries with large owner-occupier sectors and/or large social housing sectors, substantial income in kind from housing ought to be added to the income measure to make it comparable with income in countries where most people rent privately.

Each of these problems, of course, will affect comparisons of rates of poverty and inequality as well as comparisons in average income. Gardiner et al. (1995) investigate the effects on international comparisons of income distribution of differences in health and housing systems and argue that adjusting for either can significantly change results. On the other hand, they also argue that only sophisticated adjustments (which are not always made possible by the data) are worth making: for instance, examining data for the UK and France, they find that taking income pre-housing costs produces a better approximation to their ideal than the crude adjustment of taking income after housing costs.

The income measures used here and for the estimates of poverty and inequality below are measured prior to housing costs and no attempt is made to impute in-kind income from either housing or public expenditure. Any straight comparison of results across countries may be misleading and should not be given too much weight. However, as our interest here is in disparities within countries, these issues are of less concern to us than they might be - although the housing question in particular may still have some impact given very large regional variations in housing costs in countries such as the UK.

Average income has been calculated by NUTS1 region for all EU countries included in LIS. For several countries (Spain, France, Italy, Sweden and Finland), LIS datasets give NUTS2 level regional identifiers, but these have been aggregated here to NUTS1 level, making results more robust and allowing analysis at the same level of aggregation as for the UK, Germany, Belgium, the Netherlands and Austria. Denmark, Ireland and Luxembourg can also be included as single region countries. (Data are not available for the same years in all countries, however. LIS organises the data into four 'waves', of which the three most recent are used here: Wave 2 around 1985, Wave 3 around 1990 and Wave 4 around 1995. ${ }^{4}$ )

Figure 4.1 shows average household incomes after taxes and transfers by NUTS1 region for the most recent wave of data, 1994-96, for all EU countries covered

$4 \quad$ Data are available as follows for each country: Belgium 1985, 1992 and 1996; Denmark 1987 and 1992; Germany 1989 (West Germany) and 1994 (united Germany); Spain 1980 and 1990; France 1984, 1989 and 1994; Ireland 1987; Italy 1986, 1991 and 1995; Luxembourg 1985, 1991 and 1994; Netherlands 1987; Austria 1995; Finland 1987, 1991 and 1995; Sweden 1987, 1992 and 1995; UK 1986, 1991 and 1995. 
Figure 4.1: Average household income by region, LIS wave 4 (1995)

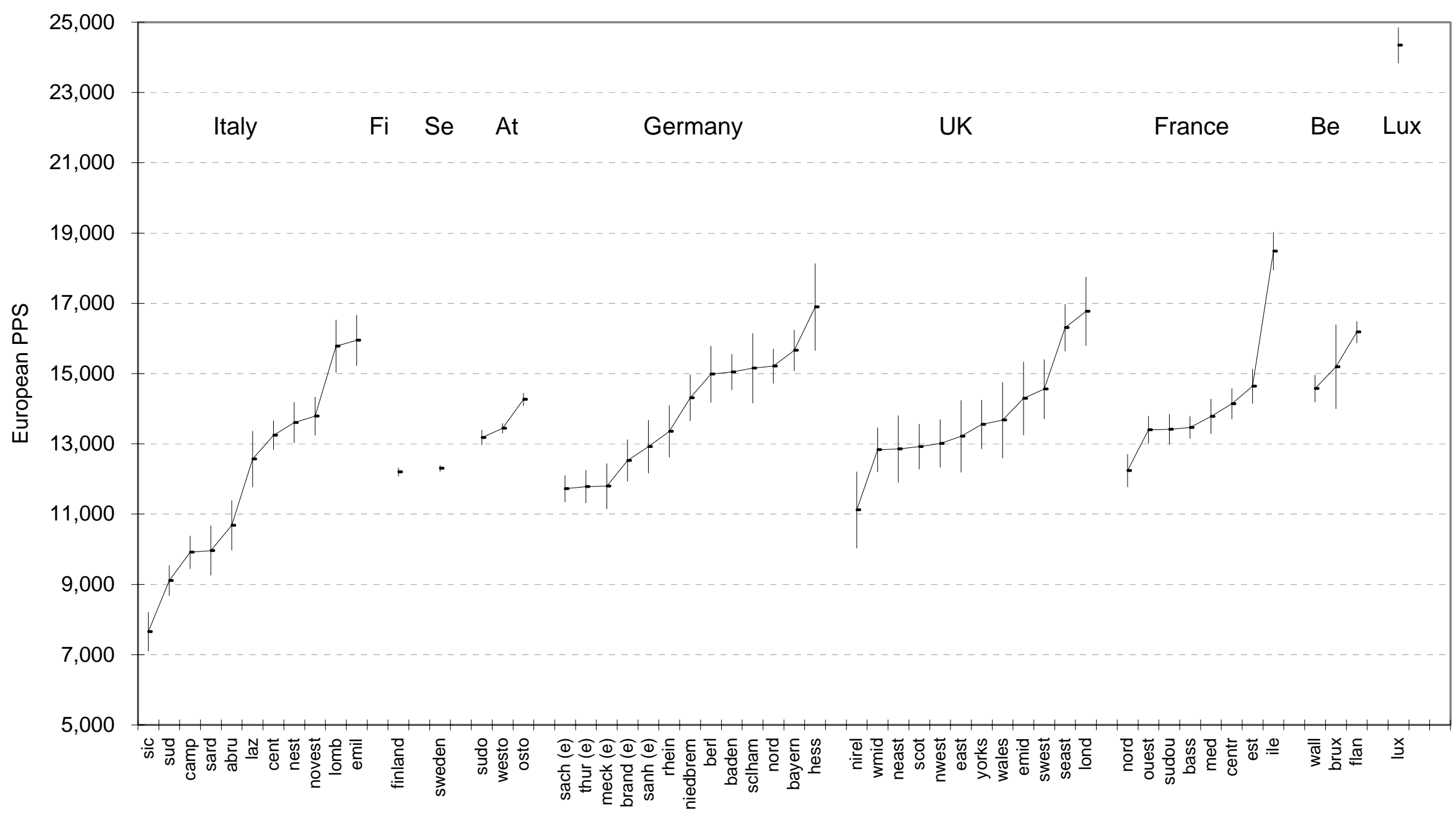

NB 1994 data for Germany, France, Luxembourg; 1996 data for Belgium. 
by this wave. ${ }^{5}$ The figure is drawn with 'cat's whiskers' showing the 95 percent confidence intervals for each estimated average. These remind us that in many cases the size of a regional sample is just too small for us to be certain, or near certain, that the region is really richer or poorer than its neighbour. In the UK case, for example, London and the South East are shown to have average household income significantly higher, and Northern Ireland income significantly lower, than that in the rest of the country, but confidence intervals for all other regions overlap. ${ }^{6}$

Table 4.1 gives number of households in the sample by region for each wave of data, and the differing lengths of the whiskers are immediately explained. Sample sizes in the LIS datasets are particularly small for Germany, and only slightly larger for Italy and the UK: in a handful of regions samples fall below 200 households. In contrast, samples are much larger for the Spanish, French and Austrian regions, and standard errors are lower as a result. In the Belgian data, samples are large for the Flanders and Wallonia regions, but very small for Brussels.

In two cases, regions have been merged so as to increase sample size and produce more robust estimates. The German city-state of Hamburg has been combined with the surrounding region of Schleswig-Holstein; and Bremen has been combined with Lower Saxony. In both instances the cities are richer than the surrounding regions, but are arguably still reasonably similar. In other cases, however, neighbouring regions are too distinctive for merges to be sensible. Little would be gained, for example, from combining Brussels with either Flanders or Wallonia or Northern Ireland with Scotland. Sicily and Sardinia are a more difficult case: as island regions on Italy's periphery they bear many similarities, yet the LIS data shows Sardinia to be significantly better off. It is probably better to have a rough idea of the position of each island than one averaged result for the two.

Keeping an eye on the whiskers, then, what does Figure 4.1 tell us about the dispersion of regional incomes in Europe? The larger countries all display considerable regional disparities, although the range is greatest in Italy. Belgian regions are clustered towards the upper end of the distribution, with Austrian regions somewhat behind. Luxembourg, well-known as the richest country in the

5 Incomes have been equivalised using the square root of the number of household members, following Atkinson et al, 1995. They have then been bottom-coded at 1 percent of equivalised national mean income and top-coded at 10 times national median non-equivalised income, following Gottschalk and Smeeding, 1997 and Jesuit et al, 2001. This limits the impact of extreme values at either end of the distribution, reducing standard errors, which is important given small regional sample sizes. All zero incomes have been dropped as in most of the LIS data sets it is impossible to distinguish between genuine zero incomes and missing values: see Atkinson et al, 1995. Finally, incomes were converted from national currencies to a European Purchasing Power Standard for household final consumption expenditure: see European Commission, 1994 and 1999.

However, these confidence intervals are rather more restrictive than they need to be. We want to be 95 percent confident that average income in region $\mathrm{A}$ is higher than that in region B. Requiring that the whiskers do not overlap represents the stricter condition of 95 percent confidence that region A's average income is higher than a value $x$ and, independently, 95 percent confidence that region B's average is lower than $x$. Calculating joint significance tests is unwieldy as it involves separate calculations for each pair of figures, so the more restrictive results are presented here. 


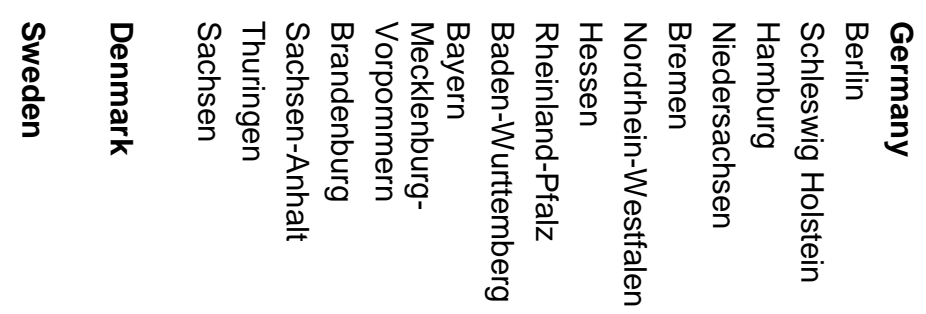

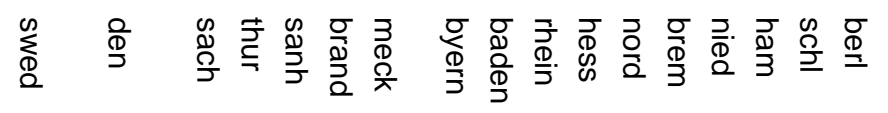

兽

$\begin{array}{ll}\vec{N} & \vec{N} \\ \stackrel{\infty}{\infty} & \mathbb{0} \\ \omega & 0\end{array}$

गु

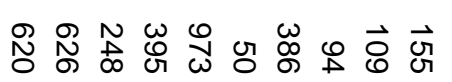

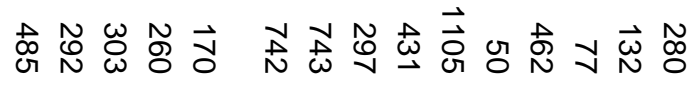

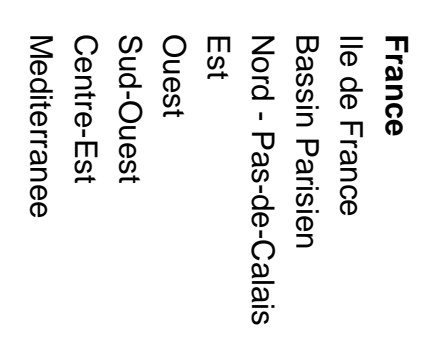

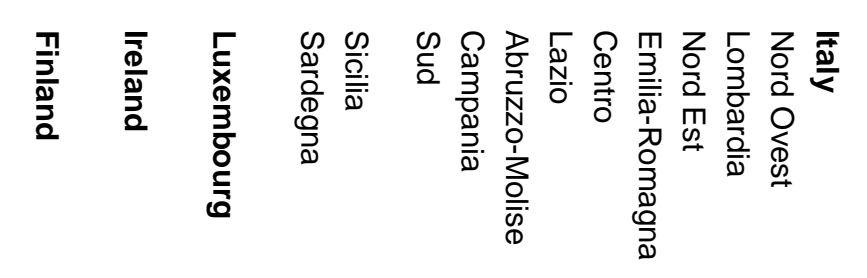

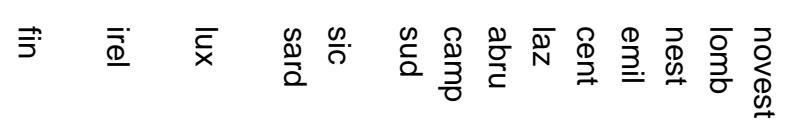

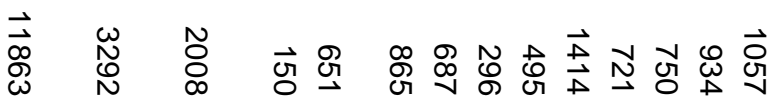

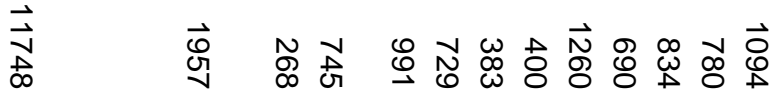

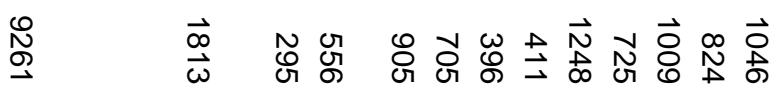

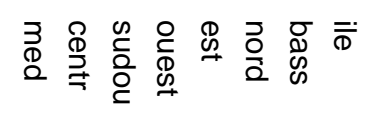

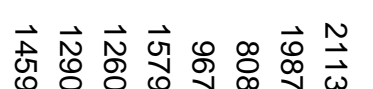

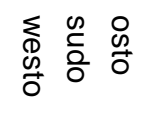

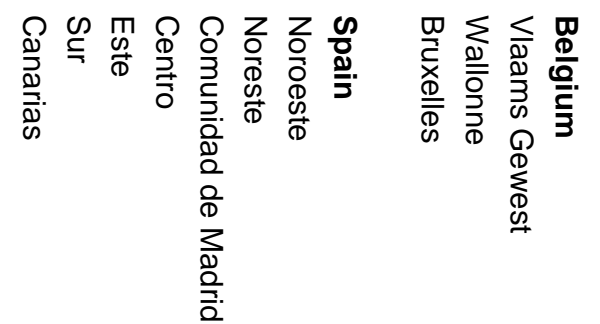

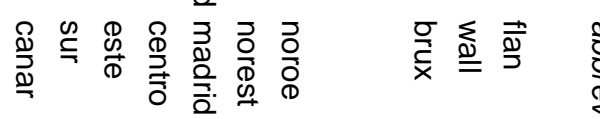

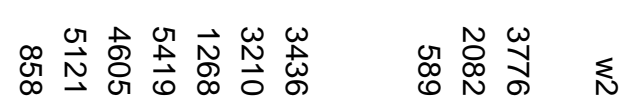

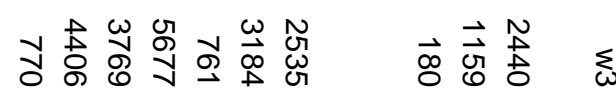

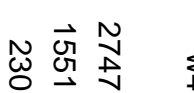

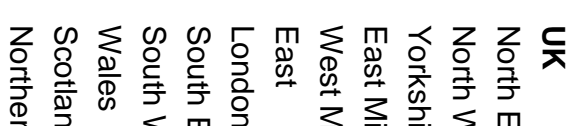

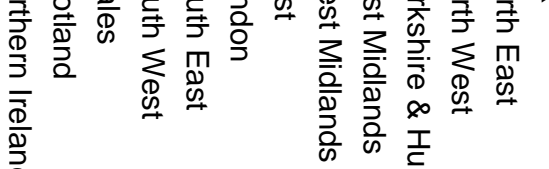

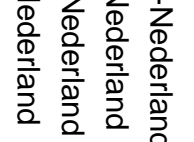
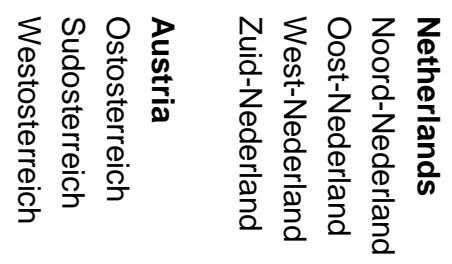

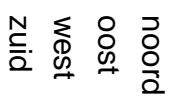

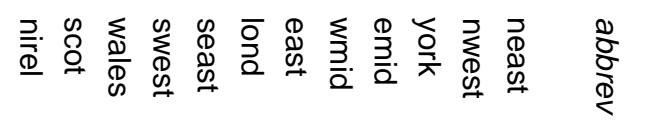

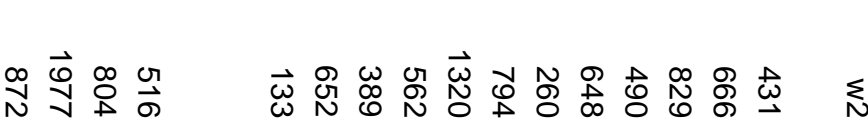

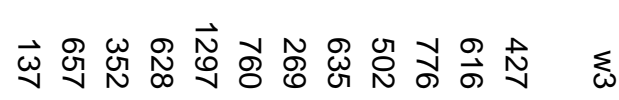

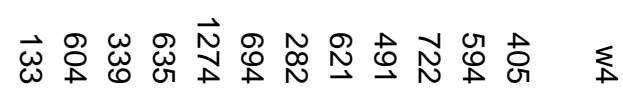


EU, turns out to have average household income far higher even than the next richest region, Ile de France (which contains Paris).

Within countries, income disparities are much as might be expected. Italy displays a clear north-south divide: the five southern Italian regions are the poorest in all countries with data available, with Sicily significantly poorer than the rest. Lazio (the region containing Rome) forms a bridge to the middle incomes of central, north-east and north-west Italy, with Lombardy (Milan) and Emilia-Romagna off on their own at the top of the distribution. The Flemish speaking area of Belgium is significantly richer than the French-speaking area, with Brussels appearing to fall in the middle, although the very small sample size for Brussels makes this result questionable. The eastern region of Austria, which includes Vienna, is significantly richer than the western region, which is in turn slightly richer than the south. In Germany, the division is broadly speaking an east-west one - although RheinlandPfalz is a West German region which ranks among the East. Beyond this, no single region stands out as much richer or poorer in Germany: samples are just too small to allow us to pick up subtleties within either group.

One interesting point is that France and the UK show surprisingly similar patterns of disparity to each other. In both, we have the rest of the country lagging well behind the capital and its surrounding area - Ile de France on the one hand and London and the South-East on the other. Both also have one region which is significantly poorer than the rest - the Northern region of France and Northern Ireland in the UK. But in France, the middle group shows some (limited) evidence of an east-west divide, while in the UK the divide is very roughly north-south (unfortunately, as for Germany, large standard errors make it difficult to separate these regions).

These geographical patterns are better illustrated in Map 4.1 which shows income quintiles for the nine countries with available data. Broadly speaking, incomes appear to fall with distance from Europe's centre, with the exception of the areas surrounding capital cities.

Figures 4.2 and Map 4.2 show the same data for 1990, which allows us to see how Spanish regions fit into the distribution. The Spanish data display an east-west division: along with Madrid, north and north-easterly regions are significantly better off than the centre, south and north-west. But even the richer Spanish regions appear on a par only with the poorer areas of the Italian south. Map 4.2 includes Spain, Denmark and the Netherlands but excludes East Germany and Austria: the wealthy zone now runs clearly down through central Europe, from Denmark through Germany to Northern Italy, along with Paris, Luxembourg and Southern England.

Figures 4.1 and 4.2 in combination let us examine the persistence of withincountry rankings over time (data for 1985 - and for Spain 1980 - are also referred to though not shown). The divisions down the middle of both Italy and Spain are clear in both periods. (In Italy the divide seems to have widened, but the 1985 wave of data belies the impression that this is a continuous trend.) Similarly, the predominance in the UK of London and the South East and in France of Ile de France is found in all years, although in both countries the relative position of the poorer neighbour - Northern Ireland and the North - seems to have gradually worsened over time: in 1985 neither region was significantly poorer than the rest of the country. At the top of the distribution, Luxembourg has been gradually extending its lead. 

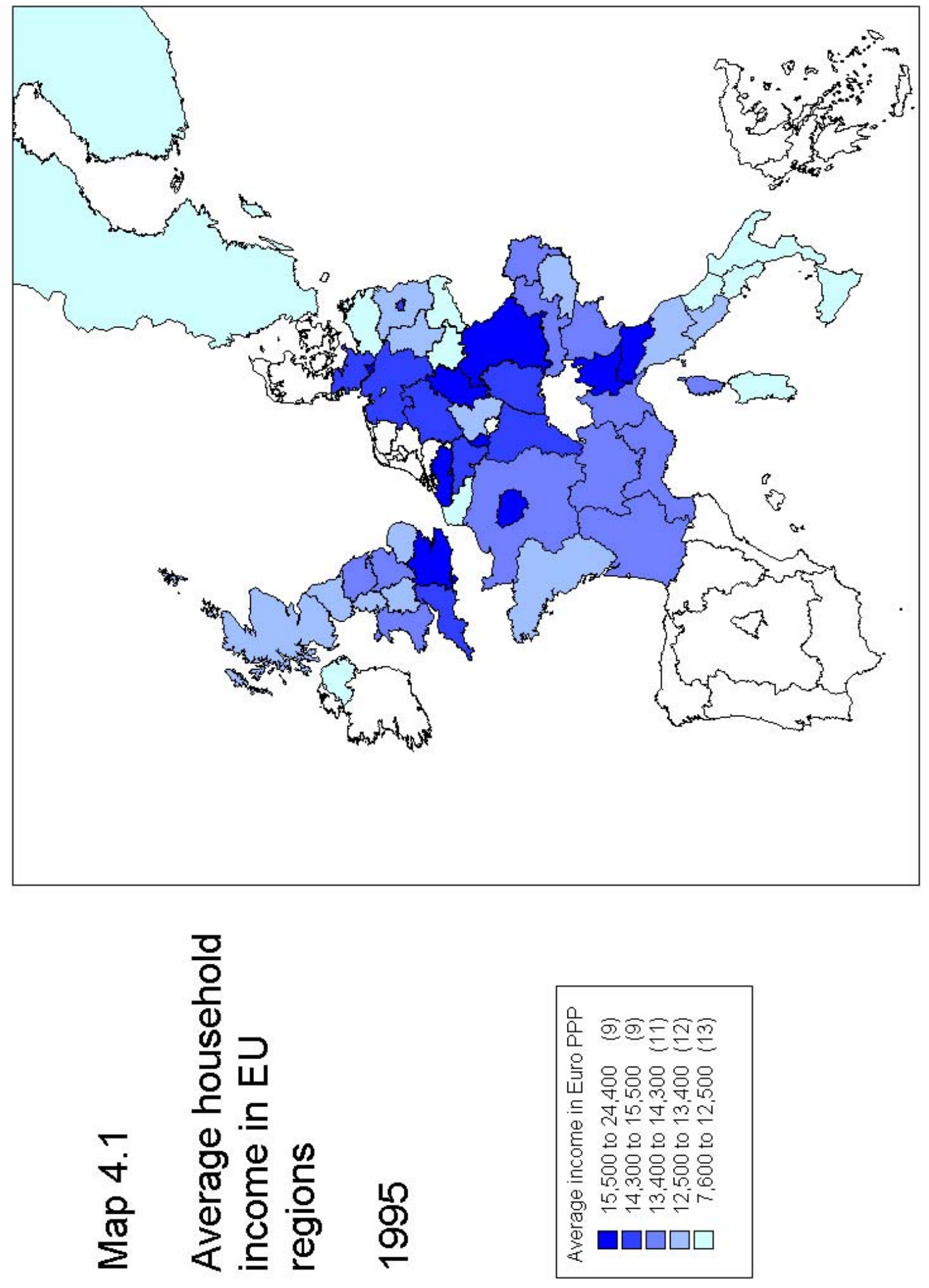

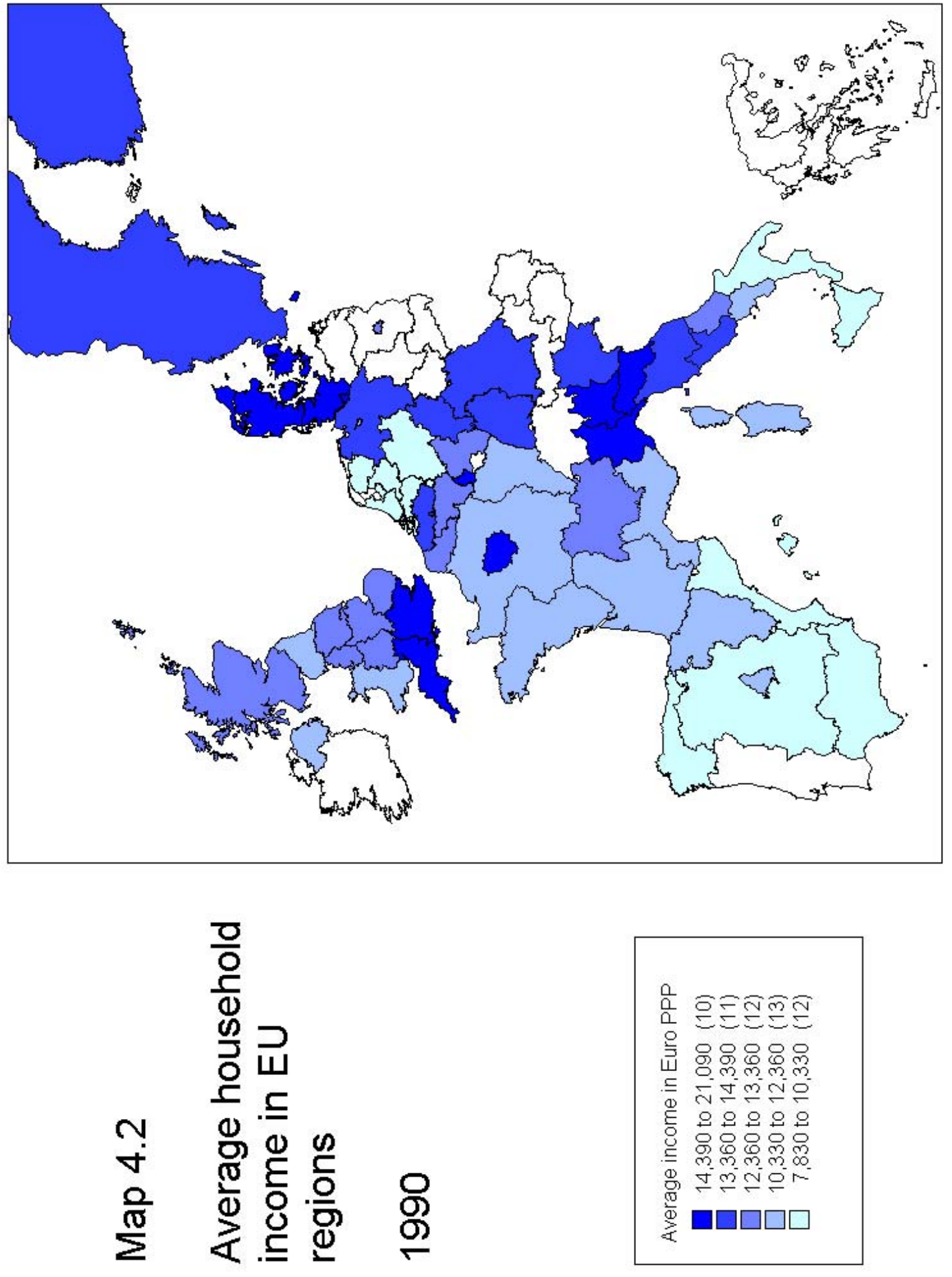

움 흘토를

产

뛈ำ

등 999999

잉్ㅇ్ㅇ్요

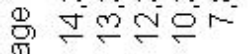

$\stackrel{\square}{2} \square \square \square \square \square$ 
Figure 4.2:

Average household income by region, LIS wave 3 (1989-91)

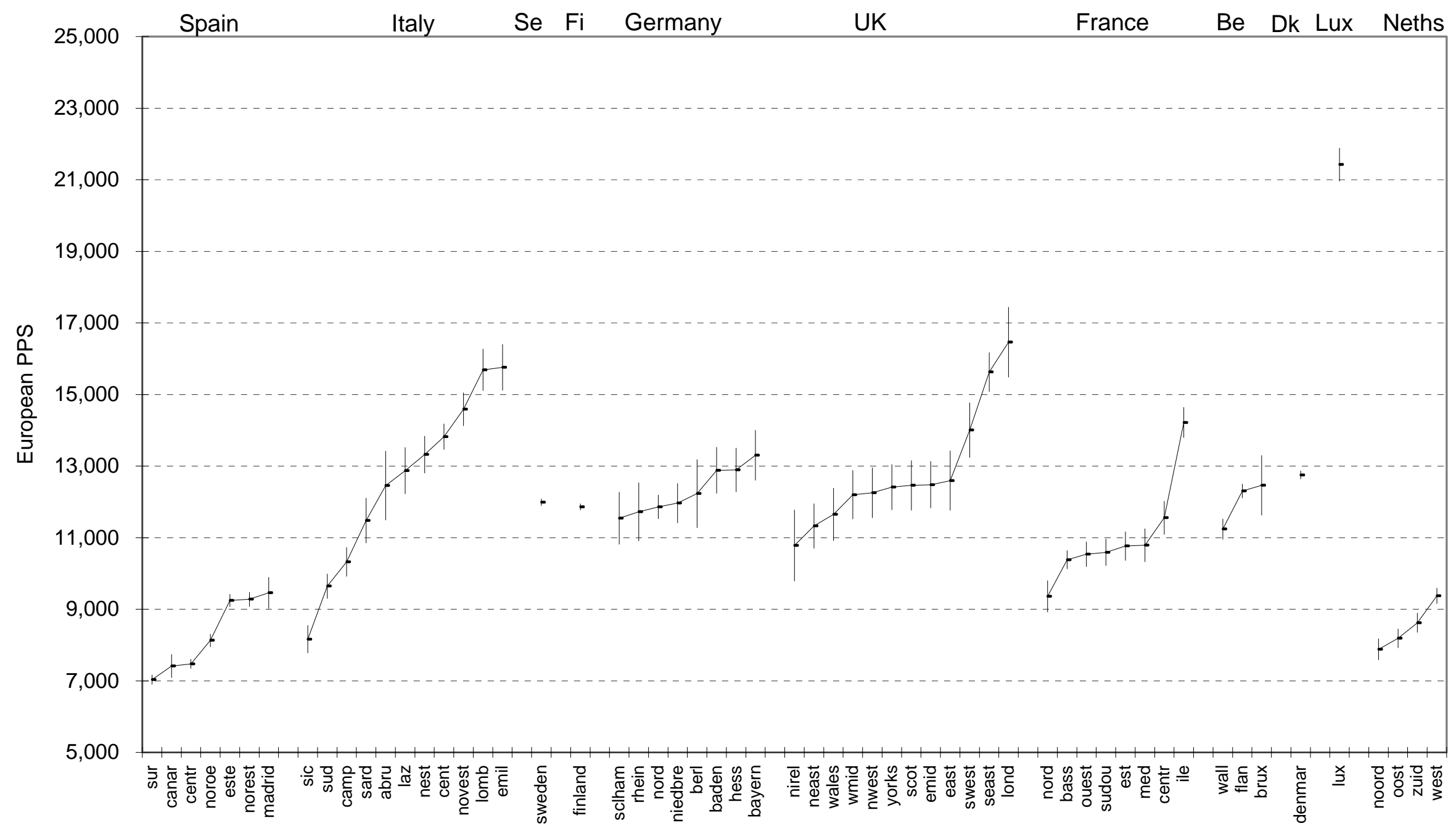

Note: Data for the Netherlands for 1987. 
In Italy, the ordering is also very consistent within the group of poorer regions (with the exception of Sardinia, for which sample sizes are very small). Sicily is always at the bottom, followed by the South, Campania and then Abruzzo. Within the richer group, Lombardy and Emilia Romagna rank persistently top, with the North East, North West and Central regions following. The North East was significantly poorer than the latter two in 1985 but seems to have caught up by 1995 . The position of Lazio also changes - significantly richer than all but the top two in 1985 , by 1995 it has fallen towards the bottom of the middle group.

Within the poorer Spanish group, the South and Central regions rank significantly below the North East in both available waves of data.

In France the Central region is consistently richer than the West, Southwest and Bassin de Paris (as is the Mediterranean, but these differences are not always significant). There is almost no consistency at all for Germany or the UK, and ranking of West German regions changes completely between the two waves, while in the UK the south-west repeatedly takes third place to London and the South East but the positions of other regions shift around. As already noted, few regional differences in either country are significant, and these shifting rankings are almost certainly explained by lack of robustness in the results due to small sample sizes.

It was argued above that average household income data is preferable as a measure of regional economic welfare to GDP per capita because the latter reflects the economic situation prior to taxes and transfers. The GDP measure ought to have the advantage of robustness, however, as it is not based on survey data. ${ }^{7}$ Figure 4.3 shows both LIS average income data for wave four and regional GDP per capita in PPP for 1995. The aim is twofold - to check how plausible the income data appears, and (insofar as it does seem plausible) to explore the extent to which the regional income distribution post-tax differs from that prior to taxation.

In most cases rankings do not change enormously, but average income is much more evenly distributed than GDP, as would be expected. In some countries, equalisation is more effective than in others: Austria and Belgium seem perfect examples of progressive taxation systems. In the UK, London is doing its bit, although results for the rest of the country are a little odd. Scotland appears to have much lower per capita income than the Southeast, as expected, but the same level of per capita GDP. GDP levels for other regions in the middle of the UK income distribution support the view that rankings based on the LIS income data are not accurate for this group. It is also surprising to find very little redistribution from the Southeast (excluding London) to the rest of the country. In light of these findings, the UK figures were checked against data for post-tax income provided by the Inland Revenue Service. ${ }^{8}$ These suggest that the LIS data substantially underestimate income for Northern Ireland and the Eastern region, and probably also underestimate income in Scotland and the West Midlands, while overestimating in

GDP data are not immune to measurement problems themselves. Cameron and Muellbauer (2000) argue that methods of constructing Regional Accounts data for the UK prior to 1995 led to serious biases in the estimations of regional employment income, and hence of regional GDP: in particular, income for the South East would have been biased downwards. But this bias had been corrected by 1995 and so should not affect the data presented here. 
Figure 4.3:

LIS average regional income 1994-5 and GDP 1995

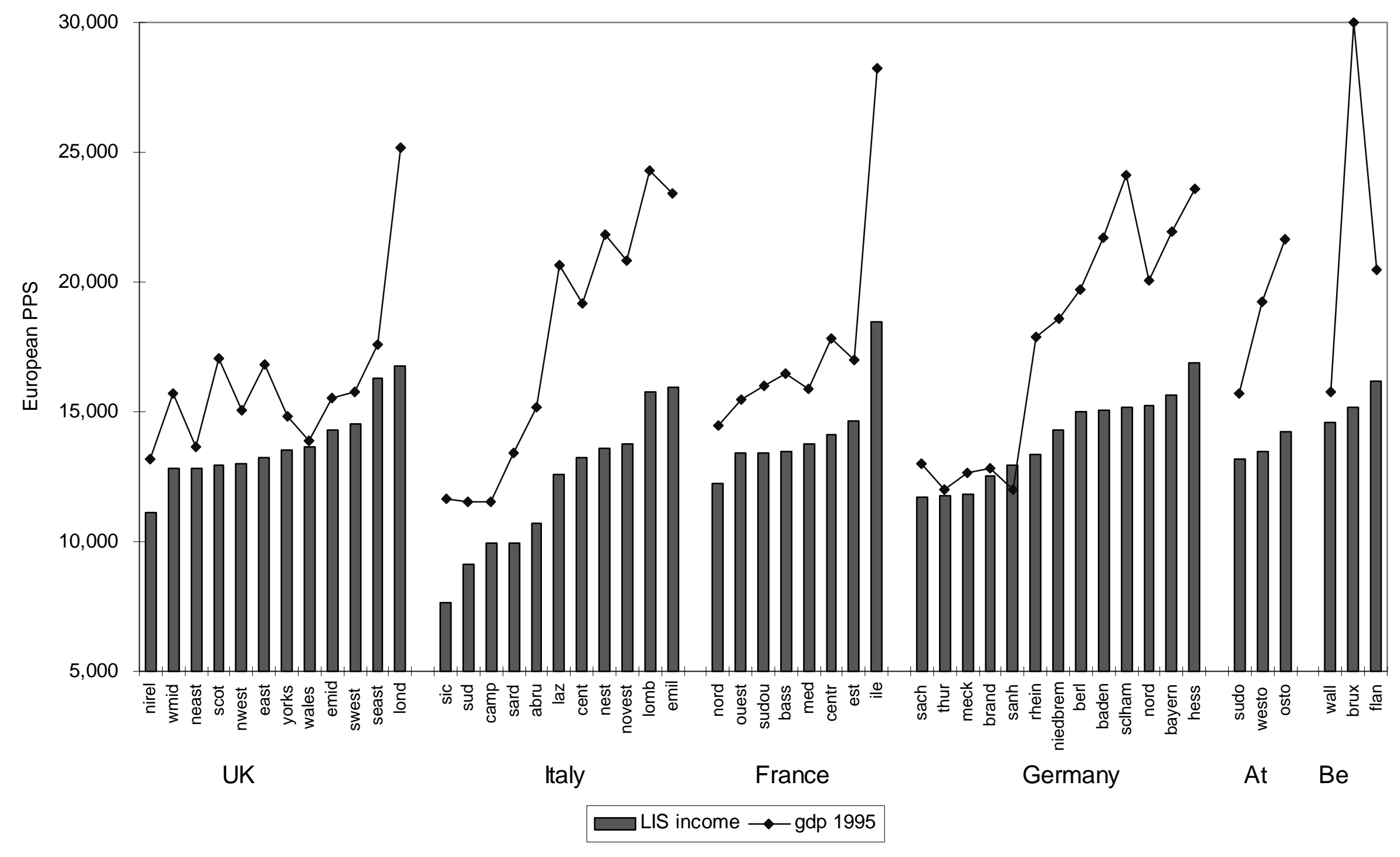

Note: LIS figures are deflated using PPPs for private final consumption; GDP using PPPs for GDP. 
Wales and Yorkshire. Further, income may be higher in London relative to the South East than the LIS data allow. Reordering regions according to IRS figures would iron out many of the bumps in the UK section of Figure 4.3.

In Germany the greater tax burden paid by the West is clear from the figure, while in Italy income is being redistributed from North to South. It is striking, however, that Sicily ends up with much (and significantly) lower per capita income than the South region or Campania, despite similar levels of GDP per capita. Similarly, Sardinia has considerably higher GDP than the rest of the south, but the difference in post-tax income is negligible - in this case, however, the small sample size for the income data is likely to be to blame.

\section{Poverty}

The problems of sample size highlighted above apply even more strongly to measures of poverty and inequality, which make greater demands on the data. Ideally, I would examine both a poverty headcount measure and a measure of the poverty gap in this section. But a regional headcount index alone proves a little too much for some of the LIS datsets, so for the moment the poverty gap is laid aside. (In addition to the poverty headcount and the poverty gap, both the Commission and the Atkinson report propose a measure of poverty persistence, but this requires the use of panel datasets which are rarely large enough to allow analysis at regional level.)

Other attempts have been made to compare regional poverty rates using LIS data. The starting point has been state level analysis for the USA: Rainwater et al. (2001) compare the child poverty rates of individual states in the US, Canada and Australia with the national rates of some EU countries. Jesuit et al (2001) extend this work to include regional breakdowns for France, Italy and Germany, this time examining overall poverty. However, they use a NUTS2 level breakdown for France and Italy (merging regions in two or three cases), which exacerbates the sample size problem, and they find few disparities which can be stated with statistical certainty. Aggregating regions to NUTS1 level allows us to make some improvements on this.

Before we look at any data we need to decide how to define poverty. While relative poverty lines are used as standard across Europe, they raise the question, relative to whom? In particular, recent debate has focused on whether a common EU poverty line should replace individual national lines (see e.g. Atkinson, 1998; de Vos and Zaidi, 1998). The EC definition adopted in 1994 plumped explicitly for national lines, defining the poor as those with 'resources ... so limited as to exclude them from the minimum acceptable way of life in the member state in which they live' (Eurostat, 1997, p.3). But some have argued that this definition loses validity as European integration proceeds, and that there is a growing case for a single EU line.

Here the question is the opposite one: in talking about poverty at regional level, ought we to move down from a national poverty line to individual regional

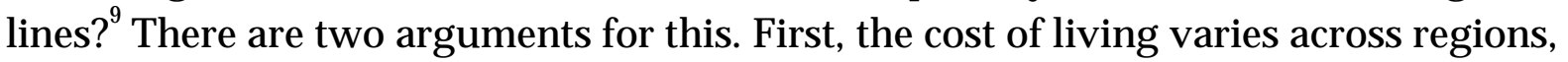
so the resources needed to achieve a given standard of living will differ within a

A single EU poverty line could also be applied across regions, of course. This is not done here so as to keep the paper from growing too large: in the current context, the difference between poverty rates based on national and regional poverty lines seems the more interesting one. 
country as well as between countries. This will be particularly important when income is measured prior to housing costs, but housing costs are not the only variable factor. Second and more fundamental, the set of requirements for participation may themselves vary. Just as there are ways in which our reference group is arguably growing outwards from the nation to the wider European community, in other ways the relevant comparison group is still likely to be our own town or region. To participate in a 'minimum acceptable way of life' we need to be able to dress, eat and travel in similar ways to our friends and colleagues. We need to be able to take up an invitation within our own social context and to reciprocate in kind. Our needs, then, are dependent on the community in which we live. Rainwater et al. (2001, p.37) take the approach of a regional reference group, arguing that 'this brings the definition of a poverty line closer to the social reality of the lives of the people being studied'. (As Micklewright 2002, p.16 points out, the region or state is probably far too aggregated a unit for this. But a regional line will still be closer than a national line.)

At the same time, however, there are other ways in which our reference group remains very much wider than the region. With the advance of technology we are more aware of conditions elsewhere: a child growing up in the south of Italy today is likely not only to see Milanese children on television but to talk to them over the internet. In addition, there is a strong argument that our reference group coincides with the level at which policy affecting living standards is made, whether or not we are affected on a day-to-day level by the situation of other citizens. ${ }^{10}$ Would it be acceptable that one section of society could afford to eat only baked beans, as long as they all lived in the same region and did not know anyone who ate any differently? As discussed in Section 2, injustice is one of the reasons regional differences are important.

I would argue that a study of regional well-being needs to include indicators of poverty measured under both definitions; both on the grounds of multiple reference groups, and because regional variations in the cost of living cannot easily be controlled for.

Figure 4.4 presents 1995 regional poverty rates using a national standard: the poverty rate is defined as the share of individuals living in households with income below 60 percent of the national median. The data are presented in the same format as the household income figures, with cat's whiskers illustrating the 95 percent confidence intervals. ${ }^{12}$ It is immediately clear that LIS data can tell us less about

Following this line, we belong to several reference groups at the same time - local, regional, national and international.

An alternative way to deal with the second issue would be to use a regional cost-of-living index to adjust the poverty line. This is an approach supported by Citro and Michael (1995, pp.182-201), who call for improvements in data collection to allow it to be done properly for the US. Borooah et al. (1996) developed such an index for the UK, showing considerable cost disparities in a number of commodity groups. But for the EU in general, regional cost-ofliving indices do not appear to exist: this does not seem to be an area which Eurostat has taken up.

Bootstrapping has been used to estimate confidence intervals for all poverty and inequality measures presented (see Efron and Tibshirani, 1993). 
Figure 4.4:

Regional poverty rates $1994-5$ using a national poverty standard

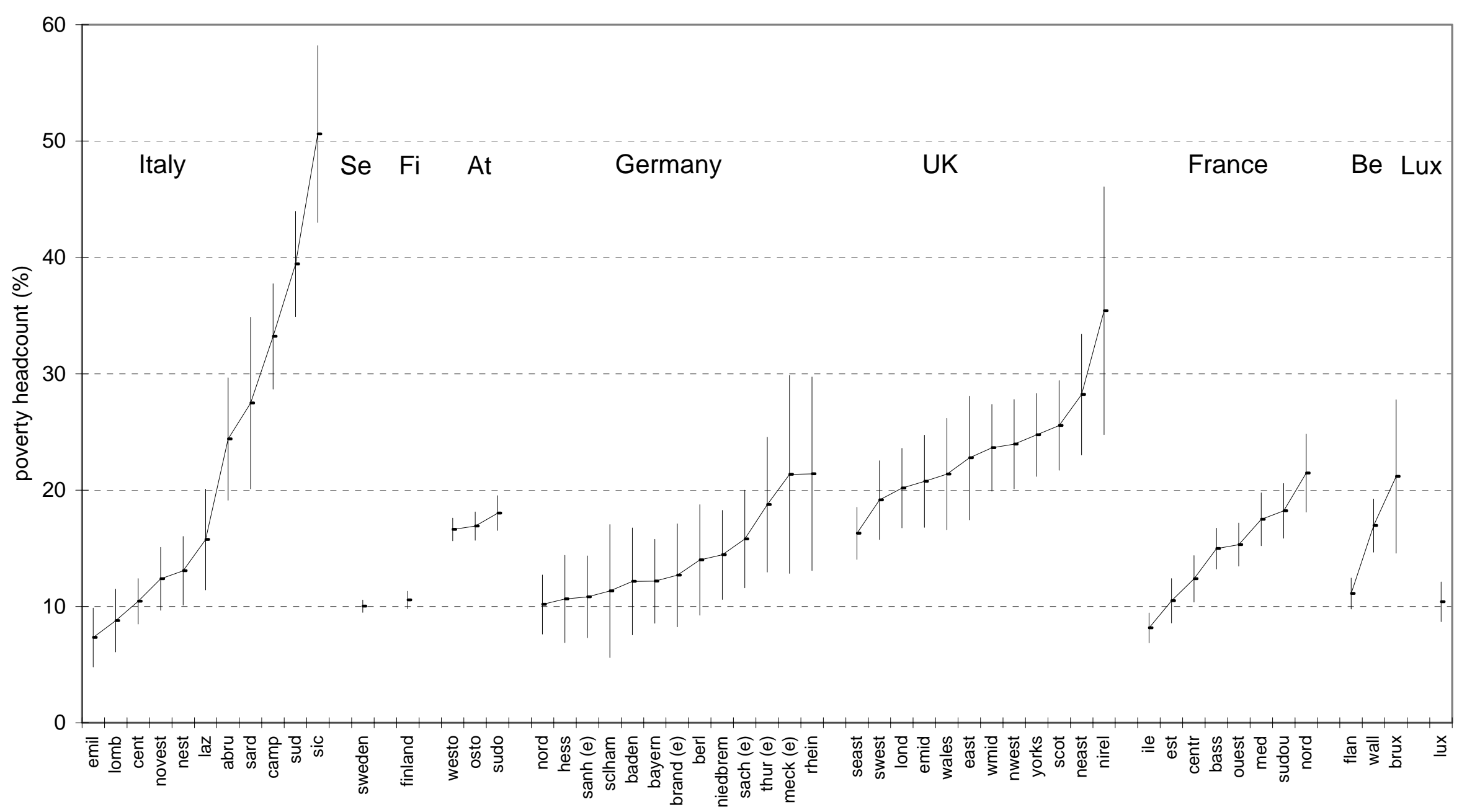

Note: Data for Belgium for 1996. 
regional poverty than about regional average income, but there are still some clear differences in poverty rates which are statistically significant.

To a large extent, of course, these differences reflect the differences in average standard of living presented above. In Italy the north-south divide is clear, with poverty in Sicily in particular higher than in any other region: as many as one in two Sicilians live on incomes below half the Italian median. Italy also shows the greatest regional dispersion: poverty rates in the north are among the lowest in Europe, dropping below ten percent in Emilia-Romagna and Lombardy. It is perhaps striking just how few of Europe's regions have poverty rates below this ten percent level, which is the national rate in Sweden and Finland.

The poorest regions of France and the UK appear to have the highest poverty rates in both countries, although the UK data in particular suffers from large standard errors: poverty in Northern Ireland can only be estimated with 95 percent confidence as between 25 and 45 percent. In these countries, poverty is lowest in Ile de France and in the South East of the UK. Most UK regions have poverty rates higher than most French regions, as might be expected from differences in national rates of poverty.

Belgium shows considerable disparity across its three regions: poverty in the Flemish-speaking area is significantly lower by several percentage points than in Brussels or Wallonia. This contrasts with the clustering of the three Austrian regions, only slightly smaller in size.

The main exception to the rule that average living standards drive regional poverty rates is Germany, although once again standard errors are too large for this to be a very solid conclusion. East and West German regions are found at both ends of the German poverty rankings: in the East, poverty ranges from around 10 percent in Saxony-Anhalt to around 20 percent in Mecklenburg. This may reflect the ongoing impact of the socialist inheritance in parts of East Germany. In addition, poverty appears to be higher in London than in the rest of the South East, reflecting the welldocumented high levels of inequality within the capital.

As a check on the UK figures, they were compared to results from another source, the Family Resources Survey, which has much larger sample sizes than the LIS Family Expenditure Survey data (24,000 households for the UK in total, rather than 7,000). FRS data are for 1995/96 and are taken from Bardgett and Vidler (2000, p.25). The poverty line used is 50 percent of national mean income, so is different than the 60 percent of the median used for the LIS calculations. However, DSS (2001) table 3.11 shows no more than a one percentage point difference between regional poverty rates measured using these two lines for 1999/00 FRS data. An additional problem is that the FRS data are for income after housing costs: data from the DSS source above suggest that this will only make a difference to results for London (where poverty is much higher after housing costs) and to Wales (where poverty is somewhat lower once housing costs are taken into account).

The comparison shows a strong correlation between most datapoints in the two series, with four exceptions. Poverty in London is much higher using the FRS data, but this reflects the impact of looking at income post-housing costs, as discussed. The small sample sizes appear to be affecting results for just three regions. First, poverty in the East seems overestimated - according to FRS data the East has the second best poverty performance in the UK, just behind the South East. Second, poverty in Scotland also seems to be overestimated by the LIS data, while in Wales 
the rate is underestimated (a result which we can assume would be stronger were housing costs treated in the same way in both series). That the re-rankings required are not more extensive is fairly encouraging, given that the UK is one of the LIS countries with the most severe sample size problems. We can bear the specific results in mind when we come to compare regional poverty rankings to performance on other indicators.

Figure 4.5 shows the poverty rate for the 1990 wave of data, with Spain included. As for Italy, Spanish poverty rates show the same clear division displayed by average incomes: the centre and south of the country have poverty rates in the twenties, while poverty in the North and Northeast regions and Madrid is significantly lower. Poverty rates in southern Spain appear to be on a par with those in much of the UK, but are lower than those in parts of southern Italy.

Finally, the low poverty rate for Brussels in this wave compared to the much higher rate for 1995 suggests that the sample for Brussels is just too small to be of use.

The pattern of poverty across the EU can be seen in Map 4.3 (Spanish data for 1990 are included). Not surprisingly, this is something of an inverse of the map of average income presented earlier. Poverty is highest in southern Spain and southern Italy and in northern England and Scotland, with the lowest rates running down through western Germany and eastern France to northern Italy, as well as in Paris. (Remember that no data are available for Portugal or Greece).

How different does the picture of poverty look if poverty is defined against a region-specific poverty line - 60 percent of regional median income? Unfortunately, as Figure 4.6 shows, this seems to be asking just a little bit too much of the LIS data. (Data for Spain for 1990 and for the Netherlands for 1987 are included in the figure.) For most countries only the extremes stand out: in Italy it is notable that it is the poorest region, Sicily, which has the highest poverty rate even where a regionspecific poverty line is used. The highest poverty in Spain is in the Canaries, also one of the poorest regions, but in most countries the opposite is the case, with the richer regions showing the highest poverty rates on this measure. This is true of London and the South-East, of Ile de France, of the Vienna region of Austria and of the Western Netherlands. West German regions for the most part have higher poverty rates than regions from the former East Germany. (Figure 4.7 shows the same data ordered by poverty rankings using a national standard to show how regional rankings change within countries, while Map 4.4 shows the change in the EU-wide pattern of poverty. Almost all the UK other than Northern Ireland now falls into the worst quintile, and the poor performance of many of the capital regions is also clear.)

\section{Inequality}

Why do we want to measure inequality as well as poverty? While poverty indicators focus on incomes at the bottom of the distribution, the size of the gap between the very top and the bottom is also relevant to the well-being of a society. An exclusive focus on poverty measured using a poverty line based on median income suggests that the position of the richest is of no concern to anyone else. But the incomes of the richest influence morale and can distort certain markets, such as the housing market; while the very rich also opt out of public services with potentially damaging effects. 
Figure 4.5: Regional poverty rates $1989-91$ using a national poverty standard

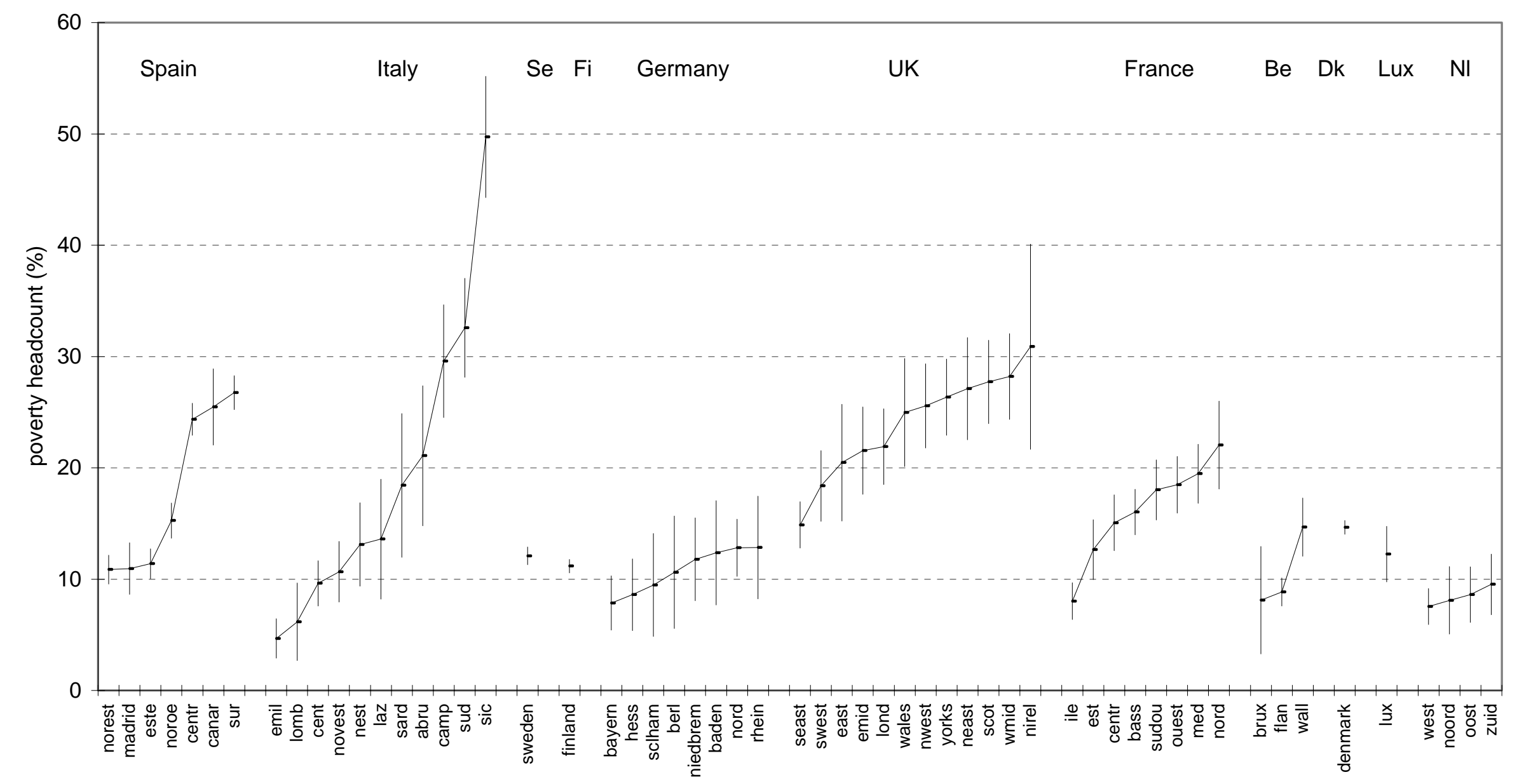

Note: Data for Netherlands for 1987. 

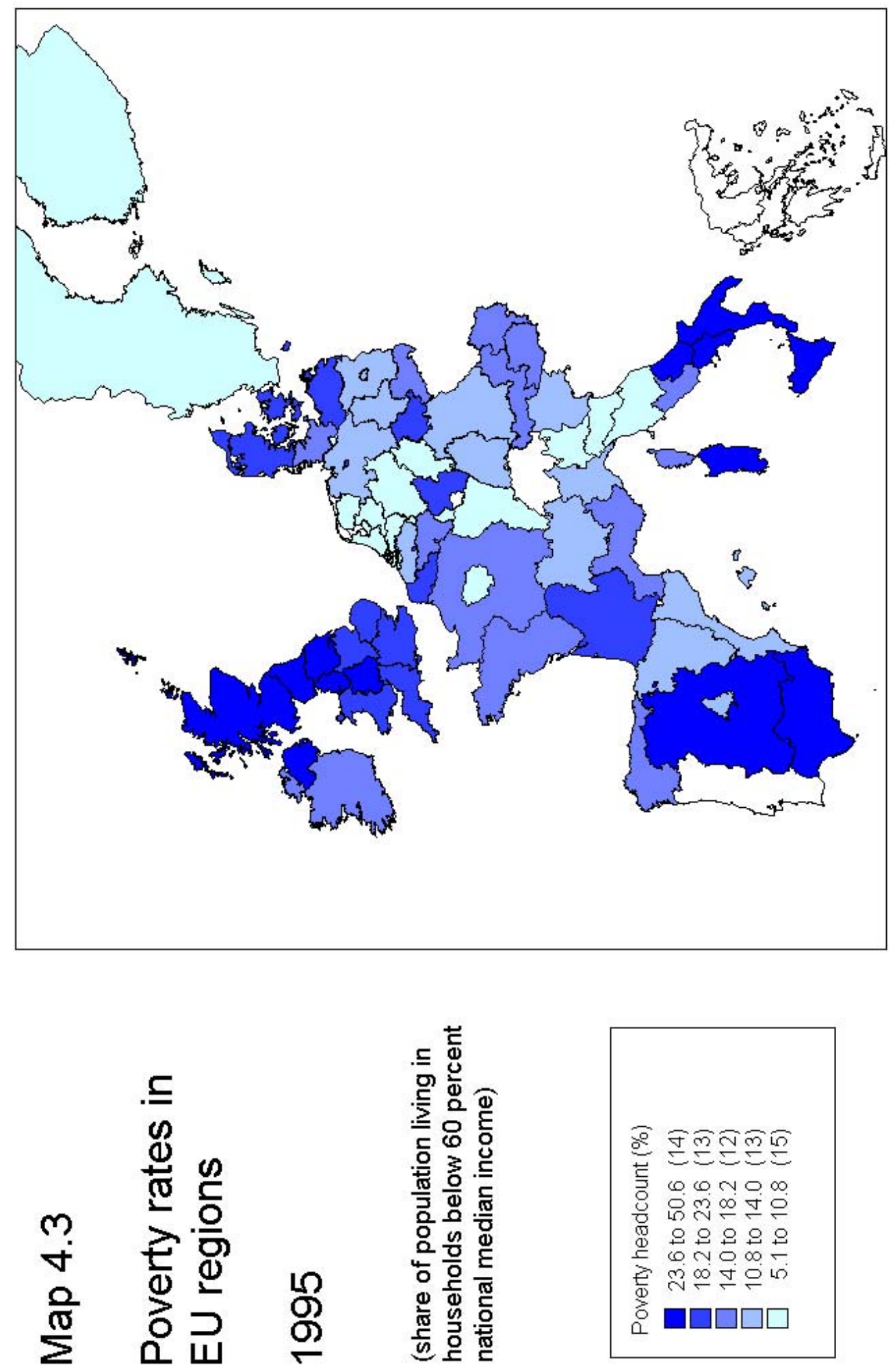
Figure 4.6:

Regional poverty rates $1994-5$ using a regional poverty standard

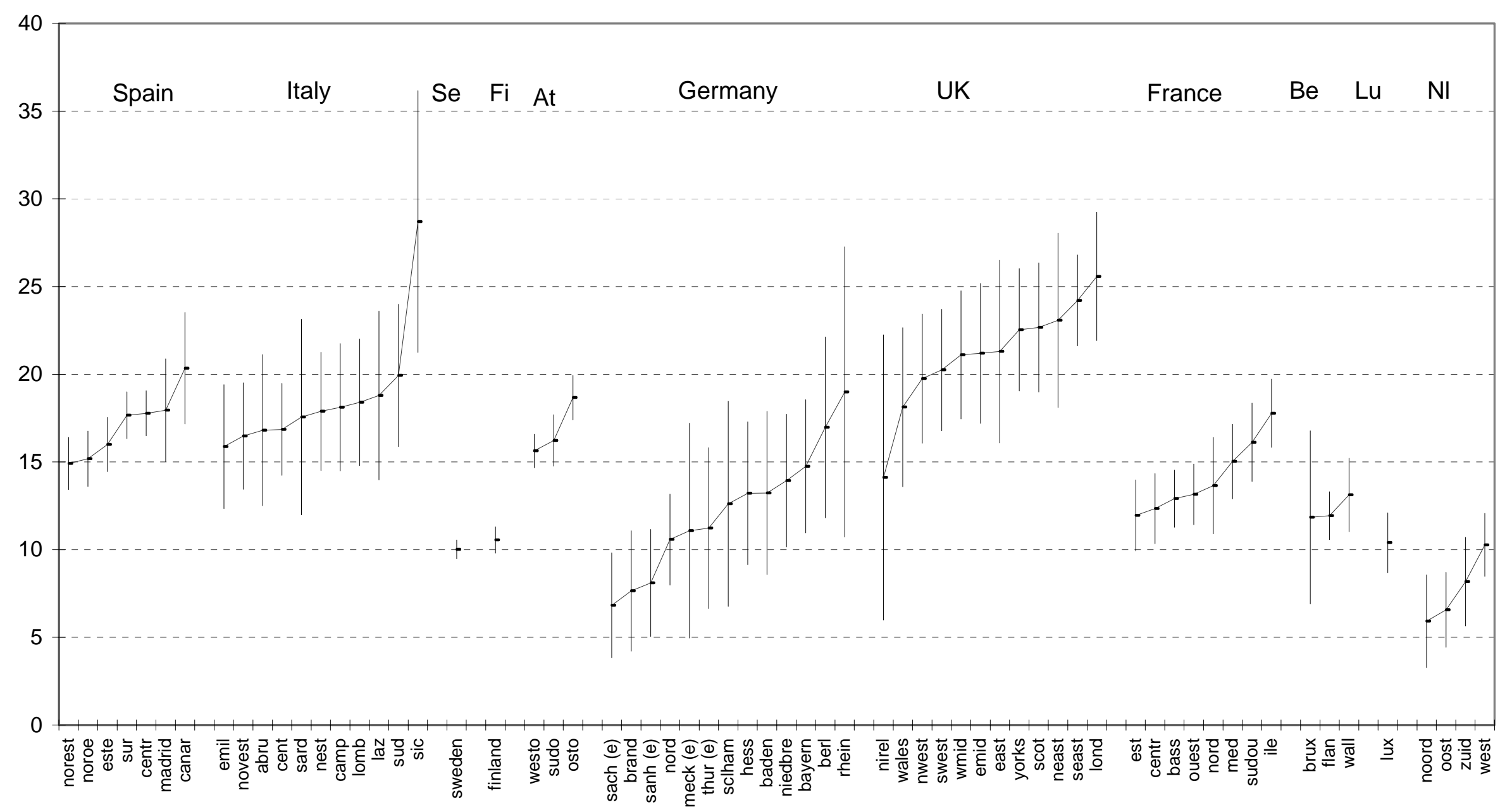

Note: Data for Spain are for 1990; for Belgium 1996; and for the Netherlands 1987. 
Figure 4.7: Regional poverty rates $1994-5$ using a regional poverty standard (ordered left to right by regional poverty rates using a national standard)

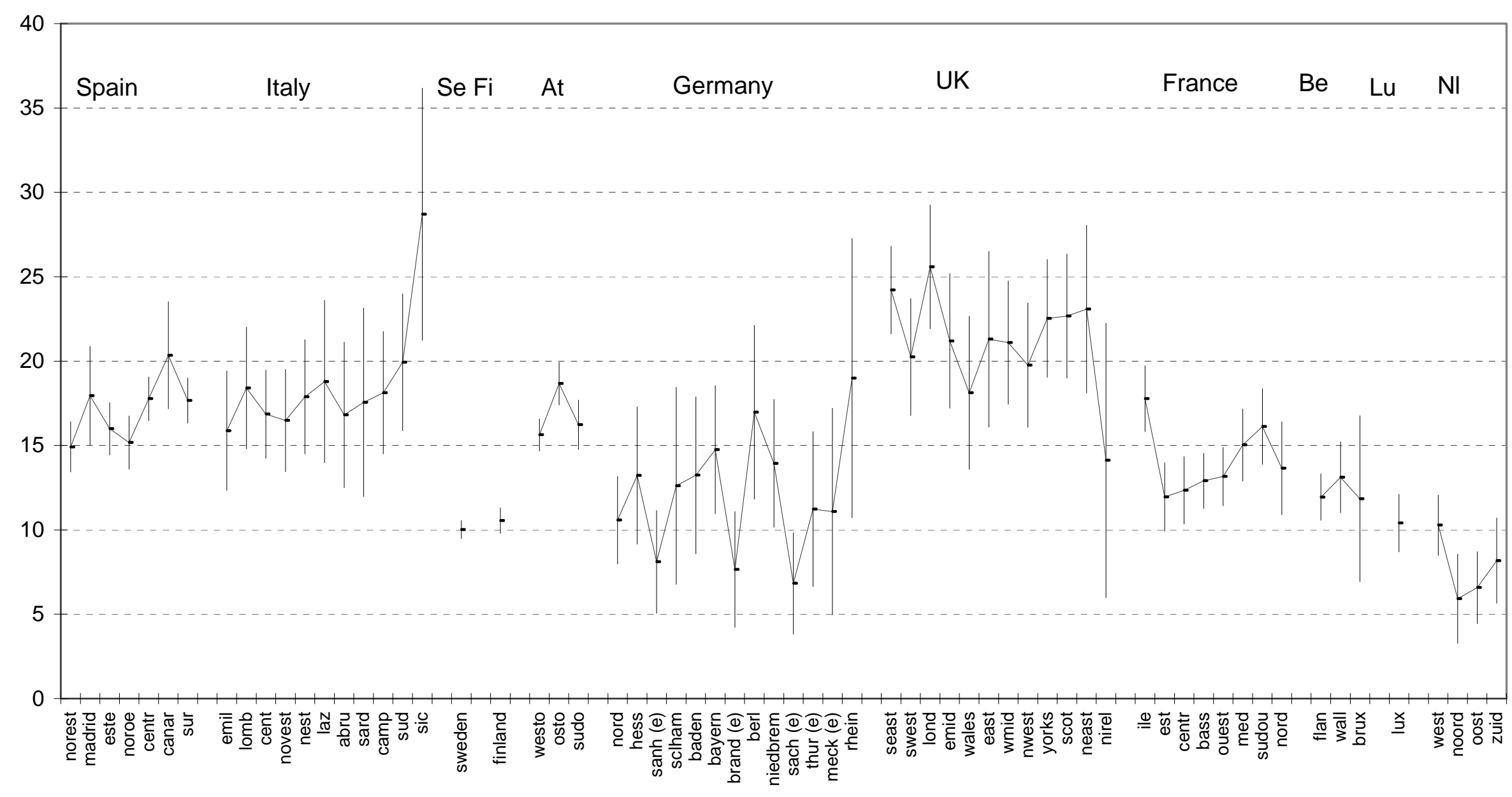

Note: Spain data are for 1990; Belgium for 1996; Netherlands for 1987. 

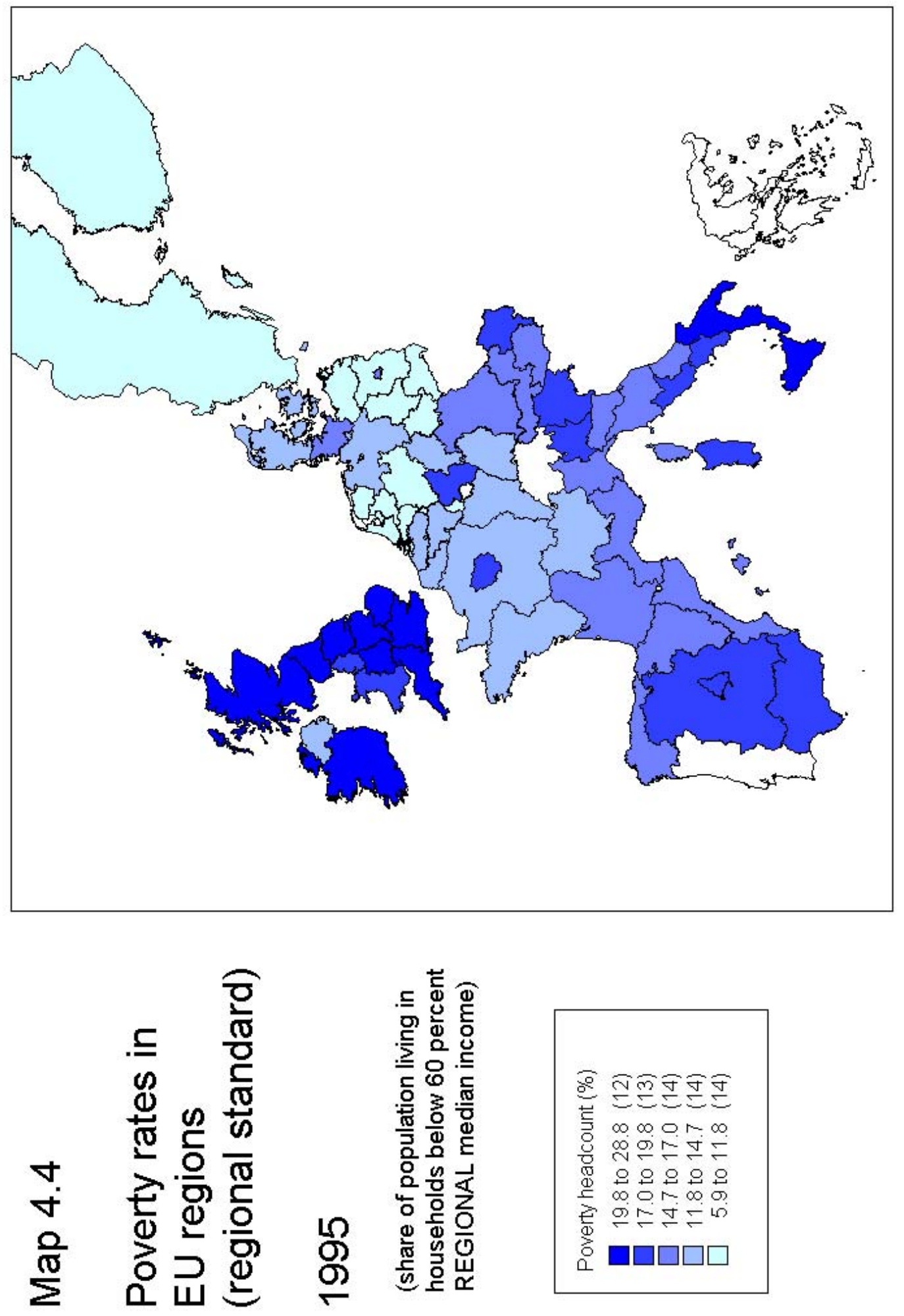
'If the range of income, top to bottom, is soaringly wide... it becomes impossible for everyone to mix on reasonably equal terms and to have a sensible share of the normal accoutrements of social life' (Age Concern, cited by Barry, 1998, p.1).

If our interest is in the length of the income distribution, the decile ratio would seem the best choice of inequality indicator, as opposed to a more general measure such as the Gini, which is more sensitive to change in the middle of the distribution than at the extremes.

(Atkinson et al. argue in favour of the Commission's choice of a quintile share ratio. They support a quintile share ratio as opposed to a quintile ratio on the grounds that the latter can get worse even when the distribution has become less unequal; e.g. in the case of a transfer from the person at the top of the bottom quintile to someone at the bottom. The quintile share ratio is chosen rather than the decile share ratio because decile shares will be more sensitive to influence by outliers. But quintile shares are themselves still sensitive to such outliers. In the regional case, with small sample sizes, the arguments in favour of choosing a share ratio do not seem strong enough to dislodge the decile ratio.)

The decile ratio is presented in Figure 4.8. Countries are ordered left to right by national poverty rate, to increase the amount of information conveyed, and within countries regions are ordered left to right by average household income. Levels of inequality tend to be higher in countries with higher poverty rates, as would be expected. But there is a split between countries in which higher income regions have higher inequality and those in which the opposite is true. In Germany, the Netherlands, Austria and the UK, the decile ratio tends to rise as regional income rises; while in Spain and Italy, it is the poorest regions in which inequality is highest. While standard errors are large, as the figure illustrates, this can be said with statistical confidence at least for those regions at the extremes of the distribution in each country.

Finally, it is worth noting that national decile ratios in every country fall roughly in the middle of the regional spread of decile ratios for that country. This is not inevitable: if inequality between regions was very high, we might find regional decile ratios to be lower than national decile ratios. If the richest ten percent of the UK population all lived in London and the poorest ten percent in Northern Ireland, for instance, the UK decile ratio would be higher than the ratio for either region on its own. But in practice, in each country, there are regions where internal inequality is higher than it is across the country as a whole.

\section{Housing}

The last aspect of material well-being which ought to be covered here is the quality of housing. While in most cases prices for private goods are similar for everyone, housing is a significant exception. Widely varying housing systems across the EU, and the differing rents facing occupants of social housing and those in the private sector even within a country, mean that income may tell us little about the housing options available to a household. In turn, housing conditions clearly have an important impact on health, and are likely to affect other aspects of life as well: overcrowding might be expected to affect children's education, for instance, as well as the tranquillity of household relations. 
Figure 4.8: Decile ratio by region 1994-5

(countries ordered left to right by national poverty rate; regions ordered left to right by regional average income)

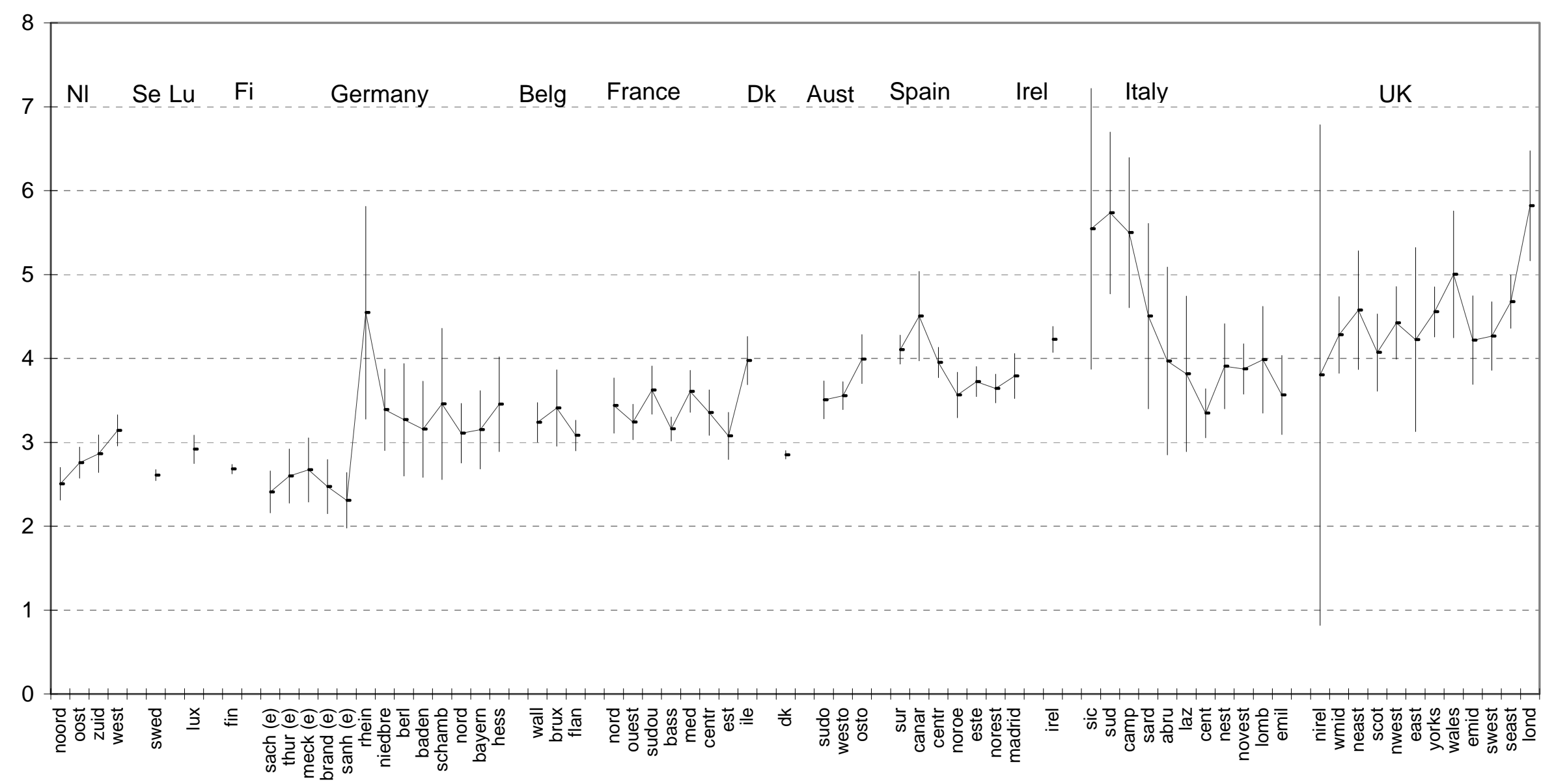

Note: Spain data for 1990; Netherlands and Ireland 1987; Belgium 1996. 
Despite their importance and the fact that many countries collect quite detailed information on housing, the first comparable source of data on housing conditions has only recently become available. A European Commission publication on housing from 1993 included a very limited selection of indicators by member state (and this represents only the very best-case scenario for a regional-level analysis): the share of owner-occupied dwellings, the share of pre-1919 dwellings, the share with a bath or shower and the share with central heating (European Commission, 1993). Since then, the European Community Household Panel (ECHP) has increased the possibilities for cross-national study: the panel includes a series of questions on housing conditions including overcrowding, the presence of a number of basic amenities, adequate heating facilities and the existence of damp and rot.

The ECHP contains NUTS1 level breakdowns for all countries except Germany, the Netherlands and Sweden (no data at all are available for Sweden). Household sample sizes are provided in Table 4.2, which shows that samples tend to be smaller than in the LIS datasets. However, questions about housing conditions require a simple yes/no response, ('Do you have any of the following problems with your accommodation?'), and aggregating these responses to regional level is much less demanding of the data than the calculation of average equivalised household income.

Figure 4.9 presents the share of households by region reporting three or more of a list of six housing problems: no indoor toilet; no hot running water; shortage of space; a leaky roof; pollution, grime or other environmental problems; and crime or vandalism in the area. Countries and regions are ordered left to right by poverty rate (lowest to highest). Housing conditions are clearly worst in Portugal and Greece. Within several countries there is a broad but imperfect correlation between the rate of regional income poverty and the extent of housing problems, although this does not hold for France or the UK. Re-ranking the UK regions according to FRS data, as discussed above, would improve the correlation, shifting Scotland and the East to the left and Wales to the right. But the poorest UK region, Northern Ireland, appears to have the second lowest level of housing problems in Europe, with less than two percent of households suffering three of the six problems, only just ahead of the East, where less than one percent of households are sufferers.

\section{Productive life}

The intention in this section is to reflect the sense of worth and well-being which comes with useful activity, rather than to focus on the financial benefits of employment: the latter are covered by the material well-being indicators discussed above. There is therefore no reason why productive activity should be identified exclusively with paid employment, excluding voluntary work and unpaid care. At the same time, the quality of paid employment is also relevant: the share of jobs which are tedious and unfulfilling should be reflected.

What we really want, then, is a survey question along the lines of 'How fulfilling do you find your main activity?' In its absence, the rate of unemployment seems a disappointing but safe best option. This will exclude those in unhappy jobs, 


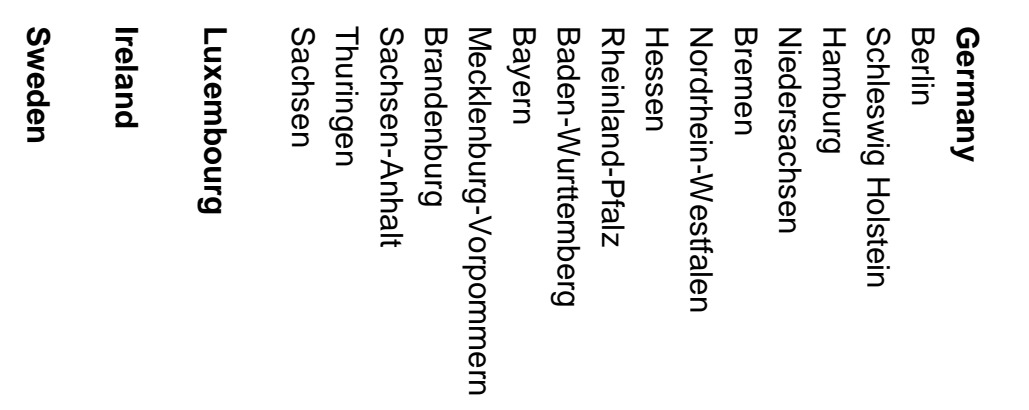

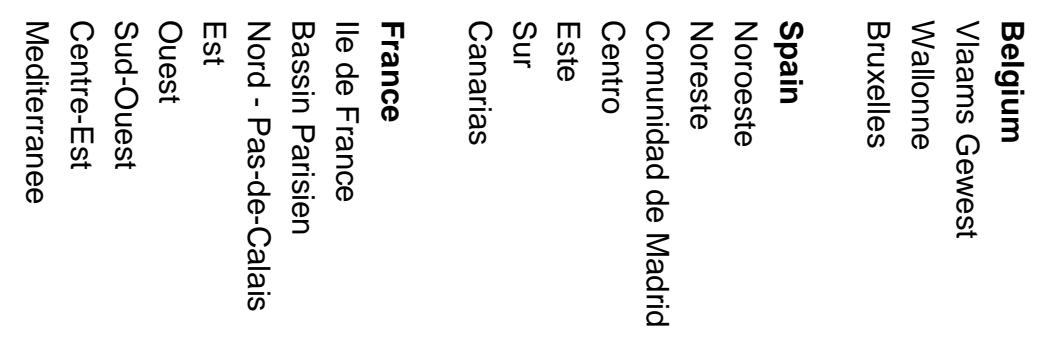

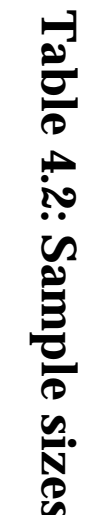

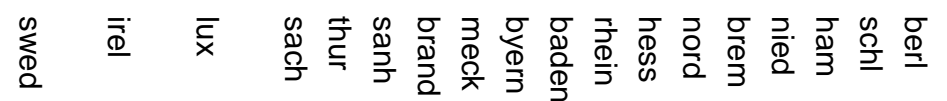

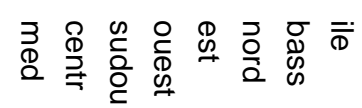

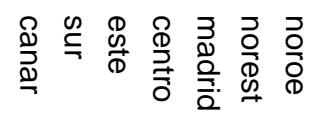

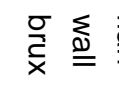

: 迎

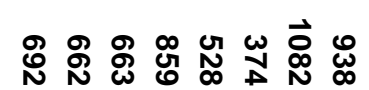

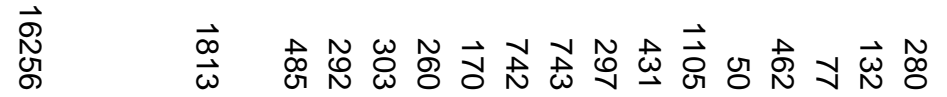

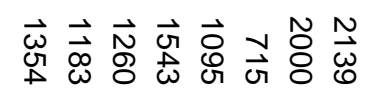

IImpremen'

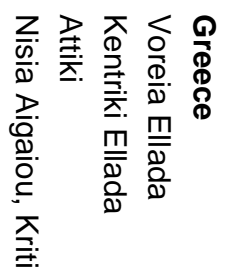

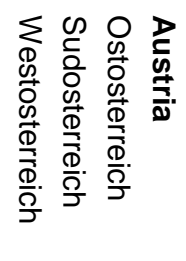

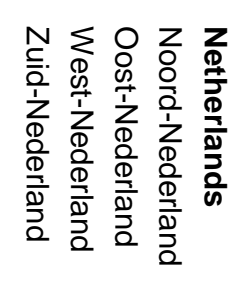

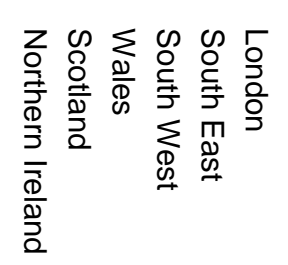

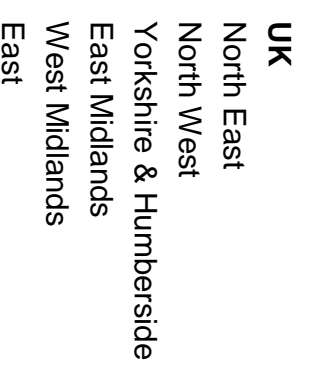

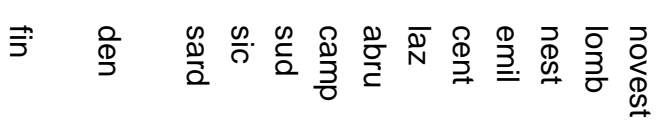

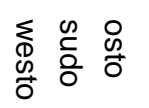

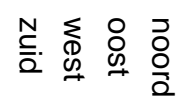

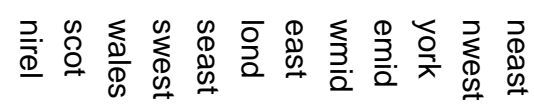

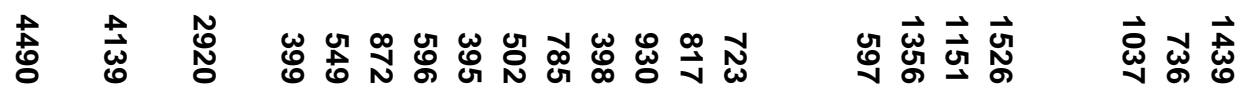

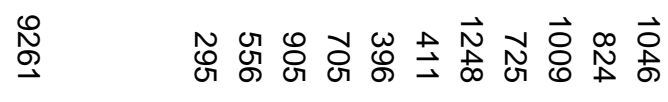

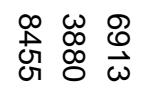

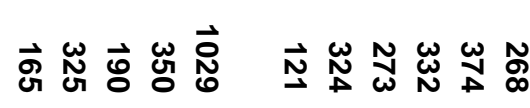

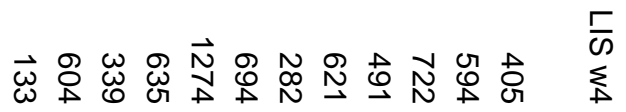


Figure 4.9

Share of households in housing that suffers from three or more out of six problems (ECHP 1996)

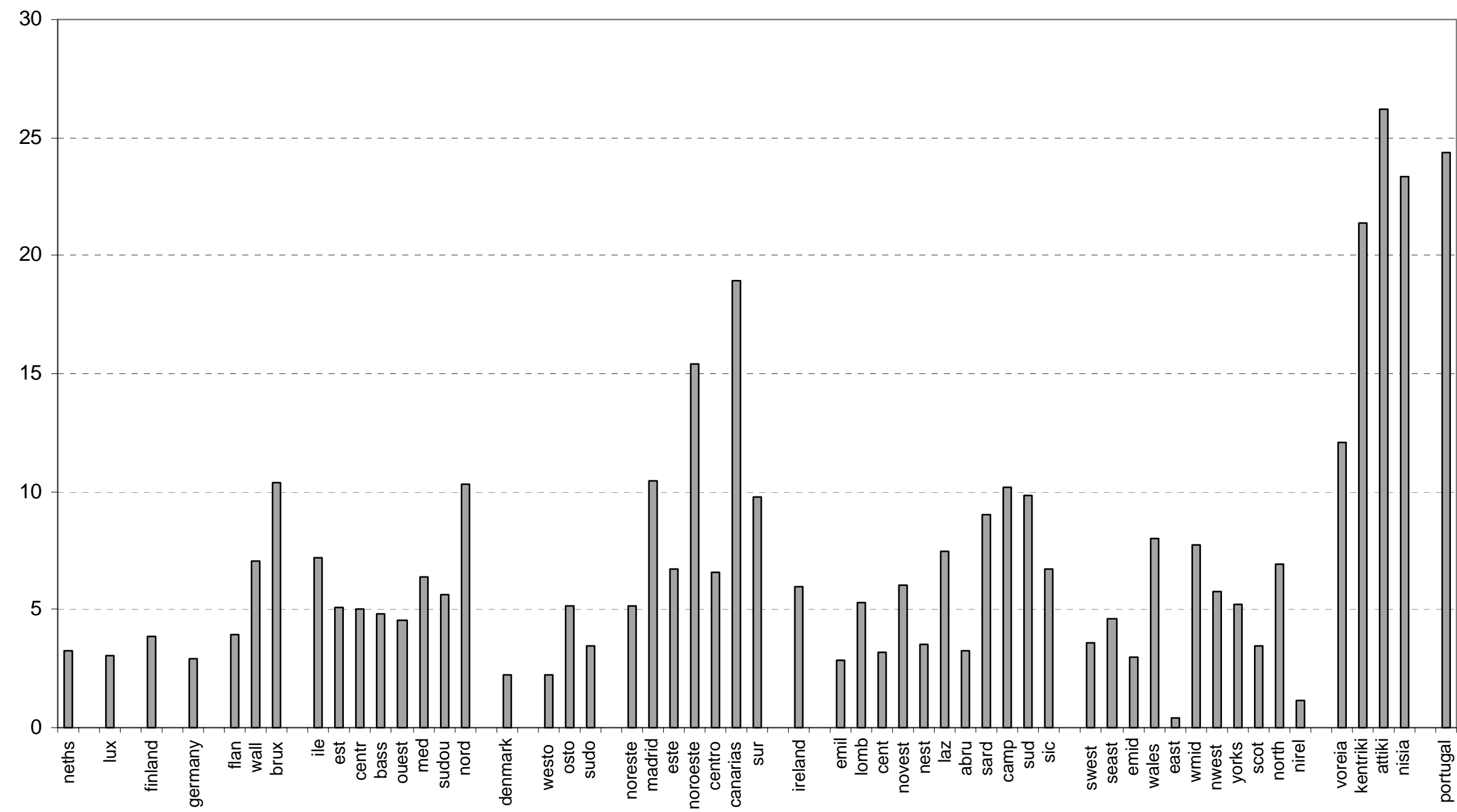

Notes: (1) Countries are ordered by national poverty rates (lowest to highest); and regions are ranked in the same way except for Greece, where no data are available.

(2) The six housing problems are: no indoor toilet; no hot running water; shortage of space (subjective response); leaky roof; pollution, grime or other environmental problems; and crime or vandalism in the area. 
and this seems inevitable, but it does also make sure that we exclude those happily engaged in non-labour market activity.

Counting only the unemployed as not in productive work excludes an additional group, however, which we can go some way towards identifying - those who would like to work but are excluded from the labour force, either due to illness, or because they have excluded themselves (perhaps retiring early) because few jobs are available. The size of this group is likely to vary across countries, across regions and over time, making it important to pick them up. In the UK, for instance, the numbers of people claiming benefit for long-term sickness or invalidity rose steadily through the 1980s and the first half of the 1990s (see e.g. Beatty and Fothergill, 1999, p.9). How far this reflects a genuine rise in long term disability and how far it is due instead to a reclassification of some benefit recipients (as Beatty and Fothergill propose) is irrelevant in the current context. Either way, those affected are neither officially unemployed nor participating, as far as we can tell, in productive activity.

Alongside the rates of unemployment and long term unemployment, therefore, this section examines a 'not-in-work' indicator, calculated as the total working-age population (in or out of the labour force) less those in paid employment. This indicator immediately raises other difficulties - we have taken care above to ensure that unpaid care-givers, for instance, do not classify as without productive activity, yet here they are suddenly thrown in as such. The problem might be thought of as one of Type I and Type II error: either we include as not-inwork some people who should not be there, or we exclude some who should be. As there is no way to get the perfect measure using the available data, we look at measures which err on both sides.

It should be clarified at this point that the data used here are from the European Community Labour Force Survey. Access to the raw LFS data is not permitted under confidentiality rules, so we are limited to results made available through the Eurostat New Cronos Database and through various print publications. ${ }^{13}$ This prevents us from exploiting the data's full potential. For instance, printed results from the 1999 LFS allow us to identify reasons for inactivity by region, including categories for 'inactive due to illness', 'inactive due to family responsibility', 'inactive in retirement', 'inactive in education' and 'inactive thinking no work' (Eurostat, 2000a, Table 66). This looks to be just what we need, but all data are given for the total inactive population of all ages, meaning that any differences across regions or countries could be explained simply by differences in the age structure of the population. A similar breakdown for the population aged 25-59 would be ideal.

The raw data could also be used to calculate alternative indicators which are not provided in published sources. In particular, the proportion of individuals living in households where no member is in work is an important measure of well-being, not just as a strong predictor of poverty (for which we have a separate indicator) but also because the absence of any links at all to the labour market is likely to exacerbate the extent to which members of a household feel dispensable. It may also affect the aspirations of any children in the house. The share of the population living in jobless households is put forward by both the Commission and the Atkinson 
report as a key exclusion indicator, alongside the unemployment and long-term unemployment rates, but it is not available at regional level in published data. ${ }^{14}$

\section{Unemployment and long-term unemployment}

Figure 5.1 shows national and NUTS1 level unemployment rates for 1997. ${ }^{15}$ (Unemployment is measured according to the ILO definition.) Unemployment varied from 2.5 percent in Luxembourg to 30 percent in the southern region of Spain. High unemployment is found right across Spain: only in East Germany and Southern Italy are rates as high, with unemployment in the North and Mediterranean regions of France also above the 15 percent mark and higher than the Spanish North-East.

It is of little surprise to find that unemployment rates are in general strongly negatively correlated with average incomes and positively correlated with poverty rates as discussed in Section 4, although there are exceptions. Unemployment shows a clear North-South divide in Italy, with rates ranging from just 5-6 percent in the North-East, Lombardy and Emilia-Romagna to 25 percent in Campania and Sicily; rates in all the former East German regions are above 17 percent, compared to between 5 and 12 percent in the West (Berlin falls in the middle at 13 percent). The South has the lowest average income and among the highest poverty rates in Spain, although the Canaries and Central region have similar rates of poverty and much lower unemployment.

In France, however, while the North ranks as the lowest income, highest poverty region, the Mediterranean falls in the middle of the income distribution despite high levels of unemployment. And in the UK, unemployment is highest in the North-East but second highest in London - although overall levels of unemployment are relatively low in the UK, and regional disparities are the lowest of any of the larger EU countries.

In both Belgium and Greece unemployment is also higher in the capital or capital region: in Brussels the rate is 13 percent, similar to Wallonia but twice as high as in Flanders. Nearly 12 percent are unemployed in the Athens region of Attiki, compared to less than 5 percent in Nisia Aigaiou, which covers the Greek islands.

Figure 5.2 plots the unemployment rate against the share of the unemployed who have been out of work for at least twelve months. Only five countries are shown for reasons of clarity; all other countries are found in the centre of the figure. Between 30 and 60 percent of the unemployed are long-term unemployed in most regions, although the Italian south and Lazio stand out at the higher end, with upwards of 70 percent out of work for more than a year.

We might expect the share of the long term unemployed to be higher in high unemployment regions, and this is true for some countries, such as Italy, but not all.

More precisely, the Commission proposes the long-term unemployment rate and the share of jobless households; while the Atkinson report puts forward the unemployment rate, longterm unemployment rate and the share of individuals living in jobless households. 
Figure 5.1: Unemployment rates 1997

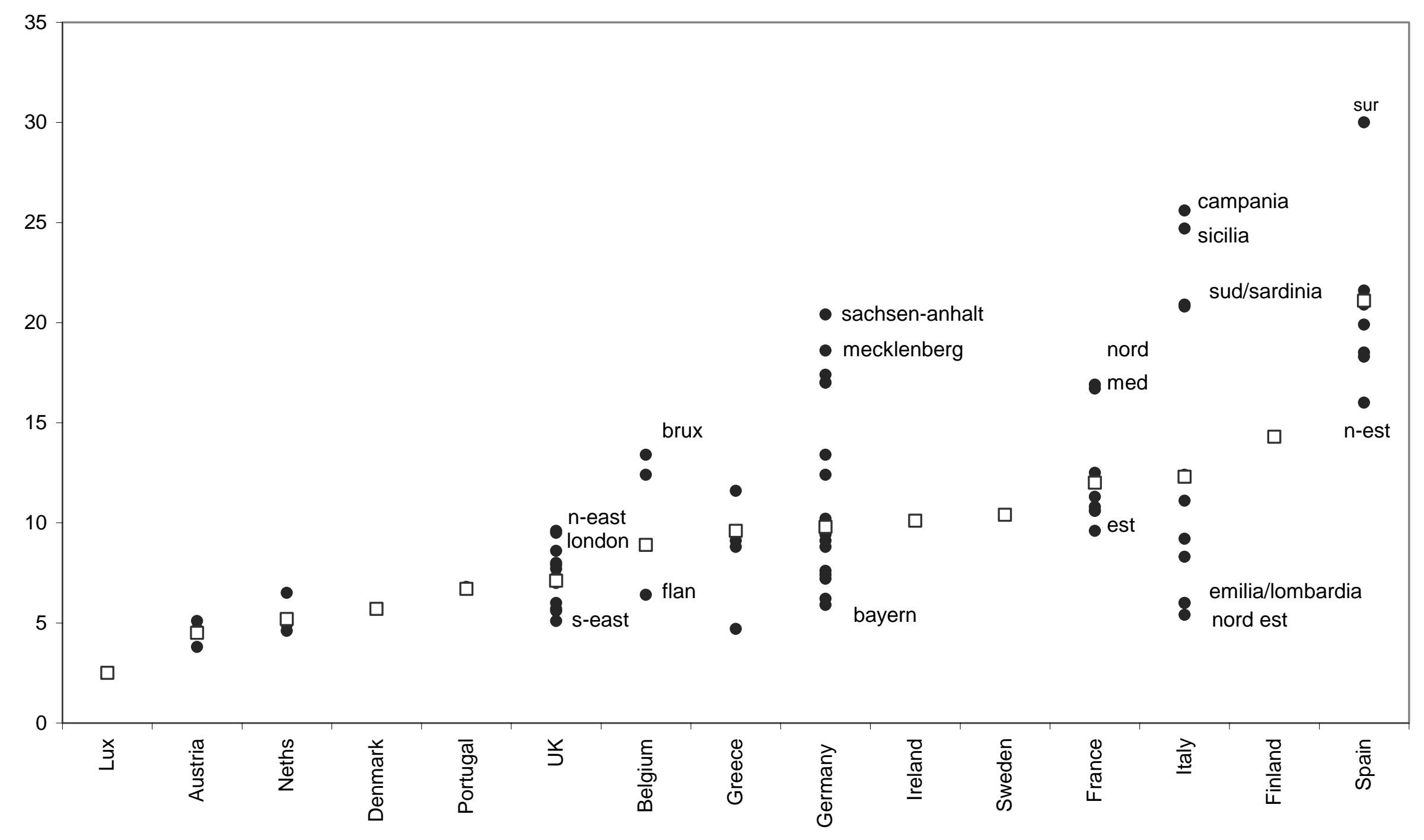


Figure 5.2: Unemployment and long term unemployment 1997

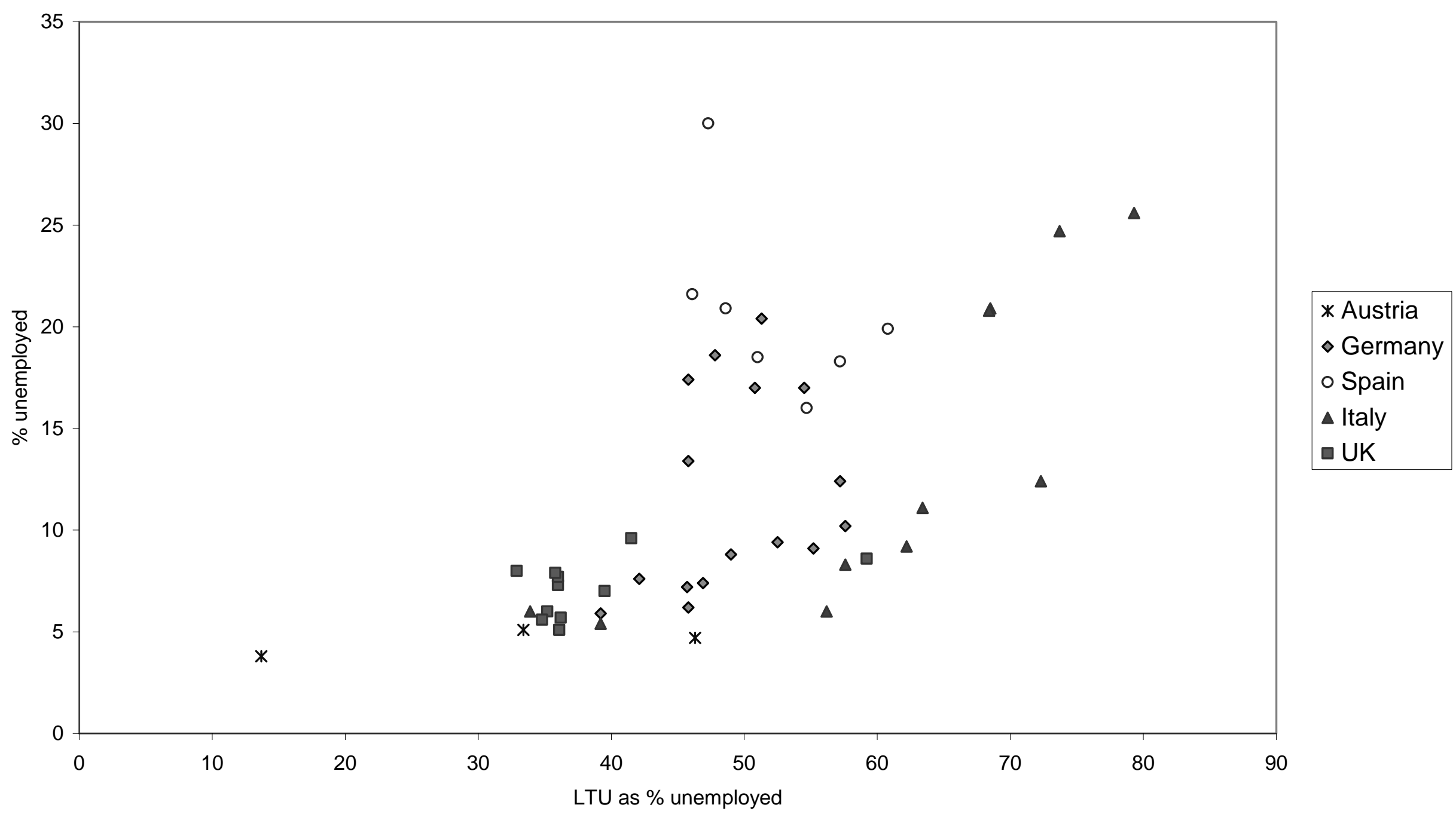


Spain and Germany in particular show little relation between the two indicators. In Austria, very low regional disparity in unemployment is found to disguise substantial differences in the nature of unemployment: almost half of the unemployed in Eastern Austria (including Vienna) have been out of work for more than a year compared to 14 percent in the west. The same is true of the UK: 60 percent are long-term unemployed in Northern Ireland, compared to 30 to 40 percent in the rest of the UK.

\section{The 'not-in-work' rate}

Figure 5.3 shows the percentage of males aged 25-64 who are not in work - the male 'not-in-work' rate. The male rate is likely to be a more reliable indicator than the female rate, in part because of the lower likelihood of a Type II error of the kind outlined above (fewer men than women work as unpaid carers), and in part because of the eccentricities of the Eurostat data, as explained in the footnote below. ${ }^{16}$

The relationship between the not-in-work rate and the unemployment rate is strongly positive: correlations by country vary between 0.85 and 0.99 with the exception of Austria (0.75) and Greece, to which we return below.

However, in almost all cases the degree of regional disparity is lower for the not-in-work rate than for the unemployment rate, using a mean-independent measure of dispersion such as the coefficient of variation; something which may not be immediately obvious from a comparison of Figures 5.1 and 5.3. This appears to be because, while not-in-work rates are almost universally higher than unemployment rates, the difference tends to be greater in low unemployment regions. In Southern Italy, for instance, unemployment is at 20-25 percent and the share of men not in work at 30 to 35 percent; while in the north the unemployment rate lies between 5 and 10 percent and the not-in-work rate at 25 percent.

In the UK, the difference between top- and bottom-ranking regions is nearly twofold for both series. More than 27 percent of working age men in the North-East, Wales and Northern Ireland are without work, compared to 16-17 percent in the

The 'not-in-work' rate is calculated in principle as the sum of the inactive population and the unemployed population over the total population of working age. But there are a few complications imposed by the data. First, Eurostat give the active population in ten year breakdowns only, allowing us to take the active population of either 25-54 or 25-64, but not 25-60. For men it makes sense to use the population of 25-64 and for women the population of 25-54, because of the earlier retirement age for women in most countries. Second, for both genders the unemployment rate is only available for the population of 25 plus, with no further breakdown. Hence for women the not-in-work rate can only be calculated as:

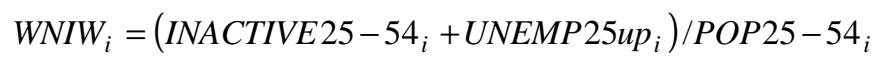

and for men as:

$M N I W_{i}=\left(I N A C T I V E 25-64_{i}+\right.$ UNEMP25up $\left._{i}\right) / P O P 25-64_{i}$

Thus the female not-in-work rate will be overestimated by the number of unemployed women of 55 plus and the male rate by the number of unemployed men of 65 plus. There should be few men in the latter category, and the male rate should hence be a more reliable estimate. 
Figure 5.3: Male not-in-work rate 1997 (men 25-64)

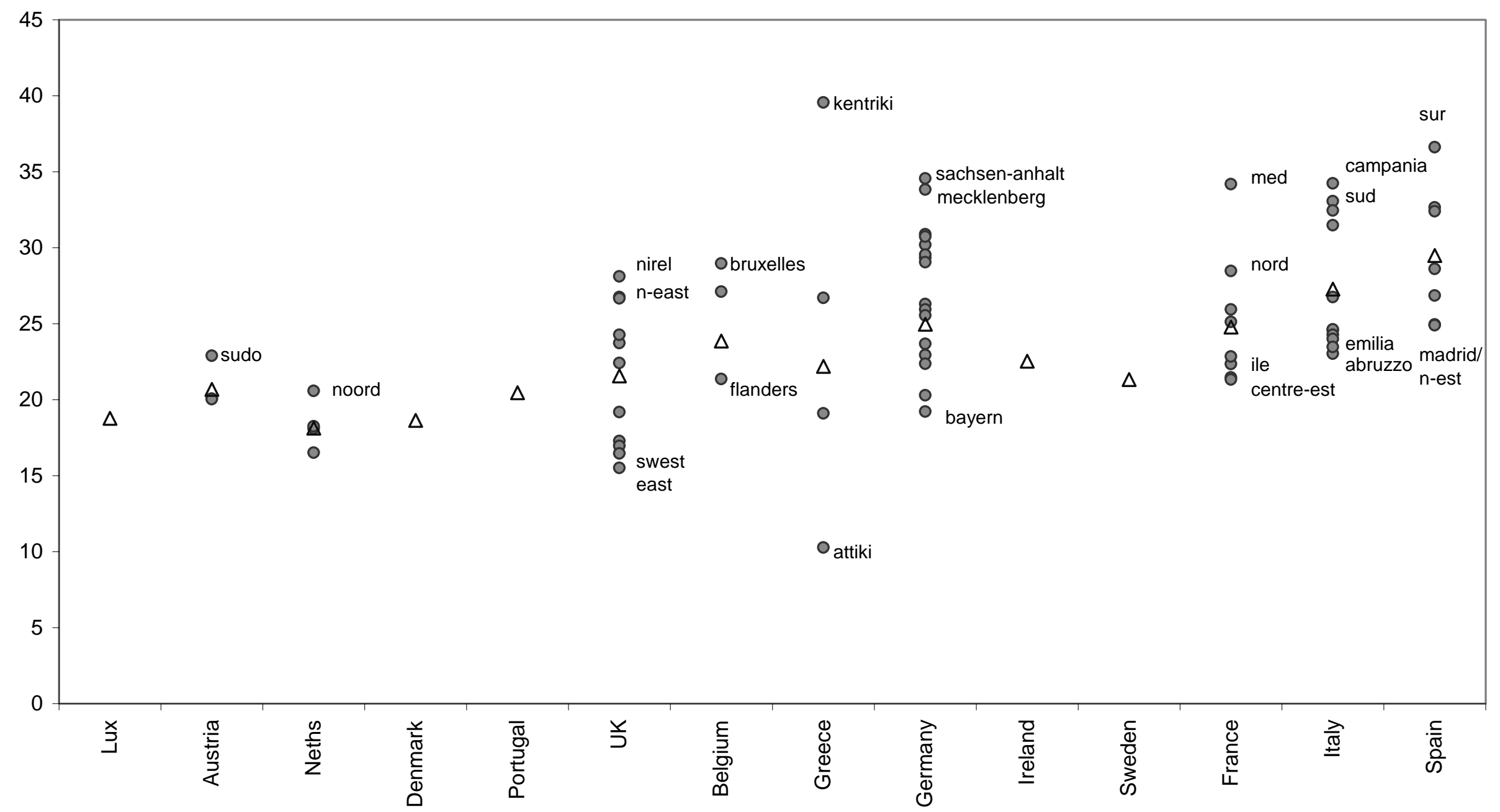


East, the South-West and South-East. (The not-in-work rate cannot be calcuated for London separately.)

In Germany, regional dispersion is considerably lower and the east-west divide less sharp than for unemployment: Berlin, Bremen and Saarland have not-inwork rates as high as all but the top two East German regions. In France, the not-inwork rate is considerably higher in the Mediterranean region than in the North, areas with very similar rates of unemployment, but this could reflect a high number of people taking early retirement to this area.

The real surprise, however, is Greece, where the coefficient of variation is much higher for the not-in-work rate (the only country where this is the case) and where the correlation between the two series is negative. Not-in-work rates vary from 10 percent in Attiki (with the highest unemployment) to 40 percent in the central region of Kentriki. There appears to be significant hidden unemployment in parts of Greece, suggesting that the unemployment rate may be misleading as an indicator.

\section{Cyclical changes in unemployment}

This section has concentrated so far on a single point in time, and has not discussed the stability of either regional rankings or the degree of dispersion over time. Regional rankings tend to persist, at least in the medium-term, and do not jump about from year to year. But it is worth pointing out that regional unemployment disparities do have a strong cyclical element: during a boom, employment tends to take off faster in areas which had lower unemployment to begin with, leaving other regions further behind. Figure 5.4 illustrates, showing national average unemployment and the NUTS2 coefficient of variation over the last decade for three countries. (Coefficients of variation have been calculated using regional population weights.) In both Sweden and the UK, there is a strong negative correlation between unemployment and regional disparities. ${ }^{17}$ Belgium, Spain, Greece, Portugal and Finland would have made equally good examples - all have negative correlations of over 0.50 . The case of France shows that this relationship does not hold everywhere: the rise in overall unemployment during the 1990s has not affected regional disparities. However, changes in unemployment have been small in France, and regional disparities were low to begin with.

The implication is that, where certain indicators are concerned, care needs to be taken in interpreting differences in regional measures of dispersion over time as well as across countries. Low regional unemployment disparities may simply reflect recession. This is of particular interest given that the coefficient of variation of regional unemployment rates has now been officially adopted as the indicator to be used to reflect the regional dimension of social inclusion.

Because of missing data, coefficients of variation for Sweden are calculated using six regions between 1990 and 1996 and eight regions in 1997 and 1998. For the UK, 29 regions are used between 1987 and 1994 (excluding London, Wales and Scotland) and 37 regions between 1995 and 1998. In both cases, the inclusion of the missing regions makes only a negligible difference to the results. For France, 22 regions are used in all years. 

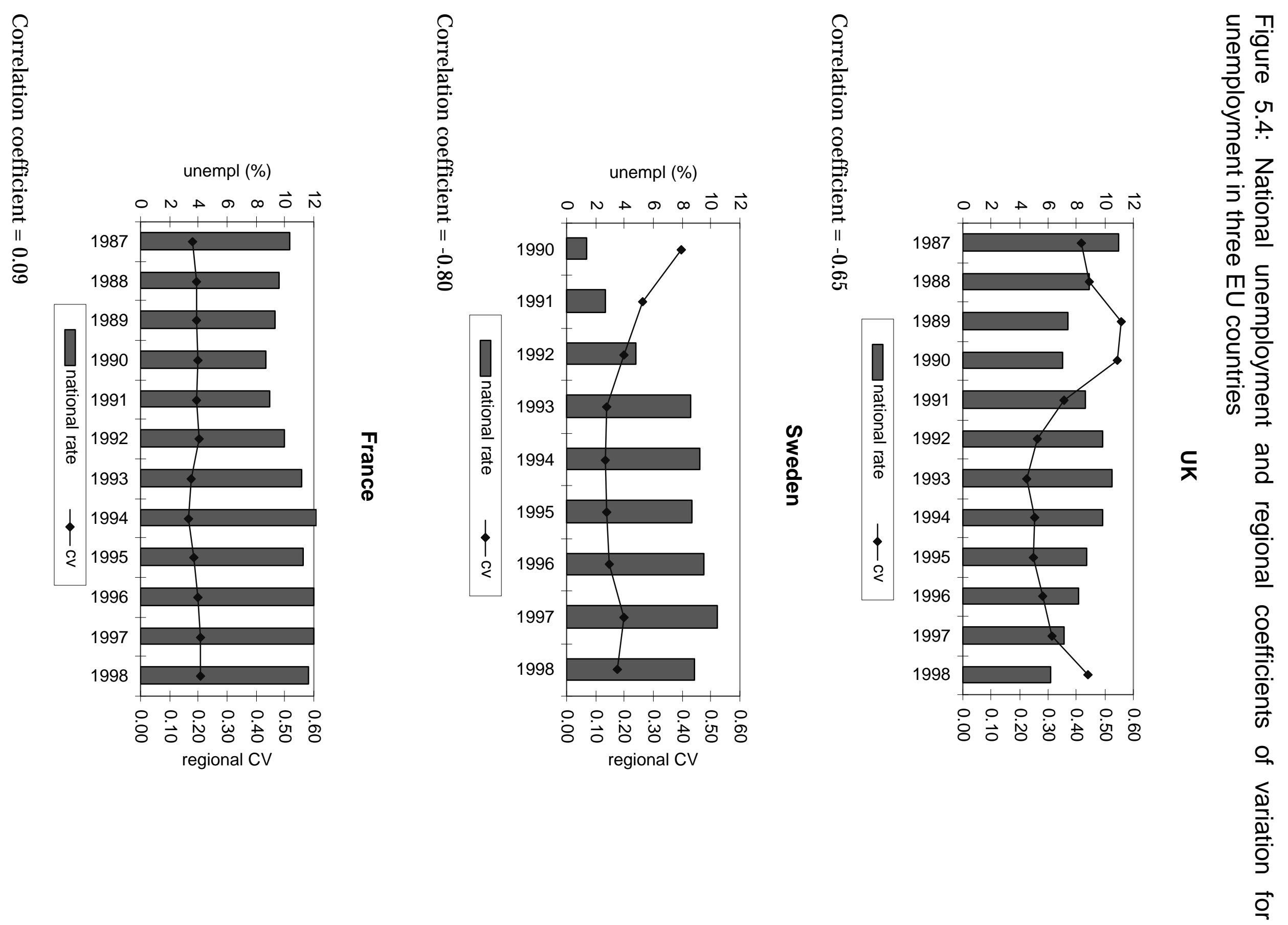


\section{Education}

We are looking here for an indicator which picks up the true benefits of education what people gain from education which enables them to make the most of future opportunities in the labour market and in their social, political and cultural lives. In other words, we want outcome indicators - what do people know, what skills do they have - rather than what might be thought of as input indicators (education expenditure) or process indicators (how many people sit through each level of education).

In the absence of alternatives, it is the latter two types of measure which have been used most frequently to compare the performance of education systems across countries. In the last five years there have been a series of surveys which begin to address the gap, aiming to measure learning achievement and literacy skills in ways which are internationally comparable. In 1995 and again in 1999 the Third International Mathematics and Science Study (TIMSS; Beaton et al 1996 and 1996a) tested school-children in over 50 countries on proficiency in maths and science. Between 1994 and 1998 the International Adult Literacy Survey (IALS; OECD 1995, 1997 and 2000) assessed 'functional literacy' among adults aged 16 and over in up to 21 countries, where this covered (for example) the ability to read and understand instructions on a medicine bottle and to interpret a railway timetable. The OECD's PISA survey (Programme of International Student Assessment), carried out in 2000, is in effect a young people's version of IALS, assessing 15 year olds in 32 countries on 'preparedness for adult life', including maths, science and reading skills (OECD 2000a).

There are a number of comparability questions surrounding each one of these studies, but in any case, neither TIMSS nor IALS include samples large enough to allow regional analysis. (TIMSS samples average 3750 per country; IALS 3400). In the PISA study (for which data are not yet available for analysis), only Germany and the UK have explicitly stratified by region, although regional estimates may be possible in some other countries: samples vary between 5,000 and 7,000 (Andreas Schleicher, personal communication).

We are thus pushed back to process indicators. The first indicator examined here is the share of the population aged 25 to 59 who have completed at least upper secondary education (ISCED level 3). This might be thought of as second best in more ways than one. First, as noted, it does not tell us what people have gained from their education, though there is clearly likely to be a strong relation between staying on in school and literacy and other skills. The final report on the IALS project shows a correlation in every country between educational attainment and literacy proficiency - and of course it would be rather disturbing if this were not the case (OECD, 2000, Figure 2.4; and see also Denny et al, 2000, Table 3 for more detail on the UK and Ireland). But the correlation is far from perfect, which is also not surprising - for one thing, ISCED level does not reflect additional learning such as adult literacy classes taken later in life.

A second and related issue which arises when using ISCED levels is how comparable the levels really are across countries. This is the main factor driving the particular choice of ISCED 3 as the cut-off point: it seems to avoid more of the crossnational consistency problems than other options might. The range of qualifications 
covered by the ISCED 3 umbrella is enormous - in the UK some will complete a one year vocational course while others will do A levels and go on to university. But in most EU countries it is not compulsory to complete upper secondary education, so all those with ISCED 3 qualifications will have made a choice to continue in education. ${ }^{18}$ This seems a clearer dividing line to choose than the line between school and university, as the distinction between certain vocational upper secondary qualifications in some countries and tertiary qualifications in others may be unjustified.

In practice, there do seem to be large differences in employment probabilities across EU countries between individuals with no higher than ISCED 2 qualifications and those with ISCED 3 (Steedman and McIntosh 2001, p.567). Furthermore, completion of ISCED 3 appears to be the best choice across countries if we are trying to proxy literacy. OECD 2000, figure 2.4 shows that for most countries the literacy gap between those who complete upper secondary education and those who do not is considerably larger than the gap between those completing upper secondary and those completing tertiary. Steedman and McIntosh finish their study of the usefulness of the ISCED framework by concluding that 'for adults, ISCED 2 [i.e., non-completion of ISCED 3] is a reliable measure of attainment across EU countries' (p.580).

The third problem with the indicator is that it covers the whole adult population: some of the people included would have made the decision about whether or not to stay on in school in 1954. To an extent, of course, their situation is still highly relevant (although, as noted, some may since have enhanced their learning if not their formal qualifications). We are not interested only in the wellbeing of the young. But as a policy-related indicator it is not very helpful, as it will give us a misleading picture of how regions are performing today. Some regions may still be similarly positioned, but in others things are likely to have changed dramatically, with many more young people staying on in education than their parents and grandparents did. A measure covering the whole population will also be affected by the nature of adult immigration to the region: regions with a high concentration of graduate jobs (such as those containing capital cities) will have much higher levels of ISCED 3 attainment simply because graduates are attracted to the area. A better indicator, then, would cover just young people, perhaps those in their late teens or early twenties. Indeed, the education measure proposed by Atkinson et al. and included in the Laeken list is the share of those aged 18-24 who have not completed ISCED 3 and are not in education or training leading to an equivalent qualification.

This is not out of the question for a regional analysis: the data used here are from the European Union Labour Force Survey and breakdown by more detailed age groups is possible in principle. For example, figure E12 in European Commission (2000) provides the data at national level for 22 year olds. As noted above, the extraction of particular tables of data from the LFS can be requested for a fee. But this paper relies on the data which are publicly available, supplementing them with a second indicator which should reflect very much the same thing - the

In Belgium and Germany it is compulsory to continue at least part-time in education until the age of 18. (European Commission, 2000, p.17). 
proportion of 17 year olds in education or training in 1995/96 (Eurostat, 1999, Table H1). The main disadvantage of this is that it is not available for Belgium, France, Italy, Greece or the Netherlands at NUTS1 level, and not all at NUTS2.

Figure 6.1 shows the share of the population aged 25-59 who had at least ISCED level 3 qualifications in 1997. The figure gives the national average for each country along with the best and worst performances at NUTS1 level. (The x-axis reminds us of the number of regions in each country.) Disparities are very low in several of the smaller countries, but the four regions of Greece differ dramatically: only 35 percent of adults in Kentriki had completed secondary education, compared to 63 percent in Attiki (the Athens region), better than the best performance in half the remaining member states. (This fits with the relative levels of GDP per capita in these two regions, and also with the not-in-work rates discussed above. Four times as many working age men are without work in Kentriki as in Attiki). In Spain and Italy the overall numbers are lower, but the dispersion a little less. In Spain, the pattern strongly reflects that seen above in the discussion of income disparities: the worst performances are in the south and central regions and the Canary Islands, and the best in the East, North-East and Madrid, with the North-West falling in the middle. In Italy, there are a few changes to the picture. Sardinia, Sicily, Campania and the South have the lowest shares with completed ISCED 3, and Emilia-Romagna and Lombardy rank towards the top, but the highest share is in Lazio, reflecting the concentration of government jobs in Rome. In addition, the North-East, North-West and Central regions all rank below the significantly poorer region of AbruzzoMolise, although the differences in education level are only a few percentage points.

In the UK and France, disparities are somewhat smaller and the overall levels higher. Disparities do not fit any clear pattern. The best performances are in Scotland and the South West, where around 60 percent of the population have completed upper secondary education, and the worst in the West Midlands and Wales with 50 percent. In the rest of the country the share hardly varies, falling between 53 and 56 percent. Performance in France is lowest in the poorest region, the North, but the South-West beats Ile de France and the Centre-East into second place.

Given that it is compulsory in Germany to contiune with some form of education until at least the age of 18, it is no surprise that German regions rank top on ISCED 3 qualifications: even the bottom-ranking region, Bremen, does better than any other NUTS1 region in Europe besides Denmark. The German results show a clear East-West split - but this time it is the East German regions with the stronger performance.

But how accurately does this picture reflect the situation of younger generations? Figure 6.2 is a scatterplot of the ISCED 3 variable for the 25-59 age group against the share of 17 year olds who were in full time education in 1995/6, for all countries for which data are available. For all regions outside East Germany, the share of 17 year olds in education is higher than the share of adults with completed upper secondary, as expected. Following on from this, the dispersion across the EU has fallen as regions push up against the ceiling of full enrolment. Participation among 17 year olds ranges from 60 to 100 percent, compared to ISCED 3 shares ranging from 30 to 95 percent.

Dispersion has not fallen within each individual country, however. In Germany, the western regions have caught up with (and in some cases overtaken) the East. But in the UK, the distribution has been stretched as the performance of 
Figure 6.1: Share of population 25-59 with completed upper secondary education (ISCED 3) 1997

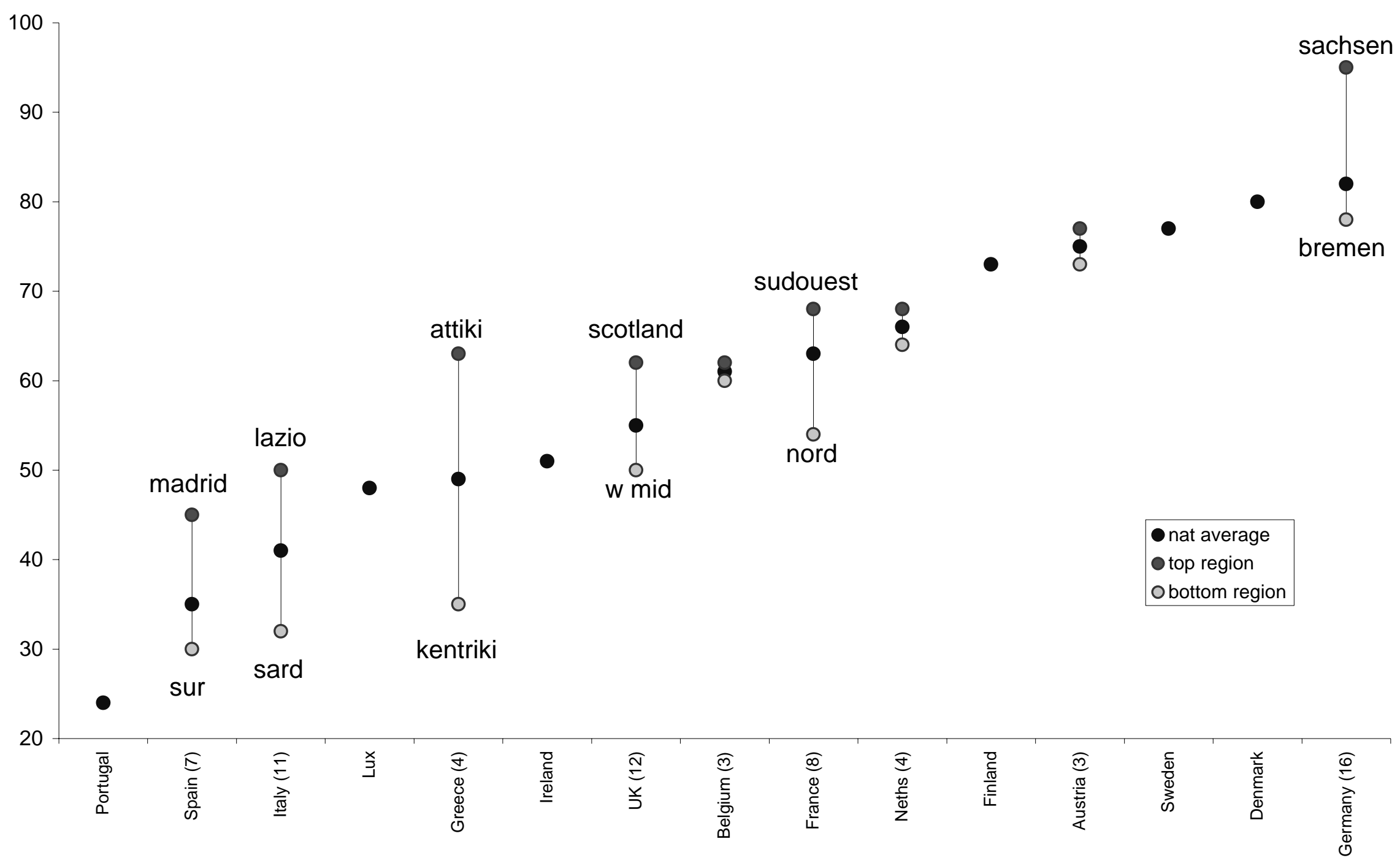


Figure 6.2: Educational attainment of general population, and share of 17 year olds in school, mid 1990s

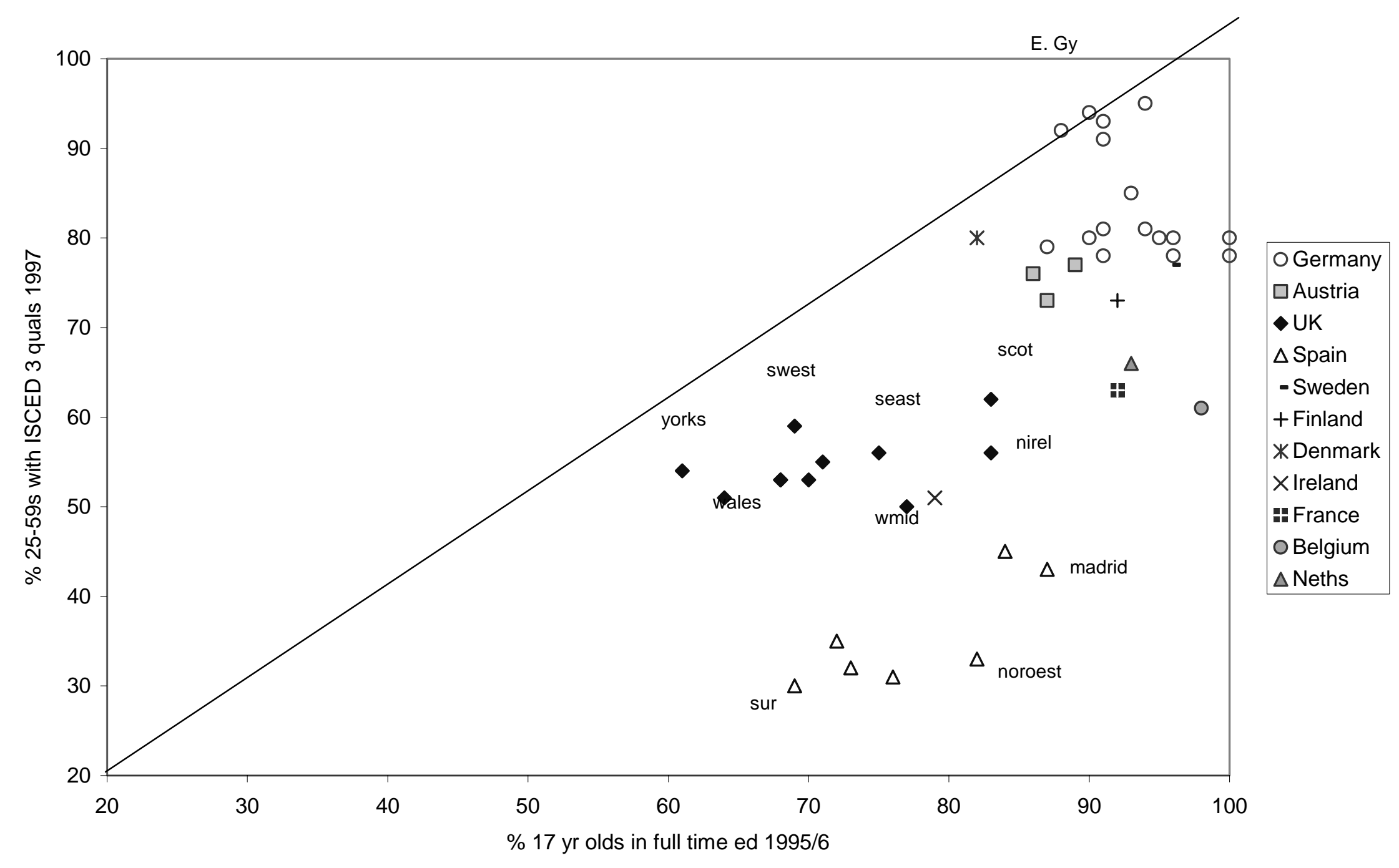


some regions outstrips that of others. Northern Ireland now ranks joint top with Scotland, with 83 percent of 17 year olds in education; while the West Midlands, which has the lowest share of adults with ISCED 3 qualifications, is now in third place in front of the South East. In contrast, the South West has fallen to the middle of the rankings, and Wales is still close to the bottom, just ahead of Yorkshire and Humberside with 61 percent. So 22 percentage points divide the UK regions on the youth education indicators, compared to just 12 percent on the adult measure.

In Spain, the distribution has neither widened nor narrowed significantly. Madrid and the Northeast are still well ahead of the rest, but the Northwest is catching up while the East has dropped well behind.

National rankings have also shifted about: in particular, the UK's relative position has seriously deteriorated, although the degree to which this has happened is overstated by the figure: it so happens that of all the countries ranked below the UK in Figure 6.1, data on 17 year old participation rates are only available for Ireland and Spain. However, both these countries appear to be catching up rapidly with northern Europe, overtaking the UK as they go. Belgium, the Netherlands, France and Finland have all caught up with Germany, Denmark and Austria, but we are unable to say anything about internal disparities in the youth variable in these countries.

\section{Health}

Ideally, a combination of mortality and morbidity indicators would be used to measure regional health, but comparable morbidity statistics are hard to come by. No EU wide source of information on morbidity at regional level exists, although national health surveys may allow for analysis at the level of the health authority: by combining several years of data this can be done for the Health Survey of England, for instance (see Bajekal, 1999). But even if similar health surveys exist for other EU countries, differences in methodology may make cross-country comparability of the results problematic.

However, the ECHP contains a series of questions on self-assessed health status (e.g. 'How is your health in general?). Responses to these questions are used in this section as a complement to mortality indicators.

\section{Mortality Indicators}

Two mortality indicators are examined - the infant mortality rate (IMR) and the standardised mortality ratio (SMR). The infant mortality rate, measuring deaths in the first year of life, reflects the quality of two factors important to health more widely - primary health care and nutrition (in this case among pregnant women). ${ }^{19}$ It is not a problem which has been wiped out in the EU: while even the highest European levels of IMR are negligible compared to those in poorer parts of the world, they still represent thousands of unnecessary deaths a year. If all EU 
countries had had the same under-5 mortality rate as Sweden in 1995, there would have been 10,000 fewer deaths in that year (Micklewright and Stewart, 2000, p.30).

The standardised mortality ratio gives an overall mortality measure which takes account of differences in the age structure of populations in different regions. Life expectancy at birth is the more standard measure used, and is the indicator adopted at Laeken, but it is not available by region, while the SMR can be calculated from Eurostat raw mortality data. ${ }^{20}$ The SMR provides in any case a fairly good proxy for life expectancy. ${ }^{21}$ Deaths from all causes taken together (and to both genders) are looked at here, but Eurostat data could be used to examine differences in SMRs from specific causes and with breakdown by gender. The data could also be used to look at age-specific mortality rates, allowing us to examine the contribution to regional inequality of differing mortality at particular ages. (In a study of regional mortality differentials in the UK, Illsley et al (1991) show how patterns of change in age-specific death rates are disguised by the SMR.) However, while it may fail to exploit all the information on offer, for present purposes it makes sense to use a single summary indicator.

Figure 7.1 presents data for both the IMR in 1997 and the SMR in 1998. In both cases countries are ranked from left to right by per capita GDP in 1997, and national average mortality is given along with the NUTS1 extremes for each country. IMR averages appear more closely related to GDP than the figures for SMR, and in general show a lower level of regional disparity. France is the extreme case, with particularly low disparity in levels of IMR alongside quite high disparity in the SMR; while Italy stands out as the exception, with very high IMR inequality. The SMR averages for several of the low GDP countries are below those for the richer group, but Portugal and the UK are the exceptions here, with higher average SMR than their neighbours in the figure. Finally, regional disparities in both indicators tend to be higher among the countries with lower GDP. (It is worth noting, though, that GDP rankings have changed considerably over the last decade, and any relationship between GDP and either of these indicators is likely to be lagged. At national level, GDP in 1985 is much more strongly correlated with mortality in the late 1990s than is GDP in 1997: -0.76 against -0.48 for IMR 1997, and -0.49 against -0.01 for SMR $1998 .^{22}$ )

Within countries, how do these indicators relate to one other and to income? Figure 7.2 shows regional IMR and SMR, with countries ordered left to right by 1997 GDP per capita (low to high); within countries regions are ordered by LIS income

Standardisation has been carried out by the author using the indirect method (see Armitage and Berry, 1994, p.437), with deaths and populations grouped as follows: 0-14, 15-24, 25-34, 35-44, 45-54, 55-64, 65-74, 75-84, 85 plus. (Both deaths and population data are taken from Eurostat New Cronos Database.) Deaths are standardised to the 1998 EU death rates, although German data are incomplete and not included, while 1996 data are used for Italy and 1997 data for Austria and France.

At national level, the weighted correlation between the standardised mortality rate and life expectancy at birth for EU countries is -0.85 .

Transformation into logs makes negligible difference to this result. 

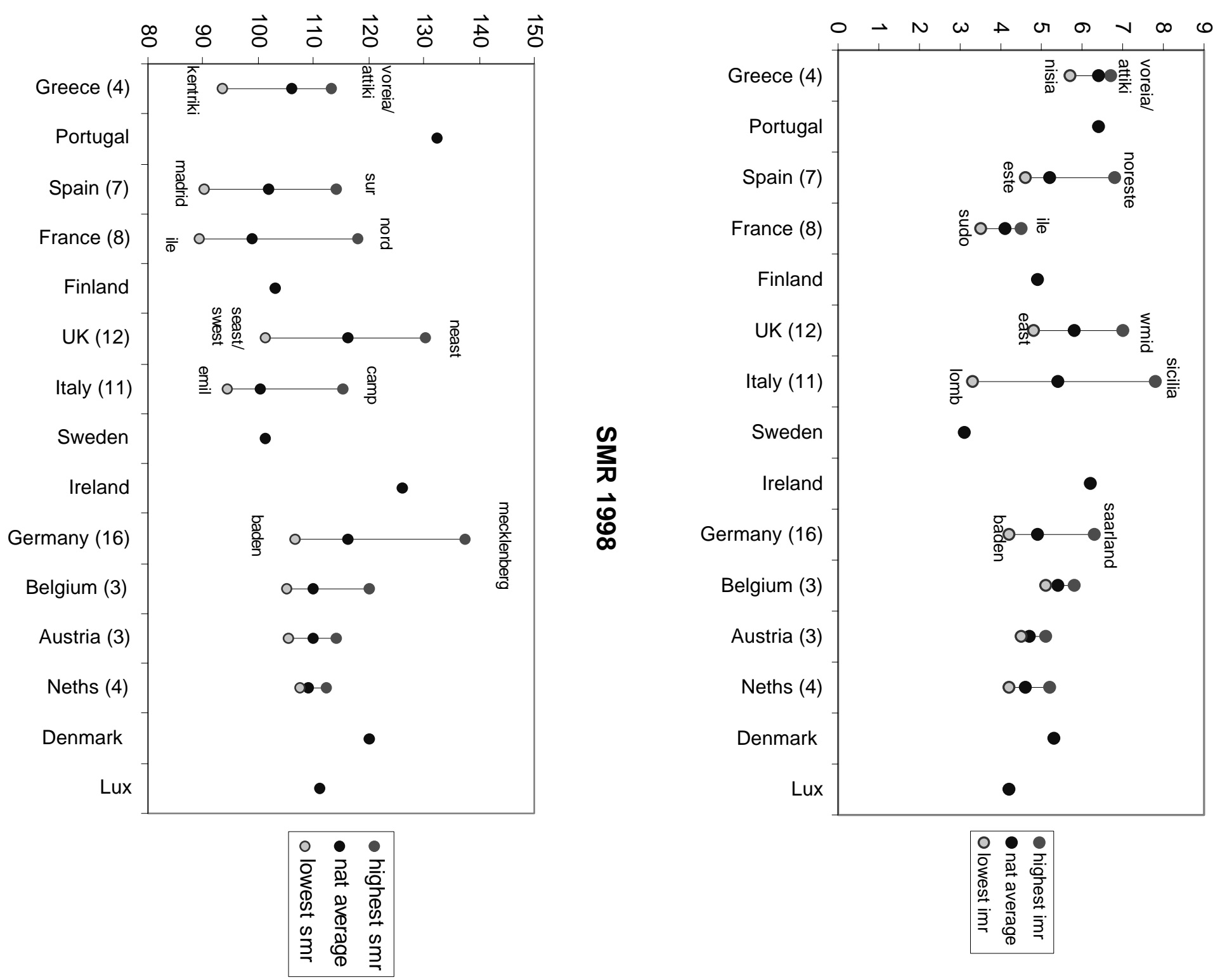

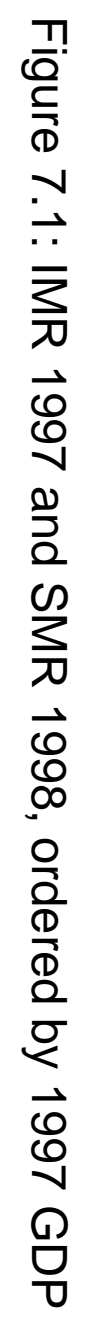


Figure 7.2: IMR 1997 and SMR 1998, ordered by GDP and average household income

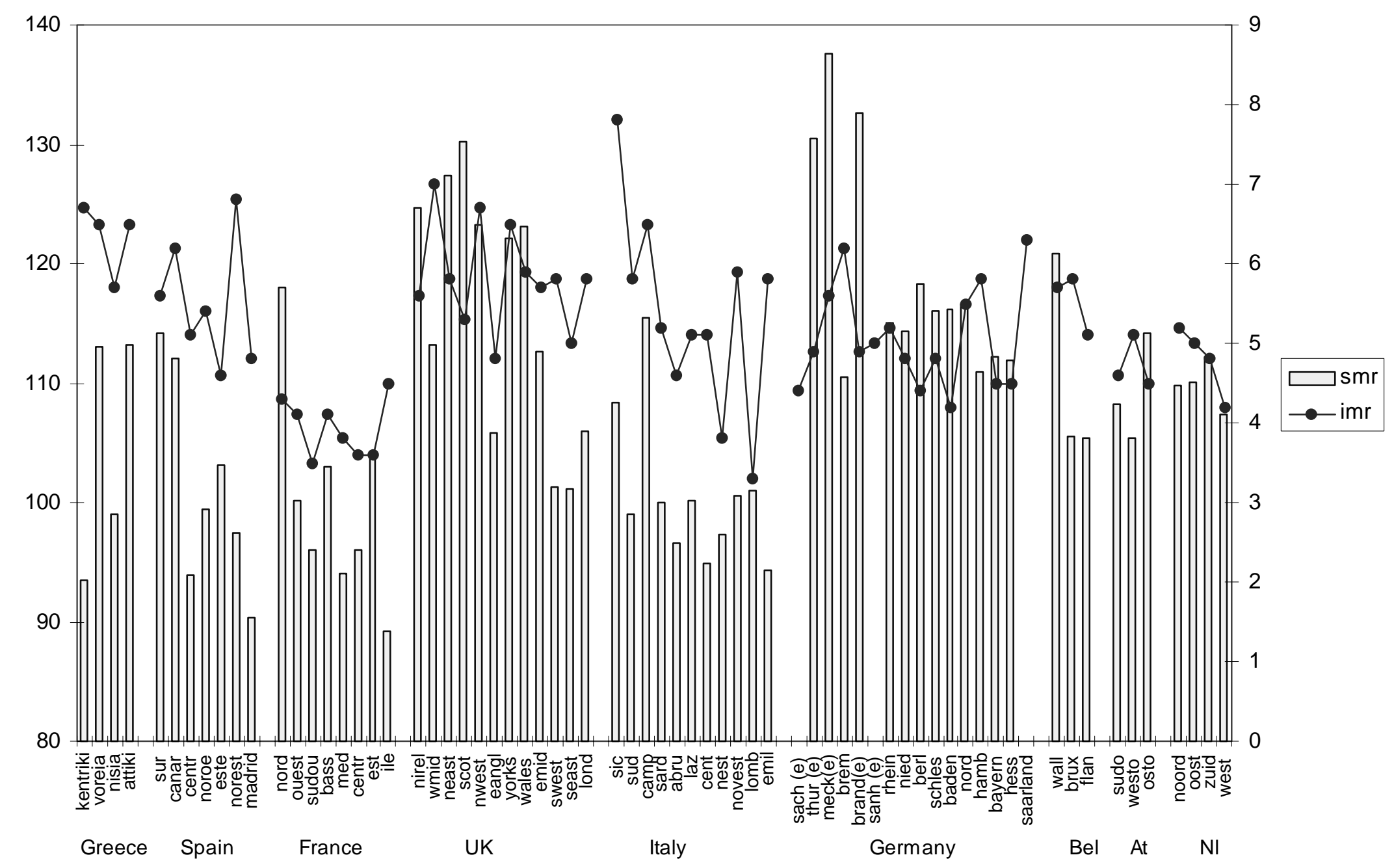


data for the most recent available wave (Spain 1990, Netherlands 1985, all others 1994/5). Greek data is ordered by regional per capita GDP in 1995.

Data for Greece are unusual in that the SMR appears to rise (broadly speaking) with GDP. The SMR is highest in the Athens region of Attiki, and IMR in Attiki is also high. Results for the Kentriki region are particularly striking: Kentriki has the fourth highest infant mortality rate of all European regions shown in the figure, but the third lowest standardised mortality ratio.

Elsewhere, both IMR and SMR appear broadly correlated with income, as expected, but in both cases certain regions stand out. Often, these regions do particularly well or badly on just one of the indicators, not on both. In Spain, the Central region has lower SMR (but not lower IMR) than income would predict, while the North-East has a relatively low SMR but the highest infant mortality in the country, considerably higher than either the East or Madrid, both with similar average income and similar poverty rates. In France, regional disparity in the SMR is much higher than for infant mortality, driven in particular by a very high relative rate in the North and a low rate in Ile de France. But Ile de France has the highest infant mortality rate in the country, while the lowest rate is found in the South-West, relatively poor according to the LIS data. Indeed, the French South-West has the second lowest IMR of all regions represented in the figure.

For the UK, it should be remembered that regional rankings are far from robust, given the large standard errors in the UK income data: in particular, the East's rightful position in the regional income distribution could be several positions to the right. This said, it still has a good record (by UK standards) on infant mortality. Northern Ireland, the North-East and Scotland all also perform well on infant mortality compared to the West Midlands, the North-West and Yorkshire. After Sicily, the West Midlands has the highest IMR of any region in the figure.

In Italy, the North-West and Emilia-Romagna both show surprisingly high levels of infant mortality, higher than anywhere in Italy but Sicily and Campania. SMR in the North-West is also higher than in either the South region or Sardinia. Indeed, these are the first indicators looked at in the paper in which the north-south divide is not clear-cut. With the exception of Sicily and Campania, the SMR shows very low regional disparity.

German regions show a strong east-west divide for SMR, but no such divide for infant mortality, reflecting the lasting impact of policies promoting early childhood health in the socialist bloc. In Belgium, Wallonia shows much higher SMR than the rest of the country, but disparities in both indicators in Austria and the Netherlands are fairly low - as is regional income disparity.

That the infant mortality rate appears scarcely more closely related to income within a country than the SMR is perhaps surprising: the factors driving overall mortality are clearly complex, but we might expect infant mortality to be quite closely related to poverty. Figure 7.3 underlines the extent to which this is not the case, showing the relationship between the rate of poverty in a region and that region's infant mortality rate for the five largest EU countries. Figure 7.4 presents the regional poverty rate and the SMR for the same countries, showing that if anything it is the latter relationship which is closer.

However, one might expect both average income and the level of poverty to have a role in explaining mortality indicators. To assess the role of each when controlling for the other, a series of regressions were run with first the SMR and then 
Figure 7.3: Regional poverty rates 1994-5 and IMR 1997

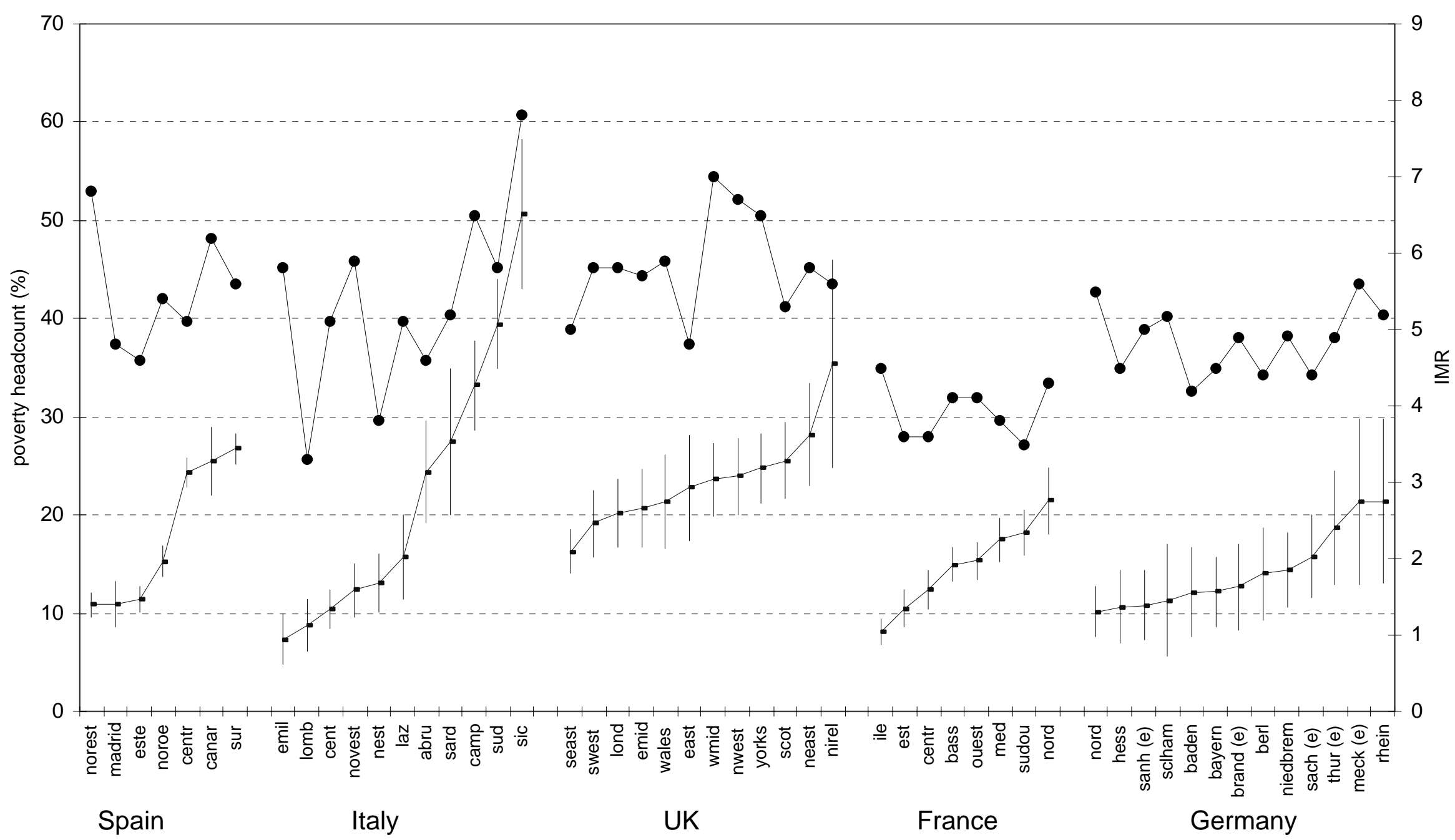


Figure 7.4: Regional poverty rates 1994-5 and SMR 1997

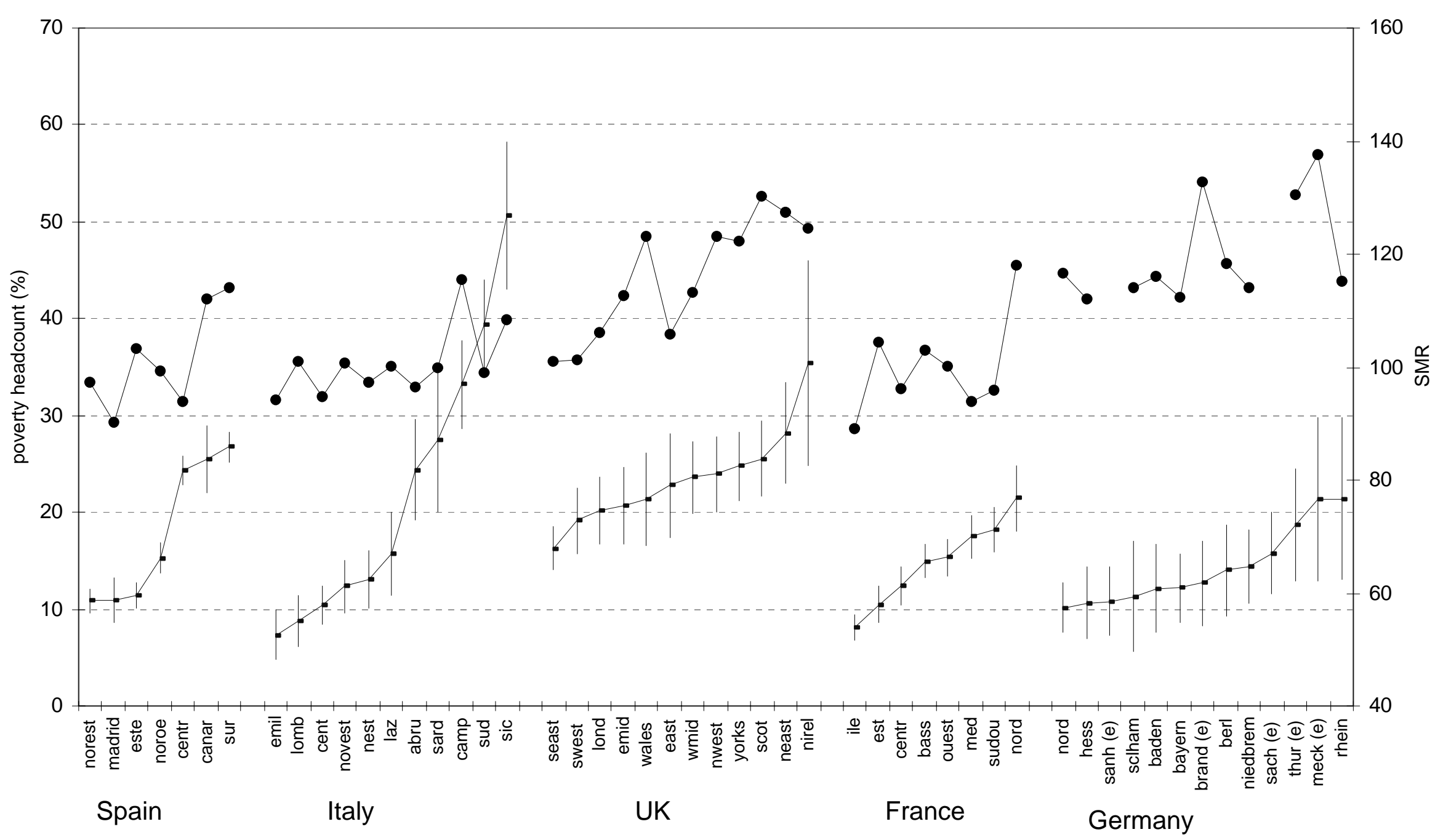


the IMR as the dependent variable. At the same time, this allowed us to explore (albeit briefly and superficially) one of the more controversial questions in research on mortality in the industrialised world today. Wilkinson (1992 and 1996) hypothesised a relationship between the level of inequality in a society and the rate of mortality, over and above the links between income and mortality. Does the Wilkinson hypothesis appears to hold for regional data?

The SMR was regressed on four potential explanatory variables, both alone and in each possible combination: average household income; the decile ratio; the poverty headcount measured against a standard of 60 percent of median national income (Poverty N); and the poverty headcount measured against a standard of 60 percent of median regional income (Poverty R). Grouping all countries together and with no country dummies, Poverty $\mathrm{N}$ was the only significant explanatory factor, alone explaining 15 percent of variation in the SMR. ${ }^{23}$ With country dummies included, average income was the strongest factor: together with the dummies, 63 percent of the variation was explained (the dummies alone explain 42 percent). ${ }^{24}$

Taking the larger countries separately, results are not always similar. In general, there is strong multicollinearity between the average income variable and Poverty N, so both together explain nothing. Average income is usually the stronger of the two. Poverty $\mathrm{R}$ tends to be insignificant, while the role of the decile ratio varies.

For France, average income alone explains 35 percent of the variation, and the decile ratio adds nothing. But for the UK and Germany, the best models include average income and the decile variable. In the UK, average income alone explains about 45 percent of variation in the SMR and the decile ratio an additional 10 percent. In Germany, average income alone explains about 75 percent of variation, with the decile ratio explaining an extra 15 percent. However, in the German case the sign on the decile variable is negative - lower inequality is associated with higher mortality (the effect, no doubt, of lower levels of inequality in the East German states). ${ }^{25}$

For Italy, the decile ratio alone is easily the best explanatory factor, explaining 46 percent of the variation, where average income explains 20 percent and Poverty $\mathrm{N}$ 30 percent. (There are very high levels of correlation between all three variables in the Italian case.) Finally, for Spain the decile ratio is the only significant variable, explaining 30 percent of variation (although even this is only significant at the 10 percent level). ${ }^{26}$

$\mathrm{N}=57$ in these regressions. The coefficient on the poverty variable was 0.48 (standard error $0.15)$.

Coefficient on average income -0.0027 (standard error 0.0005).

In the French regression, $\mathrm{N}=8$, average income coefficient -0.0031 (s.e. 0.0014 ); for the $\mathrm{UK}$, $\mathrm{N}=12$, average income coefficient $-0.0074(0.0020)$ and decile ratio 11.16 (6.09); for Germany $\mathrm{N}=9$ (several missing data points), average income coefficient $-0.0039(0.0007)$ and decile ratio -6.52 (1.95).

For Italy, $\mathrm{N}=11$, coefficient on the decile ratio 5.20 (s.e. 1.69); for Spain, $\mathrm{N}=7$, coefficient on the decile ratio $17.82(9.38)$. 
There seems then to be some tentative support here for the Wilkinson hypothesis, but these results need to be read with some care. In particular, the strongest evidence appears to be from Italy, but this may be misleading, as only small differences divide the Italian income, poverty and inequality distributions. A comparison of Figures 4.8 (the decile ratio) and 7.2 (SMR) show that it could be just the very low levels of both variables in the Central region which is ensuring that the decile ratio has a better fit with SMR than does average household income. Results from both the UK and Germany do suggest that the decile ratio has an explanatory role independent of that of income - but only in the UK case is the effect of the sign predicted. Our inequality variable is not very robust, as has been discussed, and a more precise measure may have stronger predictive power, but the current analysis provides only very weak support for Wilkinson.

The same exercise was also carried out for the IMR, although strong results were not expected: there is less reason to expect a relationship between the IMR and inequality, Figure 7.3 showed little sign of a link between IMR and poverty within countries, while strong multicollinearity between regional average income and Poverty $\mathrm{N}$ make it unlikely that separate effects will be identified for either variable controlling for the other. Taking all countries together, Poverty $\mathrm{N}$ again turned out to be the best explanatory factor, this time explaining 33 percent of the variation (twice as much as the variation in SMR). With country dummies included, Poverty $\mathrm{N}$ is still the best explanatory variable, but the dummies alone explain 36 percent of the variation and the poverty rate only an additional 11 percent. For Italy, Poverty $\mathrm{N}$ also turns out to have the best fit, alone explaining 42 percent of the varation, with average income explaining 31 percent and the decile ratio 29 percent. But for the UK, Germany, France and Spain none of the variables were significant.

\section{Subjective health}

The ECHP contains questions both on self-assessed health status and on the extent of use of medical services (e.g. number of recent visits to a doctor; whether or not the respondent has been admitted to hospital in the last twelve months). As there is evidence that higher social classes and income groups are more likely to make use of medical services, and as the role played in health care by in-patient treatment differs across countries, this section focuses on self-assessed health measures. In particular, it looks at responses to two questions. First, it considers the percentage in each region responding 'bad' or 'very bad' to the question 'How is your health in general?'. Second, it looks at the share reporting to have 'cut back on normal activity during the last two weeks due to ill-health or injury'. While the first question should reflect the respondent's wider health, the second picks up on the prevalence of shortterm illness.

Responses to the two questions are presented in Maps 7.1 and 7.2 to give us an overview of the geography of self-assessed health in Europe. It is immediately clear that the two measures give us very different pictures. General health is held to be worst in Portugal and western Spain (except Madrid), in central and southern Italy and in Wales. Southern England, Ireland and eastern France do well. But the areas most affected by illness or injury in the two weeks prior to the survey are quite different. Northern Europe is hardest hit, while Italy and Greece do best. Fewer than 


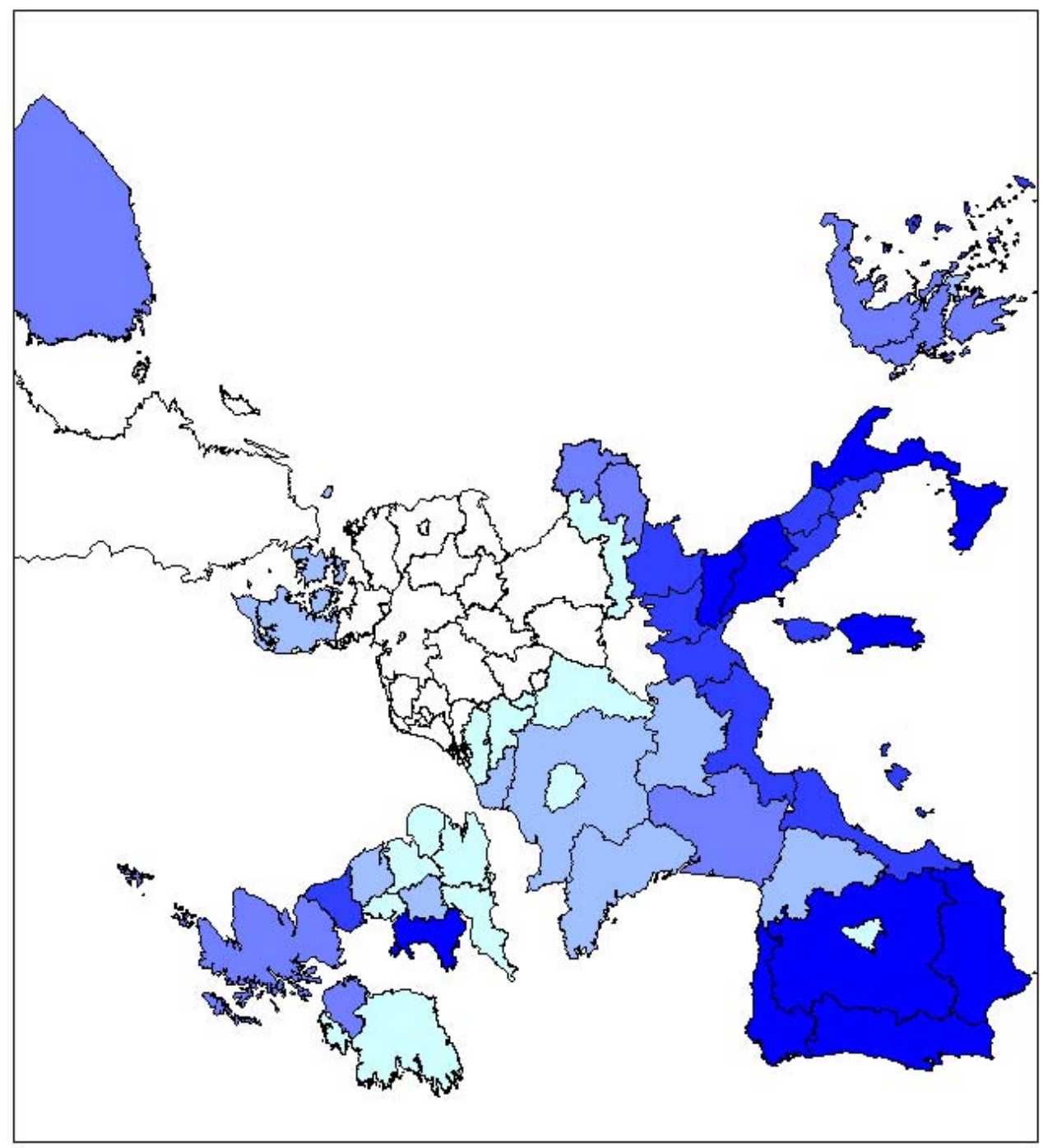

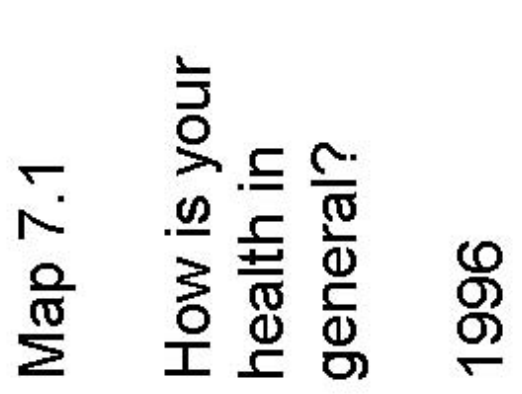

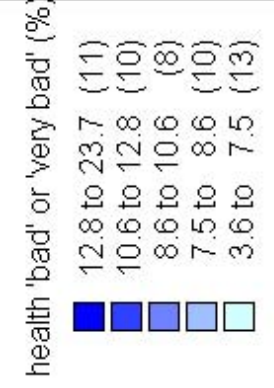



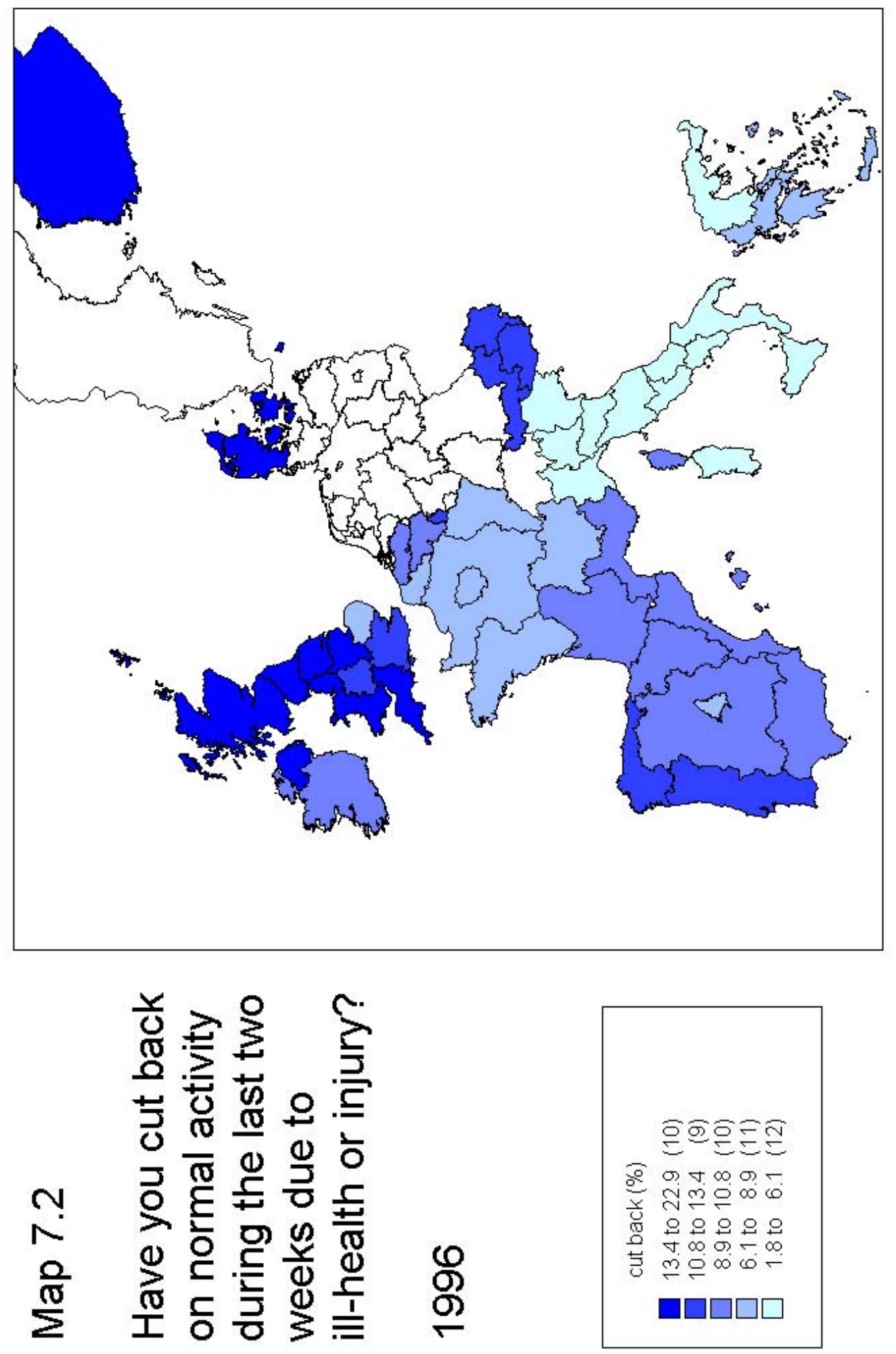
seven percent of the population have been affected in any Greek or Italian region, compared to one in five people in Scotland, Wales and North-East England. ${ }^{27}$

The second question is how well these indicators correlate with the 'objective' evidence of mortality data. Correlation between the SMR and the general health variable is of particular interest. ${ }^{28}$ But the relationship between these two measures is very weak, both across the EU as a whole and within most of the larger countries. This is illustrated in Figure 7.5, which shows the two variables for Spain, France, Italy and the UK. (The self-assessed health measure is not age-standardised, but to prevent the most serious effects of regional differences in population age-structure, results for respondents 65 years and over have been excluded: this in practice has the effect of weakening the relation with regional SMR.) Coefficients of correlation between the two series are insignificant for every country shown. For Italy, the relation is negative (though still not significant). It is interesting that both variables (uniquely among those examined in the paper) defy the Italian north-south divide, but due to quite different good and bad regional performances. Self-reported bad health in Wales is strikingly high, and calls for further investigation.

Finally, there is the issue of how the self-reported indicators relate to regional income and to rates of poverty and inequality. Do self-assessed health measures provide any evidence in support of the Wilkinson hypothesis, for instance? An exercise similar to that undertaken above came up with equally mixed results, but with different factors showing up as significant for several countries - perhaps not surprising given low levels of correlation between the two health measures. Taking all regions together, average household income is the only significant factor in explaining poor general health, accounting for some 20 percent of variation. In the UK, the best fit is provided by the same model used in the SMR regression: average income and the decile ratio between them account for 53 percent of variation. For France, the same two factors are able to explain some 47 percent of variation. For Spain, however, the decile ratio is insignificant and it is Poverty $\mathrm{N}$ in combination with average income which provides the best fit, accounting for almost 80 percent of variation - but the coefficient on the poverty variable is negative. And finally, in Italy, none of the variables turn out to be significant. This is not surprising given the strong north-south cleavages in each of the income and inequality variables and the much less clear-cut results for the health variable. Again then, while there is some support for the Wilkinson hypothesis, evidence is mixed. ${ }^{29}$

It is not clear from the ECHP documentation at which time of year the surveys were carried out; this is clearly a relevant consideration in interpreting responses to this question.

Of course, it is quite plausible that subjective health measures might in fact be correlated not with current but with future mortality, but this cannot be currently tested in the absence of earlier data on self-assessed health.

Taking all countries together, $\mathrm{N}=43$ and the coefficient on average income is -0.00059 (s.e. $0.00017)$. For Spain, $\mathrm{N}=7$, the average income coefficient is $-0.0092(0.0024)$ and the poverty coefficient is $-0.98(-2.86)$. For France, $\mathrm{N}=8$, the income coefficient is $-0.00088(0.00032)$ and the inequality coefficient is $4.92(2.39)$. For the $\mathrm{UK}, \mathrm{N}=11$, the income coefficient is -0.0019 (0.00065) and the inequality coefficient 8.67 (2.62). 
Figure 7.5: Self-assessed health from the ECHP 1996 and SMR 1998

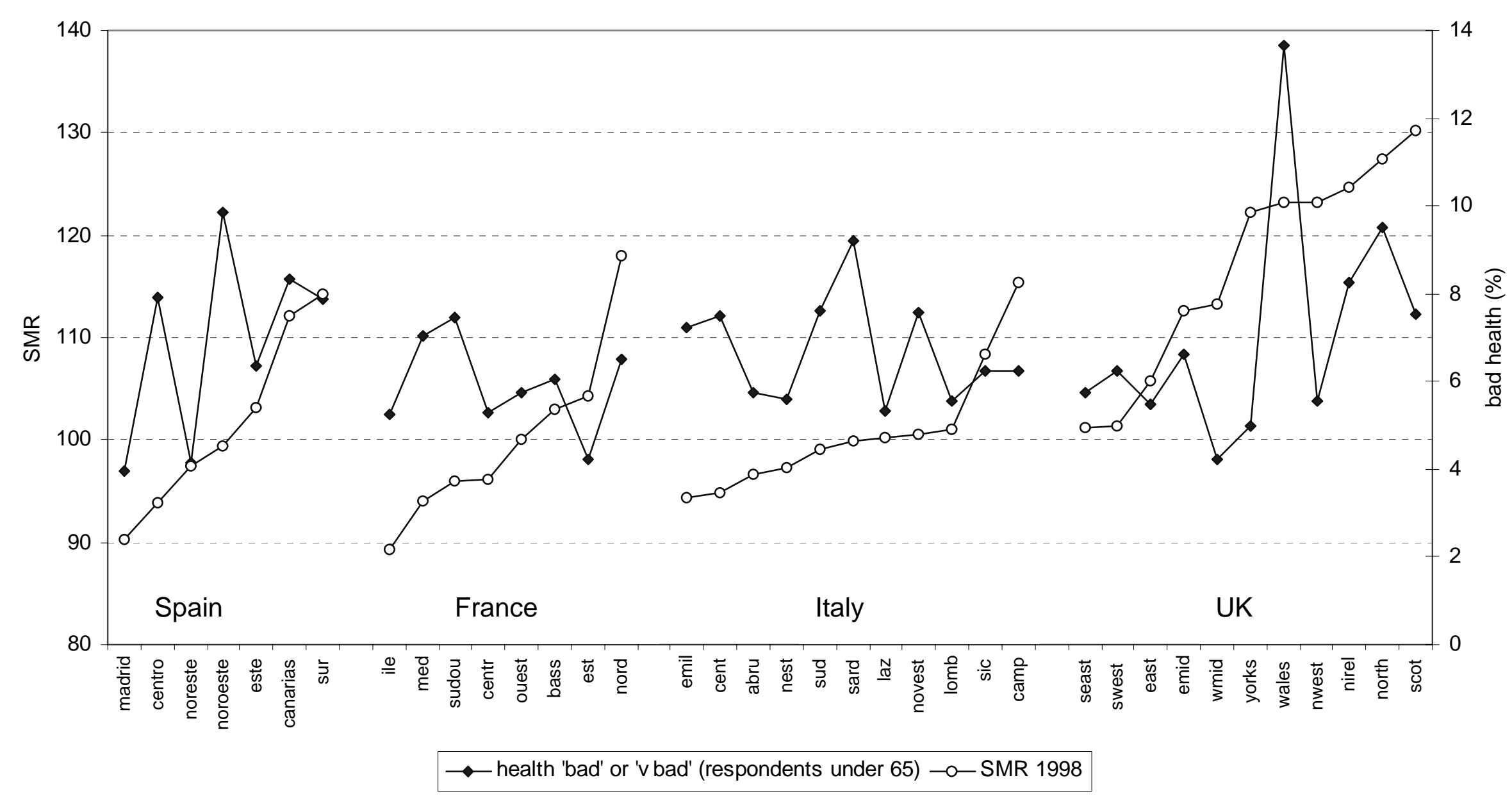




\section{Social participation}

The indicators in each of the above domains could be seen as important factors facilitating social participation; in some cases even as necessary conditions. One of the arguments for a relative poverty line, for instance, is that low relative income can exclude people from participating in everyday life. Alongside other benefits, participation in the productive sphere brings a circle of acquaintances and day to day contact with others. Without basic literacy skills many aspects of participation would become very difficult - although education can also create a divide between individuals and their communities.

But while all these factors may make social participation more or less likely, this section aims to pick up directly on the degree to which people are and feel integrated with friends, family and community. In looking for indicators, we can distinguish between three levels of participation.

First, we might want to measure integration at the most local level. Do people know their neighbours? Are they in regular contact with friends and/or family? Participation at this level might itself be separated into two aspects: does a person have the everyday human contact most people need in order to thrive; and does she have somewhere to turn in a time of crisis?

Second, we might be interested in wider participation in clubs and networks. The literature on social capital draws a distinction between 'bridging' and 'bonding' forms of capital, where bonding social capital connects one to one's own kin and community, while bridging capital stretches across social divides (see e.g. Putnam, 2000, p.22). Membership of a local running club, for instance, might bring people together across class and race lines. Bridging social capital is held to strengthen society by forging links between diverse groups of people, while also benefiting the individual by widening his circle of contacts and increasing his exposure to different sources of information: bonding social capital has been argued to be good for 'getting by' and bridging social capital for 'getting ahead' (Xavier de Souza Briggs, quoted in Putnam, 2000, p.23). As such, the degree of regional participation in clubs and societies should tell us something about the well-being of individuals in the region and perhaps also something about the health of the society in general.

Finally, there is the issue of political participation, reflecting a sense that one is involved with and able to affect wider political decisions, that one has a voice. Voter turnout rates are one weak measure of this, as abstention implies disaffection with the system and a belief that one's vote makes no difference; membership of political parties and pressure groups and participation in demonstrations might be better indicators. Ideally, we would want to look at these types of indicator alongside measures of how democratic a society really is; i.e. to examine the reality of involvement in decision-making alongside the illusion.

But are there data available that will allow us to measure these aspects of social participation at regional level? The most promising source is the ECHP, which includes several questions on social relations: frequency of contact with neighbours and frequency of meetings and phone conversations with people from outside the household are covered, although there are no questions covering access to support in the event of a crisis. Below I examine an indicator of social contact which combines 
responses to two questions: 'How often do you talk to any of your neighbours?' and 'How often do you meet friends or relatives who are not living with you?'

The ECHP also includes a question on membership of clubs and organisations, offering potential (limited) insight into the extent of regional participation in the wider community. The question provides only a two-way division between membership in any clubs and membership in none (the question gives as examples 'a sport or entertainment club, a local or neighbourhood group, a party etc.'). Beyond this, data on club membership is difficult to find even at national level. Robert Putnam's 1992 book, Making Democracy Work (p.91 onwards) uses quite detailed data on the density of different types of club at regional level for Italy, but Putnam admits to being fortunate that a census of all associations in Italy, local and national, had been carried out in the previous decade; even so, all data were for 1982. Similar and more recent censuses may, of course, have been carried out for other countries, but these have been hard to find.

Similarly, data on party membership at regional level are not easily available, while regional data on participation in demonstrations can probably be ruled out. Voter turnouts should be available by region, offering some information on political participation, at least for those countries in which voting is not compulsory, but this aspect of social participation is not examined in this paper.

The two ECHP indicators are presented in Figure 8.1. The upper part of the figure shows the share of respondents by region who report to being a member of a club or organisation, while the lower part shows the share who meet friends or relatives not living with them at least once a week and/or talk to their neighbours at least once a week. The remainder, in other words, appear to have no social contact with somebody outside the household in the average week.

The first thing to note about the club membership variable is the wide disparity in the importance of clubs and organisations across EU member states. Fewer than one in ten Greeks appear to be club members, in comparison with 60 percent of Danes. There is also a clear north-south divide within the EU, with clubs playing a much smaller role in southern Europe than in Germany, Austria, the UK and Scandinavia. The most striking internal disparity is in Belgium, with the Flemish-speaking part of the country behaving very much like the Netherlands with regard to clubs, while the French-speaking part looks just like France.

These large cross-country differences do raise questions about the cultural judgements involved in counting association membership. We argued above that clubs are valuable in offering links to wider social groups and classes, while regular social contact is likely to remain more limited and limiting. But is this necessarily the case? Can we say that the abundance of clubs is one aspect of northern life which is superior? Or does the Greek cafe offer an alternative and equally valid way of consorting across social groups? The problem is that while it seems plausible that clubs would lead to a broader set of social relationships, proving it is very hard to do.

Robert Putnam argues that the 'vibrancy of associational life' is a key indicator of 'civic sociability' (p.91) and that the number of clubs gives us an important clue as to 'which regions most closely approximate the ideal of the civic community'. Interestingly, though, while his data (which counts density of clubs, not club membership) support his hypothesis that civic life is much better developed in northern than in southern Italy, the ECHP data give a rather different impression. As 

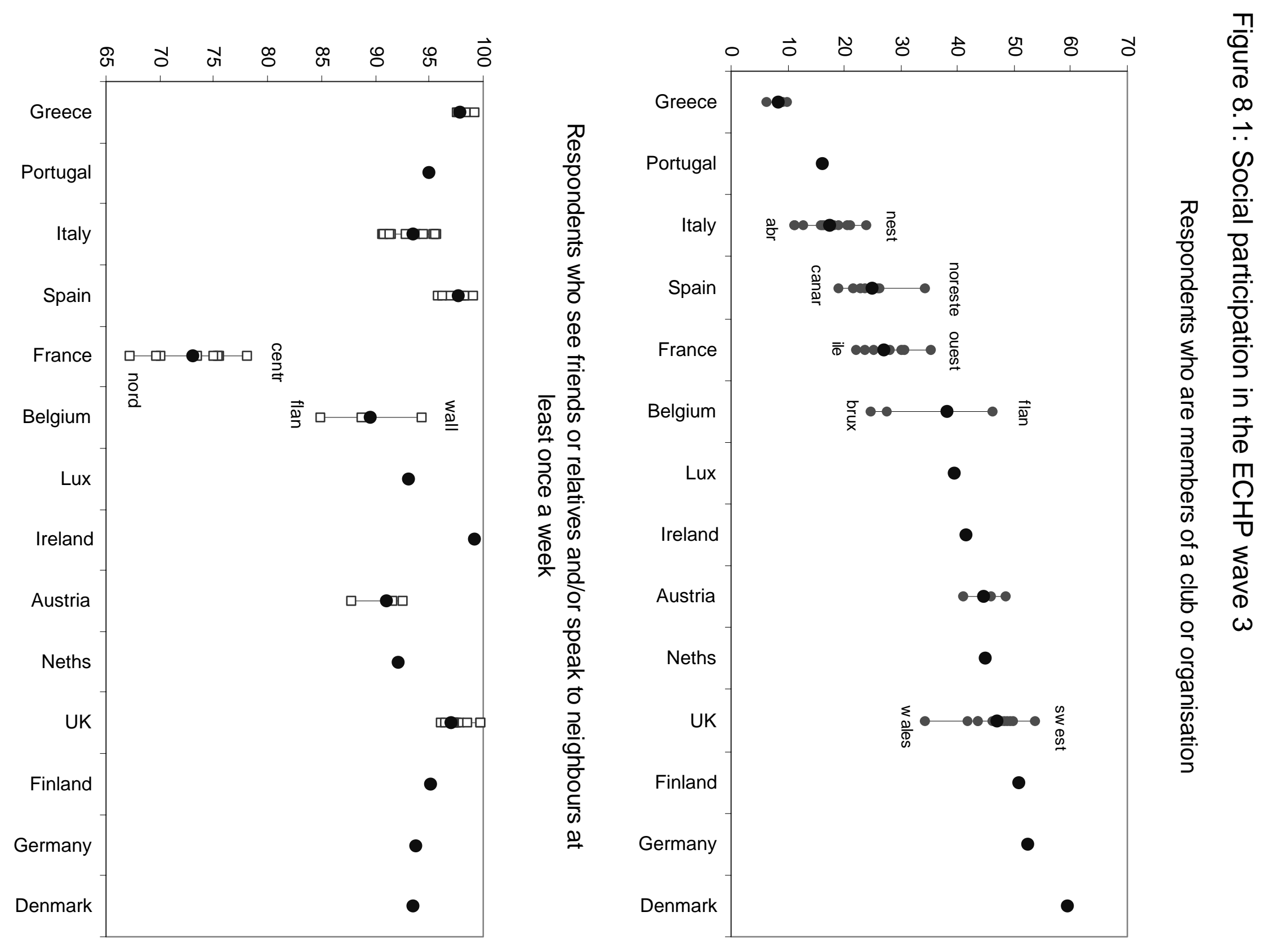
Figure 8.1 shows, regional disparity in club membership in Italy is fairly low, ranging between 11 and 24 percent of the population. Nor is there a clear northsouth divide. The North and Central regions are those where membership is highest, while the lowest levels are in Abruzzi (just south of central Italy), followed by Campania and the South region. But Sicily and Sardinia fall somewhere in the middle: membership rates in Sicily are 16 percent, compared to 18 percent in the Milan region of Lombardy.

Turning to the bottom half of Figure 8.1, we see that the social contact variable displays even lower within-country variation. Again, the largest level of disparity is for Belgium, though this time it is the Flemish speaking part where social relations are at their lowest. But the most obvious point is the very low levels of social contact recorded for France. Between 20 and 35 percent of respondents in all French regions claim that they do not meet friends or relations or speak to neighbours at least once a week. This seems unlikely and unfortunately suggests that there may be problems with the translation or coding of the variable.

\section{Conclusions}

This paper set out to explore regional disparity in a range of indicators of well-being across the European Union. It aimed to examine how far national average indicators disguise internal regional differences; and to see whether different indicators would tell the same regional story. These conclusions sum up what we have found in each of these areas in turn. First, though, they highlight the main constraints presented by existing data.

\section{Data sources and data holes}

In the light of the EU Social Agenda drawn up at the Nice summit in December 2000, the European Commission is pushing ahead with work to identify a set of target indicators of poverty and social exclusion. There appears to be a commitment to track regional disparities in at least some of these. But for certain key indicators existing data sources do not allow us to be confident about differences across regions even at a single point in time.

Most strikingly, analysis of Luxembourg Income Study data showed that existing national household surveys for several countries do not allow us to rank regions by average household income with statistical certainty, even at the heavily aggregated NUTS1 level. Poverty and inequality rates, which make greater demands on the data, are more problematic still. Results suggest that several thousand respondents per region (as in the Spanish Expenditure and Income Survey) would be needed to separate regional poverty rates, although a minimum of 1500 respondents per region (as in the French Family Budget Survey) might allow results of some usefulness. In the UK Family Expenditure Survey and German Social Economic Panel Study, with well below one thousand respondents in most regions, standard errors are just too large for results to be robust.

Indicators on employment and educational attainment present fewer statistical problems, as sample sizes in the European Labour Force Survey are huge relative to income survey samples - upwards of 10,000 households in most NUTS1 
regions, allowing significant breakdown at NUTS2 level as well. But no educational outcome measures can be tracked as the recent spurt of international surveys of learning achievement and literacy allow only very limited sub-national analysis.

Finally, the health and social participation sections of the paper drew on the European Community Household Panel as well as on administrative data on mortality. As with LIS data, ECHP data can be analysed at NUTS1 level for most EU countries, but the same problems of small sample sizes arise (ECHP regional samples are on the whole smaller than those in the LIS datasets). The variables used in the paper are constructed from responses to questions with between two ('yes' or 'no') and five possible answers, and samples are large enough to support this sort of analysis. But bigger samples would be needed to explore the interrelationships between variables at regional level, or to exploit income variables. This is an issue the Commission might bear in mind as work continues on the ECHP's successor, the EU-SILC.

\section{Regional dispersion}

With what we have, though, what can we say about the extent of regional disparities in well-being in the EU? Stepping back from the detail to summarise and compare results across domains is difficult without any dispersion measures to hold on to but it would be misleading to compare a coefficient of variation for Belgium (with three NUTS1 regions) with one for Germany (with sixteen). One way round this problem is to make comparisons only within a sub-group of countries with a similar number of regions. Table 9.1 presents coefficients of variation for three country groupings: countries in the first group contain three or four NUTS1 regions each; Spain and France in the second group have seven or eight regions; and in the third group each country contains between eleven and sixteen regions. (In each case, coefficients of variation have been calculated using weighted populations to make sure that small regional outliers do not disproportionately affect results.) The highest level of regional disparity for each indicator in each group is highlighted dark.

It is immediately clear that high regional disparities in one domain need not necessarily result in large disparities in others. For instance, Belgium has much higher coefficients of variation than other countries in its group for GDP per capita, poverty rates (measured using a national standard), unemployment, self-assessed general health and club membership, but displays relatively low disparity in inequality, educational attainment and infant mortality rates. In contrast, Greece has very low disparity in GDP per capita and a much lower coefficient of variation for unemployment than Belgium, but very high disparities for the share of working-age men not in work, educational attainment and the short-term health measure. Austria displays strong regional cohesion: the only area of high disparity is the share of the unemployed who have been out of work long-term.

The other two groups of countries show a similarly mixed story, although again in each case one country stands out as having greater disparity overall. Regional disparities are higher in Spain than in France in several areas, including the national-standard poverty rate, unemployment (just), educational attainment, infant mortality and teenage fertility. France shows greater dispersion in GDP per capita (just), poverty measured against a regional standard and short-term health, with little difference in the dispersion measures for other indicators. 
Table 9.1: Weighted coefficients of variation

\begin{tabular}{|c|c|c|c|c|c|c|c|c|c|}
\hline & Belgium & Austria & Greece & Netherlands & Spain & & Italy & UK & Germany \\
\hline observations & 3 & 3 & 4 & 4 & 7 & 8 & 11 & 12 & 16 \\
\hline GDP 1998 & 0.25 & 0.14 & 0.10 & 0.12 & 0.24 & 0.27 & 0.28 & 0.11 & 0.21 \\
\hline Average income & 0.04 & 0.04 & & 0.07 & 0.13 & 0.15 & 0.23 & 0.10 & 0.10 \\
\hline Poverty (nat std) & 0.20 & 0.04 & & 0.11 & 0.43 & 0.30 & 0.70 & 0.19 & 0.25 \\
\hline Poverty (reg std) & 0.06 & 0.10 & & 0.23 & 0.09 & 0.15 & 0.18 & 0.10 & 0.24 \\
\hline Decile ratio & 0.04 & 0.07 & & 0.09 & 0.06 & 0.09 & 0.20 & 0.06 & 0.15 \\
\hline Housing & 0.66 & 0.50 & 0.52 & & 0.51 & 0.33 & 0.51 & 0.61 & \\
\hline Unemp & 0.42 & 0.14 & 0.24 & 0.12 & 0.24 & 0.21 & 0.62 & 0.19 & 0.44 \\
\hline LTU & 0.07 & 0.56 & 0.08 & 0.10 & 0.10 & 0.05 & 0.23 & 0.13 & 0.12 \\
\hline Not-in-work & 0.16 & 0.07 & 0.59 & 0.07 & 0.16 & 0.17 & 0.16 & 0.20 & 0.18 \\
\hline ISCED3 & 0.01 & 0.03 & 0.28 & 0.03 & 0.16 & 0.07 & 0.10 & 0.06 & 0.07 \\
\hline Particip at 17 & & 0.02 & & & 0.09 & & & 0.10 & 0.03 \\
\hline SMR & 0.08 & 0.04 & 0.09 & 0.02 & 0.09 & 0.08 & 0.06 & 0.09 & \\
\hline IMR & 0.07 & 0.07 & 0.05 & 0.10 & 0.14 & 0.09 & 0.26 & 0.13 & 0.11 \\
\hline Bad health & 0.30 & 0.21 & 0.10 & & 0.25 & 0.21 & 0.15 & 0.36 & \\
\hline Cut back & 0.04 & 0.03 & 0.09 & & 0.10 & 0.18 & 0.32 & 0.27 & \\
\hline Club membership & 0.31 & 0.09 & 0.21 & & 0.16 & 0.16 & 0.23 & 0.11 & \\
\hline Spoken to friends/neighbs & 0.06 & 0.02 & 0.01 & & 0.01 & 0.05 & 0.02 & 0.01 & \\
\hline
\end{tabular}

Highest $\mathrm{cv}$ in group 
In the third group, the largest regional divisions are clearly in Italy: coefficients of variation are substantially higher than for the UK and Germany for a majority of the indicators. But disparities are higher in the UK for housing quality, SMR, self-assessed health, participation in education at 17 and the not-in-work rate.

Italy and Germany have well-documented regional cleavages, so results for Italy are of little surprise, although those for Germany may be seen as unexpected. Despite the East-West divide, German coefficients of variation for GDP, average income and poverty (national standard) are lower than for Spain or France, even though there are twice the number of German regions.

The message of Table 9.1 is that, while we can pick out Belgium, Spain and Italy from their groups as the countries with the highest levels of regional disparity overall, a high coefficient of variation in one indicator does not necessarily tell us anything at all about the level of dispersion in another. ${ }^{30}$ This is important given the recent EU decision that a single dispersion indicator, the coefficient of variation of regional unemployment rates, should be used as the sole measure of regional disparity in social inclusion. As has been discussed in the main body of the paper, there are particular problems with the choice of the unemployment rate as the indicator to track, because it is so strongly affected by the economic cycle - in many countries, as unemployment falls, regional dispersion rises, because employment booms take off in high employment regions first. But Figure 9.1 also provides evidence that the choice of any single indicator to track disparity would be arbitrary and potentially misleading.

\section{Links between aspects of well-being}

We have seen that high disparities in some indicators or domains do not necessarily mean high disparities in others. But how far does this just reflect a stretching out or compressing of a single distribution, and how far is there a reshuffling of regional positions? Do disparities reflect multi-dimensional regional divides within countries or do rankings change from indicator to indicator?

Table 9.2 presents the coefficients of correlation between regional GDP per capita in 1998 and each of the other regional indicators for the five largest EU countries. The pale highlighting shows a significant positive correlation (in the sense that better performance on GDP means better performance on the indicator in general) while the darker highlighting shows a significant negative correlation. Thus a string of pale boxes shows consistency in regional performance across indicators, implying in turn that a single indicator such as GDP per capita could be taken as a reasonable proxy for wider regional well-being. Dark boxes suggest the opposite: better performance on some indicators goes hand in hand with worse performance on others.

As expected, average household income is strongly correlated in all countries with GDP per capita, as is poverty measured against a national poverty line, with

It also tells us nothing, of course, about the average level of the indicator: dispersion indicators need to be considered in the context of the national average if they are to be used on their own as indicators of national performance. For instance, while the rate of regional disparity for poverty rates is lower in the UK than in either Germany or France, poverty rates in most UK regions are higher than in most German or French regions. 
Table 9.2: Correlation coefficients for regional well-being indicators and GDP per capita 1998

\begin{tabular}{|c|c|c|c|c|c|c|c|c|c|c|c|c|c|c|c|c|}
\hline & $\begin{array}{r}\text { Average } \\
\text { household } \\
\text { income }\end{array}$ & $\begin{array}{r}\text { Poverty } \\
\text { rate } \\
\text { (national } \\
\text { standard) }\end{array}$ & $\begin{array}{r}\text { Poverty } \\
\text { rate } \\
\text { (regional } \\
\text { standard) }\end{array}$ & $\begin{array}{r}\text { Decile } \\
\text { ratio }\end{array}$ & $\begin{array}{r}\text { Housing } \\
\text { poor on } \\
\text { at least } \\
\text { three } \\
\text { counts }\end{array}$ & $\begin{array}{l}\text { Unemp } \\
\text { rate }\end{array}$ & LTU & $\begin{array}{r}\text { Not-in- } \\
\text { work } \\
\text { rate }\end{array}$ & $\begin{array}{l}\text { ISCED3 p } \\
\text { attainment }\end{array}$ & $\begin{array}{r}17 \mathrm{yr} \text { old } \\
\text { articipation } \\
\text { rate }\end{array}$ & SMR & IMR & $\begin{array}{c}\text { Bad or } \\
\text { very } \\
\text { bad I } \\
\text { health }\end{array}$ & $\begin{array}{r}\text { Cut } \\
\text { back in } \\
\text { last two } \\
\text { weeks }\end{array}$ & $\begin{array}{r}\text { Not a } \\
\text { member } \\
\text { of any } \\
\text { club }\end{array}$ & $\begin{array}{r}\text { See } \\
\text { friends/ } \\
\text { neigbhours } \\
\text { less than } \\
\text { once a } \\
\text { week }\end{array}$ \\
\hline Erance & 0.97 & -0.74 & 0.65 & 0.68 & 0.18 & -0.36 & -0.16 & -0.44 & 0.43 & & -0.60 & 0.48 & -0.44 & -0.35 & 0.46 & 0.23 \\
\hline Germany & 0.78 & -0.45 & 0.42 & 0.54 & & -0.67 & -0.05 & -0.48 & -0.76 & 0.75 & -0.92 & 0.25 & & & & \\
\hline Italy & 0.96 & -0.92 & -0.48 & -0.83 & -0.59 & -0.92 & -0.74 & -0.84 & 0.66 & & -0.56 & -0.63 & -0.16 & 0.47 & -0.74 & -0.15 \\
\hline Spain & 0.91 & -0.81 & -0.14 & -0.34 & 0.01 & -0.74 & 0.43 & -0.87 & 0.92 & 0.58 & -0.56 & 0.09 & -0.90 & -0.51 & -0.40 & 0.25 \\
\hline UK & 0.81 & -0.53 & 0.69 & 0.70 & -0.32 & $0.03^{* *}$ & -0.57 & -0.82 & 0.32 & 0.14 & -0.59 & -0.23 & -0.73 & -0.57 & -0.49 & -0.02 \\
\hline EU total & 0.61 & -0.56 & -0.01 & -0.08 & -0.29 & -0.48 & -0.16 & -0.37 & 0.27 & 0.45 & -0.24 & -0.20 & -0.32 & -0.02 & -0.26 & 0.19 \\
\hline Total region & 61 & 61 & 61 & 61 & 47 & 68 & 67 & 67 & 67 & 37 & 61 & 68 & 47 & 47 & 47 & 47 \\
\hline
\end{tabular}

${ }^{*}$ For purposes of presentation, high GDP regions are 'expected' to have lower poverty, lower inequality, lower unemployment, higher educational attainment, lower mortality and lower teenage fertility. Highlighted correlations are significant at the 10 percent level.

${ }^{* *}$ With London excluded this correlation is -0.81 and is significant at the 1 percent level.

correlation significant at 10 percent level and of sign expected* 
poverty lower in richer regions. However, in three out of the five countries, richer regions tend to have higher inequality and higher poverty measured against a regional poverty line. Italy, and to a lesser degree Spain, are the exceptions here.

Putting poverty and inequality aside and focusing on the remaining twelve indicators, there is just one country, Italy, in which regional GDP seems a very good proxy for overall well-being. Eight out of the eleven indicators for which Italian data are available are strongly correlated with GDP - all but the two self-assessed health measures, social contact and the regional poverty rate. In Spain, Germany and the UK, GDP appears to reflect some aspects of well-being but not others, with only four or five of the indicators showing strong correlations. (ISCED3 attainment among the working-age population in Germany is significantly higher where GDP is lower, reflecting the historically high investment in education in former East German regions.) But in France not a single indicator other than average household income and the poverty rate (measured against a national standard) is significantly correlated with GDP at regional level.

On an EU-wide basis, GDP seems at first glance very well correlated with wider well-being: in addition to average household income and the national standard poverty rate, nine of the remaining indicators show a positive and significant correlation with GDP per capita. On closer inspection, it becomes apparent that the correlations are in fact much weaker than those at national level: the test statistic depends on both the strength of the relationship between two variables and the number of observations, so a larger number of regions allows us to be more certain that correlations are significantly different than zero, even at lower correlation values. None of the correlations across the EU as a whole are larger than 0.50 , while many of those within single countries are higher than 0.80 . Of course, it is not surprising that correlations are weaker when we treat the EU as a Europe of the regions: country effects will clearly be important and a simple linear relationship across all EU regions would be unlikely. But the idea is to see how far a single variable, per capita GDP, often used to rank regions across the EU as a whole, is indeed reflecting other aspects of life. The answer is that it can only do this to a limited extent.

What does this tell us about the existence of multiple deprivation among regions? So far, we have looked at correlations between indicators across the full range of regions. To examine the extent of multiple deprivation we need to focus on the worst performers on each indicator. Regions ranking in the bottom ten on each indicator in turn were identified. Are these always the same regions? To ensure that results were consistent, regions were only considered if all variables were available, making the exercise really applicable to a subset of the EU only: Austria, Belgium, France, Italy, Spain and the UK were examined. (Participation in education at seventeen was also dropped because data were missing for so many countries.)

Of the six countries (42 regions) included, there are five regions which do consistently badly, ranking in the bottom ten in between ten and twelve out of fifteen indicators. One of these regions is the Canary Islands; the other four are all in southern Italy (Sicily, Sardinia, the South and Campania). Other than these five, however, the bottom-ranked regions are a shifting group. Only three regions rank bottom in six or seven out of fifteen indicators (North East Spain, South Spain and Yorkshire and Humberside in the UK); while a further eight are in the bottom group in four or five (Central Spain, North West Italy, Brussels, and five UK regions - the 
North East, North West, Scotland, Wales and Northern Ireland). Only two regions (Western Austria and Central Italy) never fall into the bottom group - although a further thirteen rank bottom on just one indicator, and in nine out of these thirteen the indicator is either club membership or social contact, in which country determinants of outcomes are so strong as to put the variables into some doubt (six out of the eight French regions fall into this category).

There is a pattern across countries in the particular variables on which regions perform badly. The Spanish and Italian regions rank poorly on GDP, housing, poverty measured against a national standard, unemployment and the not-in-work rate, and on the general health measure. They tend to do fine on regional inequality, on all other health measures (SMR, IMR and short-term ill health) and on social contact. In contrast, the UK regions (with the exception of Northern Ireland) are not in the bottom group for GDP but do badly on all the poverty and inequality indicators, and on most of the health measures - SMR and short-term ill health consistently, and often also on IMR and self-assessed general health. Performance in Austria, Belgium and France, where no region ranks in the bottom ten on more than four indicators (and most only on one or two) is harder to classify.

\section{Summary}

To summarise, while it is clear that household surveys need to be larger for many countries if regional statistics are to be treated as robust, this paper has shown that a considerable amount can be learnt about regional disparities in Europe from currently available data. Some of the results to emerge from the evidence examined have reinforced what we already knew (Belgium and Italy are already countries with well-established regional divides, for example). But the paper has also shown that different indicators tell very different stories, both about the degree of disparity within a given country, and about the identity of the worst-performing regions. These findings are particularly important given the recent EU decision to use the coefficient of variation of regional unemployment rates as the single proxy for overall regional disparity within a country. The paper strongly supports the alternative suggestion that all inclusion indicators should instead be analysed at regional level (Atkinson et al., 2002); and has demonstrated that for many areas this is already possible - and offers some thought-provoking results. 


\section{References}

Armitage, P and G Berry (1994) Statistical Methods in Medical Research, Third Edition, Oxford: Blackwell Science.

Atkinson, A, L Rainwater and T Smeeding (1995) Income Distribution in OECD Countries: Evidence from the Luxembourg Income Study (LIS) Paris: OECD.

Atkinson, A (1998), Poverty in Europe, Oxford: Basil Blackwell.

Atkinson, A, B Cantillon, E Marlier and B Nolan (2002) Social Indicators: The EU and Social Inclusion, Oxford: Oxford University Press

Bajekal, M (1999) 'Geographical Variation in Health Indicators by Health Authority, 1994-1996: Introductory Guide and Data Definitions', Department of Health website (http:/ / www.doh.gov.uk/ public/report.htm).

Bardgett, L and G Vidler (2000) Regional Social Exclusion Indicators, Research Paper 00/71, House of Commons Library.

Barry, B (1998) 'Social Exclusion, Social Isolation and the Distribution of Income', Centre for Analysis of Social Exclusion: CASEpaper 12.

Beaton, AE, IVS Mullis, MO Martin, EJ Gonzalez, DL Kelly and TA Smith (1996a) Mathematics Achievement in the Middle School Years: IEA's Third International Mathematics and Science Study, Chestnut Hill, MA: Centre for the Study of Testing, Evaluation and Educational Policy, Boston College.

Beaton, AE, IVS Mullis, MO Martin, EJ Gonzalez, TA Smith and DL Kelly (1996b) Science Achievement in the Middle School Years: IEA's Third International Mathematics and Science Study, Chestnut Hill, MA: Centre for the Study of Testing, Evaluation and Educational Policy, Boston College.

Beatty, C and S Fothergill (1999) 'Incapacity Benefit and Unemployment', Centre for Regional Economic and Social Research, Sheffield Hallam University, July 1999.

Borooah, VK, PPL McGregor, PM McKee and GE Mulholland (1996) 'Cost-of-Living Differences Between the Regions of the United Kingdom', in J Hills (ed) New Inequalities: The Changing Distribution of Income and Wealth in the UK, Cambridge: Cambridge University Press.

Burchardt, T, J Le Grand and D Piachaud (2001) ‘Degrees of Exclusion: Developing a Dynamic, Multi-Dimensional Measure', in J Hills, J Le Grand and D Piachaud (eds.), Understanding Social Exclusion, Oxford: Oxford University Press.

Burgess, S, K Gardiner and C Propper (2001) 'Growing Up: School, Family and Area Influences on Adolescents' Later Life Chances', Centre for Analysis of Social Exclusion: CASEpaper 49.

Cameron, G and J Muellbauer (2000) 'Earnings Biases in the United Kingdom Regional Accounts: Some Economic Policy and Research Implications', Economic Journal, 110, F412-F429. 
Citro, CF and RT Michael (1995) Measuring Poverty: A New Approach, Washington, D.C.: National Academy Press.

D'Ambrosio, C, F Papadopoulos and P Tsakloglou (2002) 'Social Exclusion in EU Member States: A Comparison of Two Alternative Approaches', mimeo.

Denny, K, C Harmon and S Redmond (2000) 'Functional Literacy, Educational Attainment and Earnings: Evidence from the International Adult Literacy Survey, IFS Working Paper WP00/09

Department of Social Security (2001) Households Below Average Income 1994/5-1999/00, Leeds: Her Majesty's Stationery Office.

De Vos, K and MA Zaidi (1998) 'Poverty Measurement in the EU: Country Specific of Union-Wide Poverty lines?' Journal of Income Distribution, 8(1), 77-92.

Diekstra, RFW, CWM Kienhorst and EJ de Wilde (1995) 'Suicide and suicidal behaviour among adolescents', in M Rutter and DJ Smith (eds) Psychosocial Disorders in Young People: Time Trends and their Causes, Chichester: Academia Europaea and John Wiley and Sons, pp. 686-761.

Doyle, W, M Crawford and K Costeloe (2000) 'Maternal nutrition and birth weight', British Medical Journal, 320:941.

Efron, B and RJ Tibshirani (1993) An Introduction to the Boostrap, Monographs on Statistics and Applied Probability 57, New York: Chapman and Hall.

Erikson, R (1993) 'Descriptions of Inequality: The Swedish Approach to Welfare Research', pp.67-83 in M Nussbaum and A Sen (eds.), The Quality of Life, Oxford: Clarendon Press.

European Commission (1993) Statistics on Housing in the European Community, Luxembourg: Office for Official Publications of the European Communities.

European Commission (1994) Comparisons in Real Terms of the Aggregates of ESA: Results for 1990 and 1991, Luxembourg: Office for Official Publications of the European Communities.

European Commission (1996) First Report on Economic and Social Cohesion, Luxembourg: Office for Official Publications of the European Communities.

European Commission (1996a) The European Union Labour Force Survey: Methods and Definitions, Luxembourg: Office for Official Publications of the European Communities.

European Commission (1999) Purchasing Power Parities and Related Economic Indicators: Results for 1995 and 1996, Luxembourg: Office for Official Publications of the European Communities.

European Commission (2000) Key Data on Education in Europe, Luxembourg: Office for Official Publications of the European Communities.

European Commission (2001) Second Report on Economic and Social Cohesion, Luxembourg: Office for Official Publications of the European Communities.

Eurostat (1997) Statistics in Focus: Population and Social Conditions, No. 6. Luxembourg: Office for Official Publications of the European Communities. 
Eurostat (1999) Education Across the European Union: Statistics and Indicators 1998, Luxembourg: Office for Official Publications of the European Communities.

Eurostat (2000) European Social Statistics: Income, Poverty and Social Exclusion, Luxembourg: Office for Official Publications of the European Communities.

Eurostat (2000a) Labour Force Survey 1999, Luxembourg: Office for Official Publications of the European Communities.

Gardiner, Karen, J Hills, J Falkingham, V Lechene and H Sutherland (1995) 'The Effects of Differences in Housing and Health Care Systems on International Comparisons of Income Distribution', STICERD Welfare State Programme Discussion Paper WSP/110, London School of Economics.

Glennerster, H, R Lupton, P Noden and A Power (1999) 'Poverty, Social Exclusion and Neighbourhood: Studying the Area Bases of Social Exclusion', CASEpaper 22.

Gottschalk, P and T Smeeding (1997) 'Cross-national comparisons of earnings and income inequality', Journal of Economic Literature, 35, 633-86.

Haveman, R and B Wolfe (1995) 'The Determinants of Children's Attainments: A Review of Methods and Findings', Journal of Economic Literature, 33, pp.18291878.

Hills, J (1995) Inquiry into Income and Wealth, Volume II. Joseph Rowntree Foundation.

Hills, J, J Le Grand and D Piachaud (eds.) (2001) Understanding Social Exclusion, Oxford: Oxford University Press.

Holland, WW (1991) European Community Atlas of Avoidable Death, Commission of the European Communities Health Services Research Series, Vol. 6, Second Edition, Oxford: Oxford University Press.

Illsley, R, J Le Grand and C Mullings (1991) 'Regional Inequalities in Mortality', STICERD: Welfare State Programme Discussion Paper WSP/57, London School of Economics.

Jesuit, D, L Rainwater and T Smeeding (2001) 'Regional Poverty in the Developed World: Evidence from the Luxembourg Income Study', forthcoming as LIS working paper.

Loury, GC (1988) 'Why Should We Care About Group Inequality?', Social Philosophy and Policy, Vol.5, No.1, pp.249-271.

Madge, N and JG Harvey (1999) 'Suicide among the young: the size of the problem', Journal of Adolescence, vol 22, no 1, pp145-55.

Micklewright, J and K Stewart (2000) The Welfare of Europe's Children, Bristol: The Policy Press.

Micklewright, J (2002) 'Social Exclusion and Children: A European View for a US Debate', CASEpaper 51.

Norton, A (1994) International Handbook of Local and Regional Government, A Comparative Analysis of Advanced Democracies, Cheltenham: Edward Elgar. 
OECD (1995) Literacy, Economy and Society: Results of the First International Adult Literacy Survey, Paris: OECD and Statistics Canada.

OECD (1997) Literacy Skills for the Knowledge Society: Further Results from the International Adult Literacy Survey, Paris: OECD, Human Resources Development Canada and Statistics Canada.

OECD (2000) Literacy in the Information Age: Final Report of the International Adult Literacy Survey, Paris: OECD and Statistics Canada.

OECD (2000a) Measuring Student Knowledge and Skills: The PISA 2000 Assessment of Reading, Mathematical and Scientific Literacy Paris: OECD

Putnam, RD with R Leonardi and RY Nanetti (1992) Making Democracy Work: Civic Traditions in Modern Italy, New Jersey: Princeton University Press.

Putnam, RD (2000) Bowling Alone: The Collapse and Revival of American Community, New York: Simon and Schuster.

Robinson, P and C Oppenheim (1998) 'Social Exclusion Indicators: A Submission to the Social Exclusion Unit', IPPR mimeo, July 1998.

Scholl, TO and WG Johnson (2000) 'Folic acid: influence on the outcome of pregnancy', American Journal of Clinical Nutrition, 71:5, pp 1295S-1303S.

Social Exclusion Unit (1999) Teenage Pregnancy: Report by the Social Exclusion Unit, London: The Stationery Office.

Social Exclusion Unit (2001) Preventing Social Exclusion: Report by the Social Exclusion Unit, London: The Stationery Office.

Social Protection Committee (2001) 'Report on Indicators in the Field of Poverty and Social Exclusion', Brussels: European Union Social Protection Committee, Report No 13509/01.

Steedman, H and S McIntosh (2001) 'Measuring low skills in Europe: how useful is the ISCED framework?', Oxford Economic Papers, Vol. 3, pp. 564-581.

UNDP (1998) Human Development Report 1998, Oxford: Oxford University Press.

UNDP (2000) Human Development Report 2000, Oxford: Oxford University Press.

Wilkinson, RG (1992) 'Income Distribution and Life Expectancy', British Medical Journal, 304:165-8.

Wilkinson, RG (1996) Unhealthy Societies: The Afflictions of Inequality, London: Routledge.

Zaidi, MA and K de Vos (2001) 'Trends in consumption-based poverty and inequality in the European Union during the 1980s', Journal of Population Economics, 14, 367-390. 